\title{
Construction of a Simplified Wood Gas Generator for Fueling Internal Combustion Engines in a Petroleum Emergency
}

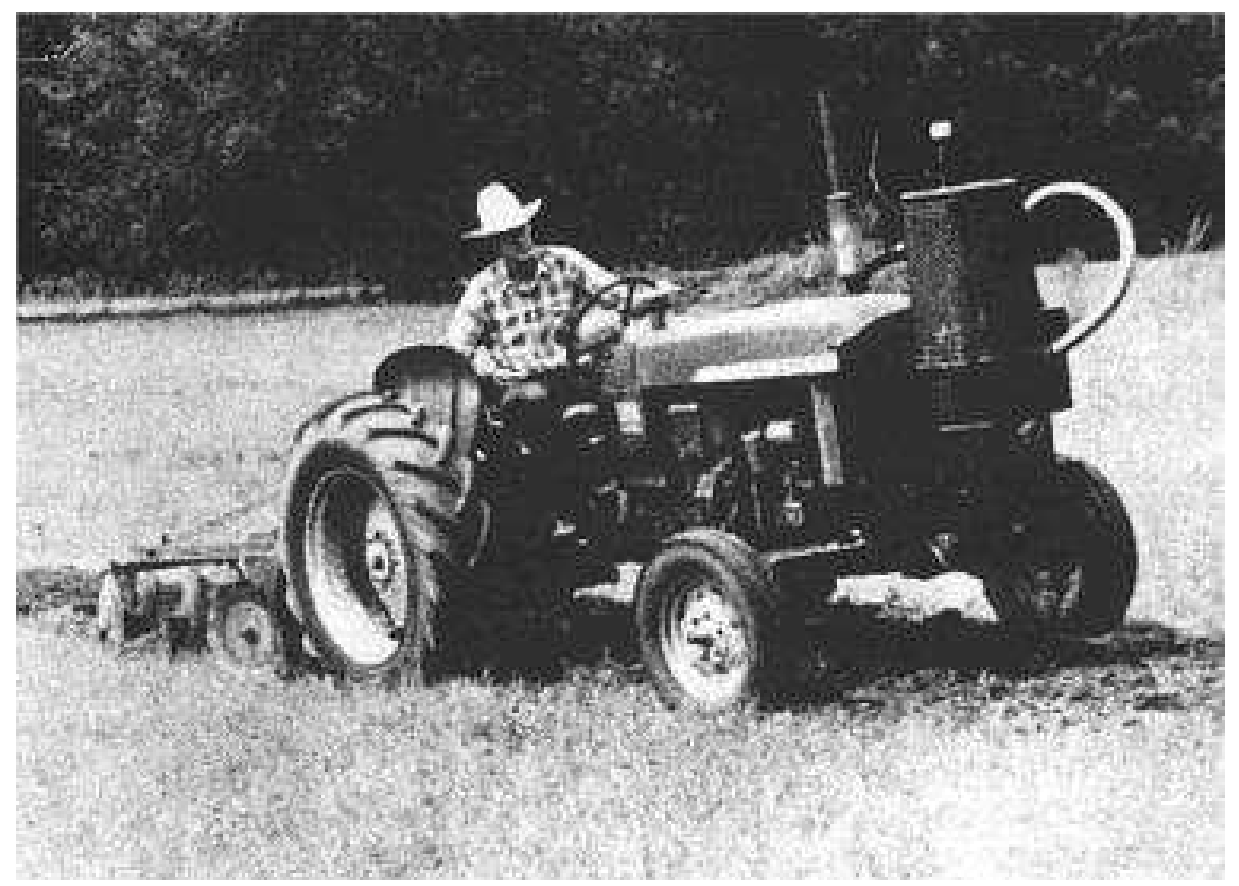

By:

H. LaFontaine, Biomass Energy Foundation, lnc. Miami, Florida

And:

F. P. Zimmerman, Oak Ridge National Laboratory, Energy Division

FEMA lnteragency Agreement Number: EMW-84-E-1737 Work Unit: 3521 D

For:

Federal Emergency Management Agency, Washington, D.C. 20472

"This report has been reviewed in the Federal Emergency Management Agency and approved for publication. Approval does not signify that the contents necessarily reflect the views and policies of the Federal Emergency Management Agency."

Date Published: March 1989

APPROVED FOR PUBLIC RELEASE: DISTRIBUTION UNLIMITED 


\section{CONTENTS}

ABSTRACT

EXECUTIVE SUMMARY

S.1. PRINCIPLES OF SOLID FUEL GASIFICATION

S.2. THE STRATIFIED, DOWNDRAIFT GASIFIER

1. WHAT 1S A WOOD GAS GENERATOR AND HOW DOES IT WORK?

1.1.INTRODUCTION

1.2.PRINCIPLES OF SOLID FUEL GASIFICATION

1.3.BACKGROUND INFORMATION

1.3.1.The World War II, Embowered Gasifier

1.3.2.The Stratified, Downdraft Gasifier

2. BUILDING YOUR OWN WOOD GAS GENERATOR

2.1. BUILDING THE GAS GENERATOR UNIT AND THE FUEL HOPPER

2.2. BUILDING THE PRIMARY FILTER UNIT.

2.3. BUILDING THE CARBURETING UNIT WITH THE AIR AND THROTTLE CONTROLS

3. OPERATING AND MAINTAINING YOUR WOOD GAS GENERATOR

3.1. USING WOOD AS A FUEL

3.2. SPECIAL CONSIDERATIONS AND ENGINE MODIFICATIONS

3.3. INITIAL START-UP PROCEDURE

3.4. ROUTINE START-UP PROCEDURE

3.5. DRIVING AND NORMAL OPERATION

3.6. SHUTTING DOWN THE GASIFIER UNIT 


\section{Contents}

\subsection{ROUTINE MAINTENANCE}

3.7.1 Daily Maintenance

3.7.2 Weekly Maintenance (or every 15 hours of operation)

3.7.3 Biweekly Maintenance (or every 30 hours of operation)

3.8. OPERATING PROBLEMS AND TROUBLE-SHOOTING

CONTENTS

3.9. HAZARDS ASSOCIATED WITH GASIFIER OPERATION

3.9.1. Toxic Hazards

3.9.2. Technical Aspects of "Generator Gas, Poisoning"

3.9.3. Fire Hazard

APPENDICES

APPENDIX I. CONVERSION FACTORS FOR SI UNITS

APPENDIX II. LIST OF FIGURES

APPENDIX III. LIST OF TABLES

APPENDIX IV. BIBLIOGRAPHY 


\section{ABSTRACT: CONSTRUCTION OF A SIMPLIFIED WOOD GAS GENERATOR FOR FUELING INTERNAL COMBUSTION ENGINES IN A PETROLEUM EMERGENCY}

\section{H. LaFontaine, G. P. Zimmerman}

This report is one in a series of emergency technology assessments sponsored by the Federal Emergency Management Agency (FEMA). The purpose of this report is to develop detailed, illustrated instructions for the fabrication, installation, and operation of a biomass gasifier unit (i.e., a 'producer gas' generator, also called a "wood gas' generator) that is capable of providing emergency fuel for vehicles, such as tractors and trucks, in the event that normal petroleum sources were severely disrupted for an extended period of time. These instructions have been prepared as a manual for use by any mechanic who is reasonably proficient in metal fabrication or engine repair. This report attempts to preserve the knowledge about wood gasification that was put into practical use during World War II. Detailed, step-by-step fabrication procedures are presented for a simplified version of the World War II, Embowered wood gas generator. This simple, stratified, downdraft gasifier unit can be constructed from materials that would be widely available in the United States in a prolonged petroleum crisis. For example, the body of the unit consists of a galvanized metal garbage can atop a small metal drum; common plumbing fittings throughout; and a large, stainless steel mixing bowl for the grate. The entire compact unit was mounted onto the front of a farm tractor and successfully field tested, using wood chips as the only fuel. Photographic documentation of the actual assembly of the unit as well as its operation is included. 


\section{Executive Summary}

This report is one in a series of emergency technology assessments sponsored by the Federal Emergency Management Agency (FEMA). The purpose of this report is to develop detailed, illustrated instructions for the fabrication, installation, and operation of a biomass gasifier unit (i.e. a "producer gas" generator, also called a "wood gas" generator) which is capable of providing emergency fuel for vehicles, such as tractors and trucks, should normal petroleum sources be severely disrupted for an extended period of time. These instructions have been prepared as a manual for use by any mechanic who is reasonably proficient in metal fabrication or engine repair.

Fuel gas, produced by the reduction of coal and peat, was used for heating as early as 1840 in Europe and by 1884 had been adapted to fuel engines in England. Prior to 1940, gas generator units were a familiar, but not extensively utilized, technology. However, petroleum shortages during World War II led to widespread gas generator applications in the transportation industries of Western Europe. (Charcoal burning taxis, a related application, were still common in Korea as late as 1970.) The United States, never faced with such prolonged or severe oil shortages, has lagged far behind Europe and the Orient in familiarity with and application of this technology.

However, a catastrophic event could disrupt the supply of petroleum in this country so severely that this technology might be critical in meeting the energy needs of some essential economic activities, such as the production and distribution of food. In occupied Denmark during World War II, $95 \%$ of all mobile farm machinery, tractors, trucks, stationary engines, and fishing and ferry boats were powered by wood gas generator units. Even in neutral Sweden, $40 \%$ of all motor traffic operated on gas derived from wood or charcoal. All over Europe, Asia, and Australia, millions of gas generators were in operation between 1940 and 1946.

Because of the wood gasifier's health risks from toxic fumes, most of such units were abandoned when oil again became available in 1945. Except for the technology of producing alternate fuels, such as methane or alcohol, the only solution for operating existing internal combustion engines, when oil and petroleum products are not available, has been these simple, inexpensive Gasifier units.

This report attempts to preserve the knowledge about wood gasification that was put into practical use during World War II. In this report, detailed step-by-step procedures are presented for constructing a simplified version of the WWII wood gas generator; this simple, stratified, downdraft Gasifier unit (shown schematically in Fig.S-1) can be constructed from materials which would be widely available in the United States in a prolonged petroleum crisis. For example, the body of the unit consists of a galvanized metal garbage can atop a small metal drum; common plumbing fittings are used throughout; and a large, stainless steel mixing bowl is used for the grate. A prototype Gasifier unit was fabricated from these instructions (see Fig. S-2); this unit was then mounted onto the front of a farm tractor and successfully field tested, using wood chips as the only fuel (see Fig. S-3). Photographic documentation of the actual assembly of the unit, as well as its operational field test, is included in the body of this report. 
These wood gas generators need not be limited to transportation applications. Stationary engines can also be fueled by wood gasifiers to run electric generators, pumps, and industrial equipment. In fact, the use of wood gas as a fuel is not even restricted to gasoline engines; if a small amount of diesel fuel is used for ignition, a properly adjusted diesel engine can be operated primarily on wood gas introduced through the intake manifold.

\section{S.1 Principles of solid fuel gasification}

All internal combustion engines actually run on vapor, not liquid. The liquid fuels used by gasoline engines are vaporized before they enter the combustion chamber above the pistons. In diesel engines, the fuel is sprayed into the combustion chamber as fine droplets which burn as they vaporize.

The purpose of a Gasifier, then, is to transform solid fuels into gaseous ones and to keep the gas free of harmful constituents. A gas generator unit is simultaneously an energy converter and a filter. In these twin tasks lie its advantages and its difficulties. In a sense, gasification is a form of incomplete combustion-heat from the burning solid fuel creates gases which are unable to burn completely because of the insufficient amounts of oxygen from the available supply of air. The same chemical laws which govern combustion processes also apply to gasification.

There are many solid biomass fuels suitable for gasification - from wood and paper to peat, lignite, and coal, including coke derived from coal. All of these solid fuels are composed primarily of carbon with varying amounts of hydrogen, oxygen, and impurities, such as sulfur, ash, and moisture. Thus, the aim of gasification is the almost complete transformation of these constituents into gaseous form so that only the ashes and inert materials remain. In creating wood gas for fueling internal combustion engines, it is important that the gas not only be properly produced, but also preserved and not consumed until it is introduced into the engine where it may be appropriately burned.

Gasification is a physicochemical process in which chemical transformations occur along with the conversion of energy. The chemical reactions and thermochemical conversions which occur inside a wood gas generator are too long and too complicated to be covered here; however, such knowledge is not necessary for constructing and operating a wood Gasifier. By weight, gas (wood gas) produced in a Gasifier unit contains approximately 20\% hydrogen (H2), 20\% carbon monoxide (CO), and small amounts of methane, all of which are combustible, plus 50 to $60 \%$ nitrogen (N2). The nitrogen is not combustible; however, it does occupy volume and dilutes the wood gas as it enters and burns in an engine. As the wood gas burns, the products of combustion are carbon dioxide (CO2) and water vapor (H20).

One of the by-products of wood gasification is carbon monoxide, a poisonous gas. The toxic hazards associated with breathing this gas should be avoided during refueling operations or prolonged idling, particularly in inadequately ventilated areas. Except for the obvious fire hazard resulting from the combustion processes inside the unit, carbon monoxide poisoning is the major potential hazard during normal operation of these simplified Gasifier units. 


\section{S.2. THE STRATIFIED DOWNDRAFT Gasifier}

Until the early 1980s, wood gasifiers all over the world (including the World War II designs) operated on the principle that both the fuel hopper and the combustion unit be absolutely airtight; the hopper was sealed with a top or lid which had to be opened every time wood was added. Smoke and gas vented into the atmosphere while wood was being loaded; the operator had to be careful not to breathe the unpleasant smoke and toxic fumes.

Over the last few years, a new Gasifier design has been developed through cooperative efforts among researchers at the Solar Energy Research Institute in Colorado, the University of California in Davis, the Open University in London, the Buck Rogers Company in Kansas, and the Biomass Energy Foundation, Inc., in Florida. This simplified design employs a balanced, negative-pressure concept in which the old type of sealed fuel hopper is no longer necessary. A closure is only used to preserve the fuel when the engine is stopped. This new technology has several popular names, including "stratified, downdraft gasification" and "open top gasification." Several years of laboratory and field-testing have indicated that such simple, inexpensive gasifiers can be built from existing hardware and will perform very well as emergency units.

A schematic diagram of the stratified, downdraft Gasifier is shown in Fig. S-1.During operation of this Gasifier, air passes uniformly downward through four zones, hence the name stratified:

1. The uppermost zone contains unreacted fuel through which air and oxygen enter. This region serves the same function as the fuel hopper in the older, World War II designs.

2. In the second zone, the wood fuel reacts with oxygen during pyrolysis. Most of the volatile components of the fuel are burned in this zone and provide heat for continued pyrolysis reactions. At the bottom of this zone, all of the available oxygen from the air should be completely reacted. The open top design ensures uniform access of air to the pyrolysis region.

3. The third zone is made up of charcoal from the second zone. Hot combustion gases from the pyrolysis region react with the charcoal to convert the carbon dioxide and water vapor into carbon monoxide and hydrogen.

4. The inert char and ash, which constitute the fourth zone, are normally too cool to cause further reactions; however, because the fourth zone is available to absorb heat or oxygen as conditions change, it serves both as a buffer and as a charcoal storage region. Below this zone is the grate. The presence of char and ash serves to protect the grate from excessive temperatures. 
The stratified, downdraft design has a number of advantages over the World War II gasifier designs. The open top permits fuel to be fed more easily and allows easy access. The cylindrical shape is easy to fabricate and permits continuous flow of fuel. No special fuel shape or pretreatment is necessary; any blocky fuel can be used.

The foremost question about the operation of the stratified, downdraft gasifier concerns char and ash removal. As the charcoal reacts with the combustion gases, it eventually reaches a very low density and breaks up into a dust containing all of the ash as well as a percentage of the original carbon. This dust may be partially carried away by the gas and might eventually begin to plug the gasifier. Hence, it must be removed by shaking or agitation. When the stratified gasifier unit is used to power vehicles, it is automatically shaken by the vehicle's motion.

An important issue in the design of the stratified, downdraft gasifier is the prevention of fuel bridging and channeling. High-grade biomass fuels, such as wood blocks or chips, will flow down through the gasifier because of gravity and downdraft air flow. However, other fuels (such as shredded chips, sawdust, and bark) can form a bridge, which will obstruct continuous flow and cause very high temperatures. Bridging can be prevented by stirring, shaking, or by agitating the grate or by having it agitated by the vehicle's movement. For prolonged idling, a hand-operated shaker has been included in the design in this report.

A prototype unit of the stratified, downdraft gasifier design (see Figs. S-2 and S-3) has been fabricated according to the instructions in this report; however, it has not been widely tested at this time. The reader is urged to use his ingenuity and initiative in the construction of his own wood gas generator. As long as the principle of air tightness in the combustion regions, in the connecting piping, and in the filter units is followed, the form, shape, and method of assembly is not important.

The wood gasifier design presented in this report has as its origin the proven technology used in World War II during actual shortages of gasoline and diesel fuel. It should be acknowledged that there are alternate technologies (such as methane production or use of alcohol fuels) for keeping internal combustion engines in operation during a prolonged petroleum crisis; the wood gasifier unit described in this report represents only one solution to the problem. 


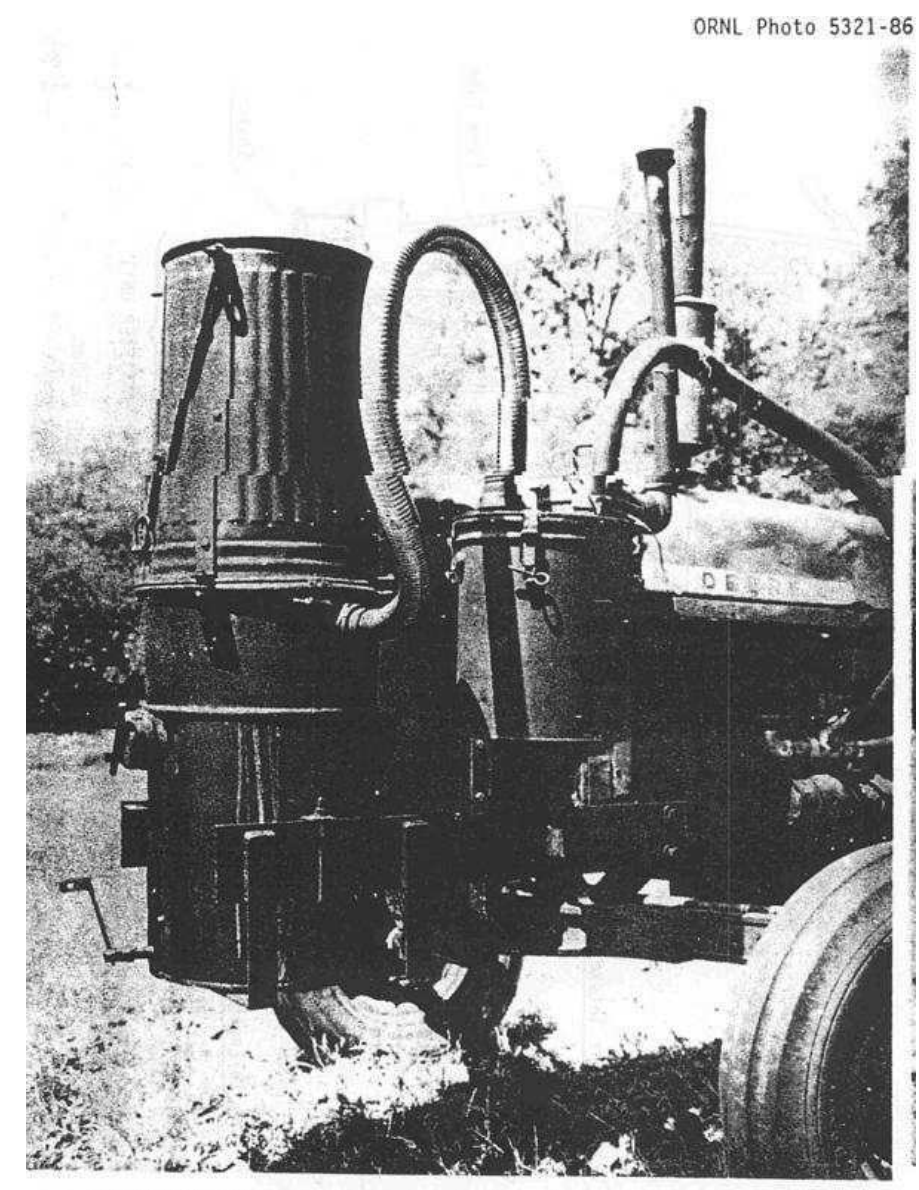

Fig. S-2. The prototype wood gas generator unit mounted onto a tractor.

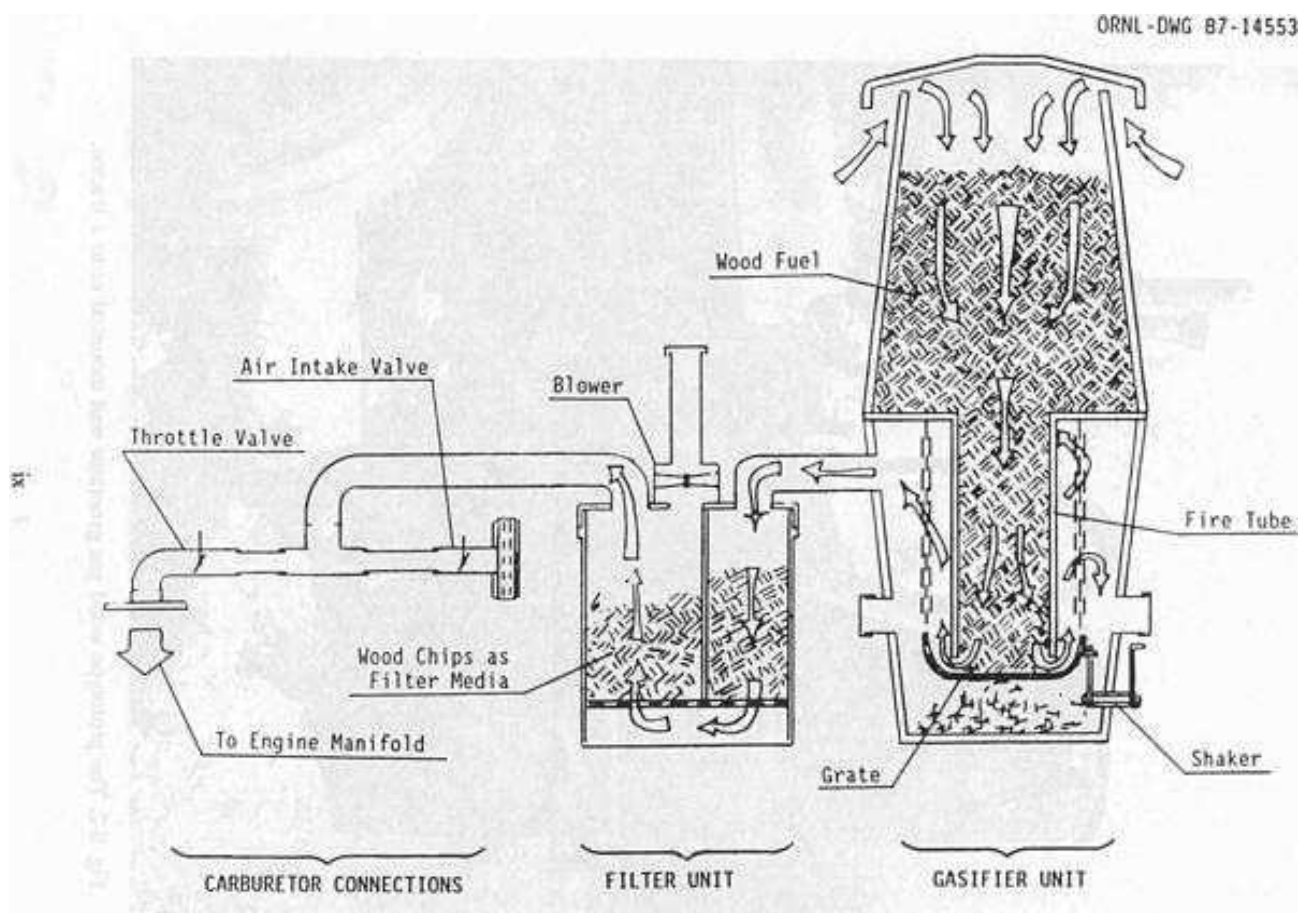

Fig. S-1. Schematic view of the stratified, downdraft gasifier. 
ORNL-Photo 5325-86

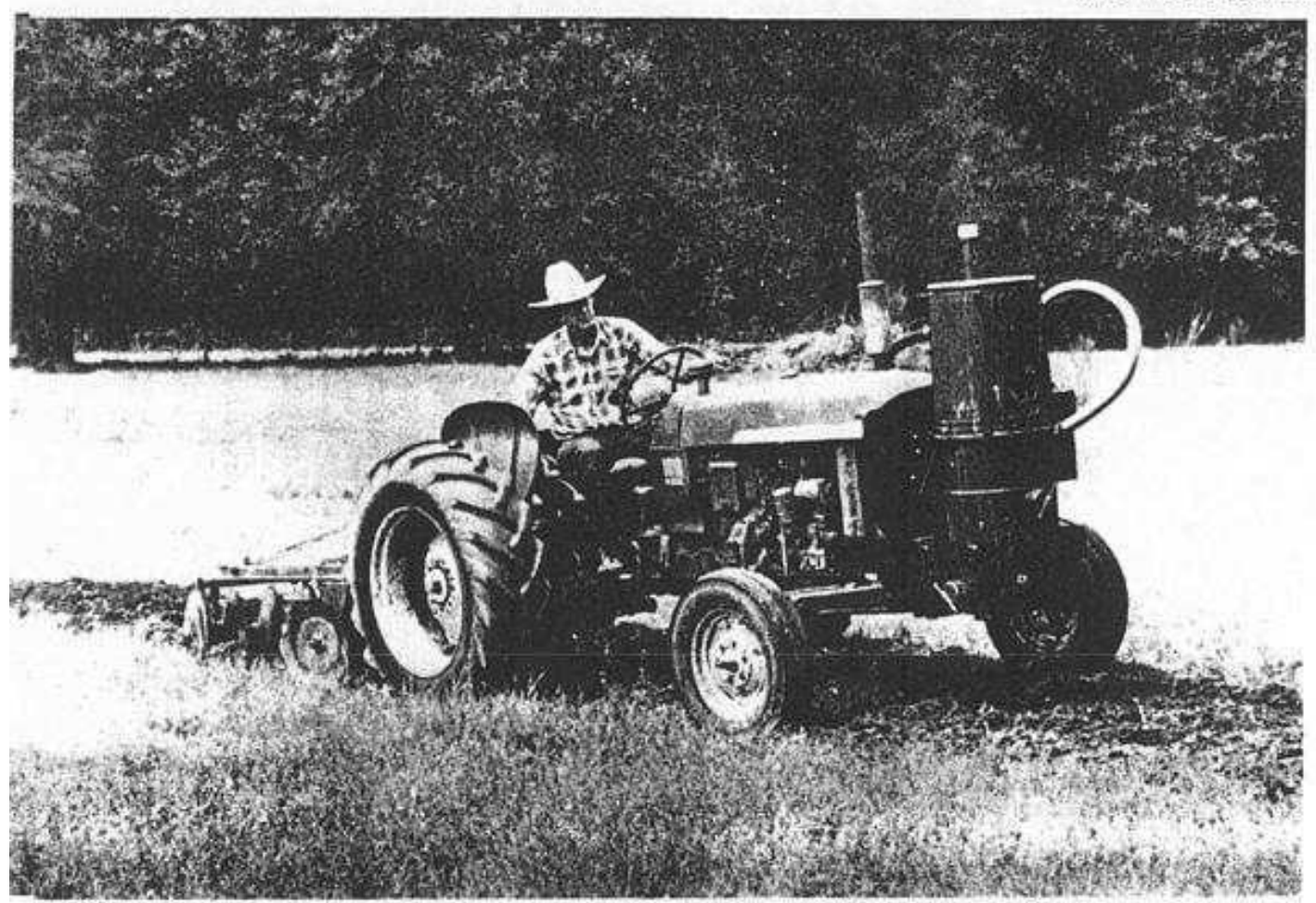

Fig, S-3. Wood gas generator unit in operation during field testing. 


\section{WHAT IS A WOOD GAS GENERATOR AND HOW DOES IT WORK?}

This report is one in a series of emergency technology assessments sponsored by the Federal Emergency Management Agency (FEMA). The purpose of this report is to develop detailed, illustrated instructions for the fabrication, installation, and operation of a biomass gasifier unit (i.e., a "producer gas" generator, also called a 'wood gas' generator) that is capable of providing emergeney fuel for vehicles, such as tractors and trucks, in the event that normal petroleum sources were severely disrupted for an extended period of time. These instructions have been prepared as a manual for use by any mechanic who is reasonably proficient in metal fabrication or engine repair.

\subsection{INTRODUCTION}

Fuel gas, produced by the reduction of coal and peat, was used for heating, as early as 1840 in Europe, and by 1884 it had been adapted to fuel engines in England. Before 1940, gas generator units were a familiar, but not extensively utilized, technology. However, petroleum shortages during World War II led to widespread gas generator applications in the trasportation industries of Western Europe. (Charcoal-burning taxis, a related application, were still common in Korea as late as 1970.)

The United States, never faced with such prolonged or severe oil shortages, has lagged far behind Europe and the Orient in familiarity with and application of this technology; however, a catastrophe could so severely disrupt the supply of petroleum in this country that this technology might be critical in meeting the energy needs of some essential economic activities, such as the production and distribution of food. This report attempts to preserve the knowledge about wood gasification as put into practical use during World War II. Detailed, step-by-step procedures are presented in this report for constructing a simplified version of the World War II, Imbert wood gas generator.

This simple, stratified, downdraft gasifier unit can be constructed from materials that would be widely available in the United States in a prolonged petroleum crisis. For example, the body of the unit consists of a galvanized metal garbage can atop a small metal drum; common plumbing fittings throughout; and a large, stainless steel mixing bowl for the grate. A prototype gasifier unit was fabricated from these instructions. This unit was then mounted onto the front of a gasoline-engine farm tractor and successfully field tested, using wood chips as the only fuel; see Fig. 1-1 (all figures and tables are presented at the end of their respective sections). Photographic documentation of the actual assembly of the unit, as well as its operational field test, is included in this report.

The use of wood gas generators need not be limited to transportation applications. Stationary engines can also be fueled by wood gasifiers to run electric generators, pumps, and industrial equipment. In fact, the use of wood gas as a fuel is not even restricted to gasoline engines; if a small amount of diesel fuel is used for ignition, a properly adjusted diesel engine can be operated primarily on wood gas introduced through the intake manifold.

However, this report is concerned with the operation of four-cylinder gasoline engines rated from 10 to 150 horsepower. If more information is needed about operating gasifiers on other fuels (such as coal, charcoal, peat, sawdust or seaweed), a list of relevant literature is contained in the Bibliography at the end of this report. 
The goal of this report is to furnish information for building a homemade wood gas generator made out of ordinary, available hardware, in order to get tractors, trucks, and other vehicles operating without delay, if a severe liquid fuel emergency should arise. Section 1 describes gasification principies and wood gas generators, in general, and gives some historical background about their operation and effectiveness. Section 2 contains detailed step-by-step instructions for constructing your own wood gas generator unit; illustrations and photographs are inciuded to prevent confusion. Section 3 contains information on operating, maintaining, and trouble-shooting your wood gas generator; also included are some very important guidelines on safety when using your gasifier system.

The wood gasifier design presented in this report has as its origin the proven technology used in World War II during actual shortages of gasoline and diesel fuel. It should be acknowledged that there are alternate technologies (such as methane production or use of alcohol fuels) for keeping internal combustion engines in operation during a prolonged petroleum crisis; the wood gasifier unit described in this report represents only one solution to the problem.

\subsection{PRINCIPLES OF SOLID FUEL GASIFICATION}

All internal combustion engines actually run on vapor, not liquid. The liquid fuels used in gasoline engines are vaporized before they enter the combustion chamber above the pistons. In diesel engines, the fuel is sprayed into the combustion chamber as fine droplets which burn as they vaporize. The purpose of a gasifier, then, is to transform solid fuels into gaseous ones and to keep the gas free of harmful constituents. A gas generator unit is, simultaneously, an energy converter and a filter. In these twin tasks lie its advantages and its difficulties.

The first question many people ask about gasifiers is, 'Where does the combustible gas come from?' Light a wooden match; hold it in a horizontal position; and notice that while the wood becomes charcoal, it is not actually burning but is releasing a gas that begins to burn brightly a short distance away from the matchstick. Notice the gap between the matchstick and the luminous flame; this gap contains the wood gas which starts burning only when properly mixed with air (which contains oxygen).

By weight, this gas (wood gas) from the charring wood contains approximately $20 \%$ hydrogen $(\mathrm{H} 2), 20 \%$ carbon monoxide $(\mathrm{CO})$, and small amounts of methane, all of which are combustible, plus 50 to $60 \%$ nitrogen (N2). The nitrogen is not combustible; however, it does occupy volume and dilutes the wood gas as it enters and burns in an engine. As the wood gas burns, the products of combustion are carbon dioxide $(\mathrm{CO} 2)$ and water vapor $(\mathrm{H} 2 \mathrm{O})$.

The same chemical laws which govern combustion processes also apply to gasification. The solid, biomass fuels suitable for gasification cover a wide range, from wood and paper to peat, lignite, and coal, including coke derived from coal. All of these solid fuels are composed primarily of carbon with varying amounts of hydrogen, oxygen, and impurities, such as sulphur, ash, and moisture. Thus, the aim of gasification is the almost complete transformation of these constituents into gaseous form so that only the ashes and inert materials remain.

In a sense, gasification is a form of incomplete combustion; heat from the burning solid fuel creates gases which are unable to burn completely, due to insufficient amounts of oxygen from the available supply of air. 
In the matchstick example above, as the wood was burned and pyrolyzed into charcoal, wood gas was created, but the gas was also consumed by combustion (since there was an enormous supply of air in the room).

In creating wood gas for fueling internal combustion engines, it is important that the gas not only be properly produced, but also preserved and not consumed until it is introduced into the engine where it may be appropriately burned. Gasification is a physicochemical process in which chemical transformations occur along with the conversion of energy. The chemical reactions and thermochemical conversions which occur inside a wood gas generator are too long and too complicated to be covered here. Such knowledge is not necessary for constructing and operating a wood Gasifier. Books with such information are listed in the Reference Section (see, for example, Reed 1979, Vol. II; or Reed and Das 1988).

\subsection{BACKGROUND INFORMATION}

The use of wood to provide heat is as old as mankind; but by burning the wood we only utilize about one-third of its energy. Two-thirds is lost into the environment with the smoke. Gasification is a method of collecting the smoke and its combustible components. Making a combustible gas from coal and wood began around 1790 in Europe. Such manufactured gas was used for street lights and was piped into houses for heating, lighting, and cooking. Factories used it for steam boilers, and farmers operated their machinery on wood gas and coal gas. After the discovery of large petroleum reserves in Pennsylvania in 1859, the entire world changed to oil - a cheaper and more convenient fuel. Thousands of gas works all over the world were eventually dismantled.

Wood gas generators are not technological marvels that can totally eliminate our current dependence on oil, reduce the impacts of an energy crunch, or produce long-term economic relief from high fossil fuel prices, but they are a proven emergency solution when such fuels become unobtainable in case of war, civil upheaval, or natural disaster. In fact, many people can recall a widespread use of wood gas generators during World War II, when petroleum products were not available for the civilian populations in many countries. Naturally, the people most affected by oil and petroleum scarcity made the greatest advancements in wood gas generator technology.

In occupied Denmark during World War II, 95\% of all mobile farm machinery, tractors, trucks, stationary engines, fishing and ferry boats were powered by wood gas generators. Even in neutral Sweden, $40 \%$ of all motor traffic operated on gas derived from wood or charcoal (Reed and Jantzen 1979). All over Europe, Asia, and Australia, millions of gas generators were in operation between 1940 and 1946.

Because of the wood gasifier's somewhat low efficiency, the inconvenience of operation, and the potential health risks from toxic fumes, most of such units were abandoned when oil again became available in 1945. Except for the technology of producing alternate fuels, such as methane or alcohol, the only solution for operating existing internal combustion engines, when oil and petroleum products are not available, has been these simple, inexpensive Gasifier units. 


\subsubsection{The World War II, Imbert Gasifier}

The basis operation of two gasifiers is described in this and the following section. Their operating advantages and disadvantages will also be discussed. This information is included for the technically interested reader only; it is intended to give the reader more insight into the subtleties of the operating principles of the wood gas generator described in this manual. Those readers who are anxious to begin construction of their own wood gas generator may skip the material below and proceed directly to Sec. 2 without any loss of continuity.

The constricted hearth, downdraft Gasifier shown in Fig. 1-2 is sometimes called the 'Imbert' Gasifier after its inventor, Jacques Imbert; although, it has been commercially manufactured under various names. Such units were mass-produced during World War II by many European automotive companies, including General Motors, Ford, and Mercedes-Benz. These units cost about $\$ 1500$ (1985 evaluation) each.

However, after World War II began in 1939, it took six to eight months before factory-made gasifiers were generally available. Thousands of Europeans were saved from certain starvation by home-built, simple Gasifier units made from washing machine tubs, old water heaters, and metal gas or oxygen cylinders. Surprisingly, the operation of these units was nearly as efficient as the factory-made units; however, the homemade units lasted for only about 20000 miles with many repairs, while the factory-made units operated, with few repairs, up to 100,000 miles.

In Fig. 1-2 the upper cylindrical portion of the Gasifier unit is simply a storage bin or hopper for wood chips or other biomass fuel. During operation, this chamber is filled every few hours as needed. The spring-loaded, airtight cover must be opened to refill the fuel hopper; it must remain closed and sealed during Gasifier operation. The spring permits the cover to function as a safety valve because it will pop open in case of any excessive internal gas pressure.

About one-third of the way up from the bottom of the Gasifier unit, there is a set of radially directed air nozzles; these allow air to be injected into the wood as it moves downward to be gasified. In a gas generator for vehicle use, the down stroke of the engine's pistons creates the suction force which moves the air into and through the Gasifier unit; during startup of the Gasifier, a blower is used to create the proper airflow. The gas is introduced into the engine and consumed a few seconds after it is made. This gasification method is called "producer gas generation," because no storage system is used; only that amount of gas demanded by the engine is produced. When the, engine is shut off, the production of gas stops.

During normal operation, the incoming air burns and pyrolyzes some of the wood, most of the tars and oils, and some of the charcoal that fills the constricted area below the nozzles. Most of the fuel mass is converted to gas within this combustion zone. The Imbert Gasifier is, in many ways, self-adjusting. If there is insufficient charcoal at the air nozzles, more wood is burned and pyrolyzed to make more charcoal. If too much charcoal forms, then the charcoal level rises above the nozzles, and the incoming air burns the charcoal. Thus, the combustion zone is maintained very close to the nozzles.

Below this combustion zone, the resulting hot combustion gases - carbon dioxide (CO2) and water vapor $(\mathrm{H} 2 \mathrm{O})$ - pass into the hot charcoal where they are chemically reduced to combustible fuel gases: carbon monoxide $(\mathrm{CO})$ and hydrogen $(\mathrm{H} 2)$. 
The hearth constriction causes all gases to pass through the reaction zone, thus giving maximum mixing and minimum heat loss. The highest temperatures are reached in this region.

Fine char and ash dust can eventually clog the charcoal bed and will reduce the gas flow unless the dust is removed. The charcoal is supported by a movable grate which can be shaken at intervals. Ash buildup below the grate can be removed during cleaning operations. Usually, wood contains less than $1 \%$ ash (by weight). However, as the charcoal is consumed, it eventually collapses to form a powdery charcoal/ash mixture which may represent 2 to $10 \%$ (by weight) of the total fuel mass.

The cooling unit required for the lmbert Gasifier consists of a water filled precipitating tank and an automotive radiator type gas cooler. The precipitating tank removes all unacceptable tars and most of the fine ash from the gas flow, while the radiator further cools the gas. A second filter unit, containing a fine mesh filtration material, is used to remove the last traces of any ash or dust that may have survived passage through the cooling unit. Once out of the filter unit, the wood gas is mixed with air in the vehicle's carburetor and is then introduced directly into the engine's intake manifold.

The World War II, Imbert Gasifier requires wood with a low moisture content (less than $20 \%$ by weight) and a uniform, blocky fuel in order to allow easy gravity feed through the constricted hearth. Twigs, sticks, and bark shreds cannot be used. The constriction at the hearth and the protruding air nozzles present obstructions to the passage of the fuel and may create bridging and channeling followed by poor quality gas output, as unpyrolyzed fuel falls into the reaction zone. The vehicle units of the World War II era had ample vibration to jar the carefully sized wood blocks through the Gasifier.

In fact, an entire industry emerged for preparing wood for use in vehicles at that time (Reed and Jantzen 1979). However, the constricted hearth design seriously limits the range of wood fuel shapes that can be successfully gasified without expensive cubing or pelletizing pretreatment. It is this limitation that makes the Imbert Gasifier less flexible for emergency use. In summary, the World War II Imbert Gasifier design has stood the test of time and has successfully been mass produced. It is relatively inexpensive, uses simple construction materials, is easy to fabricate, and can be operated by motorists with a minimum amount of training.

\subsubsection{The Stratified, Downdraft Gasifier}

Until the early 1980's, wood gasifiers all over the world (including the World War II designs) operated on the principle that both the fuel hopper and the combustion unit be airtight; the hopper was sealed with a top or lid that bad to be opened every time wood was added. Smoke and gas vented into the atmosphere while new wood was being loaded; the operator bad to be careful not to breathe the unpleasant smoke and toxic fumes.

Over the last few years, a new gasifier design bas been developed through cooperative efforts among researchers at the Solar Energy Research Institute in Colorado, the University of California in Davis, the Open University in London, the Buck Rogers Company in Kansas, and the Biomass Energy Foundation, Inc., in Florida (Reed and Das 1988). This simplified design employs a balanced, negative-pressure concept in which the old type of sealed fuel hopper is no longer necessary. A closure is only used to preserve the fuel when the engine is stopped. 
This new technology has several popular names, including 'stratified, downdraft gasification' and 'open top gasification.' Two years of laboratory and field testing have indicated that such simple, inexpensive gasifiers can be built from existing hardware and will perform very well as emergency units. A schematic diagram of the stratified, downdraft Gasifier is shown in Fig. 1-3. During operation of this gasifier, air passes uniformly downward through four zones, hence the name 'stratified:'

1. The uppermost zone contains unreacted fuel through which air and oxygen enter. This region serves the same function as the fuel hopper in the Imbert design.

2. In the second zone, the wood fuel reacts with oxygen during pyrolysis. Most of the volatile components of the fuel are burned in this zone and provide heat for continued pyrolysis reactions. At the bottom of this zone, all of the available oxygen from the air bas completely reacted. The open top design ensures uniform access of air to the pyrolysis region.

3. The third zone is made up of charcoal from the second zone. Hot combustion gases from the pyrolysis region react with the charcoal to convert the carbon dioxide and water vapor into carbon monoxide and hydrogen.

4. The inert char and ash, which constitute the fourth zone, are normally too cool to cause further reactions; however, since the fourth zone is available to absorb heat or oxygen as conditions change, it serves both as a buffer and as a charcoal storage region. Below this zone is the grate. The presence of char and ash serves to protect the grate from excessive temperatures.

The stratified, downdraft design has a number of advantages over the World War II, Imbert Gasifier. The open top permits fuel to be fed more easily and allows easy access. The cylindrical shape is easy to fabricate and permits continuous flow of fuel. No special fuel shape or pretreatment is necessary; any blocky fuel can be used.

The foremost question about the operation of the stratified, downdraft Gasifier concerns char and ash removal. As the charcoal reacts with the combustion gases, it eventually reaches a very low density and breaks up into a dust containing all of the ash as well as a percentage of the original carbon. This dust may be partially carried away by the gas; however, it might eventually begin to plug the Gasifier, and so it must be removed by shaking or agitation. Both the Imbert gasifiers and the stratified concept have a provision for shaking the grate; when they are used to power vehicles, they are automatically shaken by the vehicle's motion.

An important issue in the design of the stratified, downdraft gasifier is the prevention of fuel bridging and channeling. High-grade biomass fuels such as wood blocks or chips will flow down through the gasifier under the influence of gravity, and downdraft air flow. However, other fuels (such as shredded wood, sawdust, and bark) can form a bridge that will prevent continuous flow and cause very high temperatures. Obviously, it is desirable to use these widely available biomass residues. Bridging can be prevented by stirring, shaking, or by agitating the grate or by having it agitated by the vehicle's movement. For prolonged idling, a hand-operated shaker has been included in the design. 
A prototype design of the stratified, downdraft gasifier design has been developed. The detailed but simple design is described and illustrated in Sect. 2; however, it has not been widely tested at this time. The reader is urged to use his ingenuity and initiative in constructing his own wood gas generator. As long as the principle of air-tightness in the combustion regions, in the connecting piping, and in the filter units is followed, the form, shape, and method of assembly is not important.

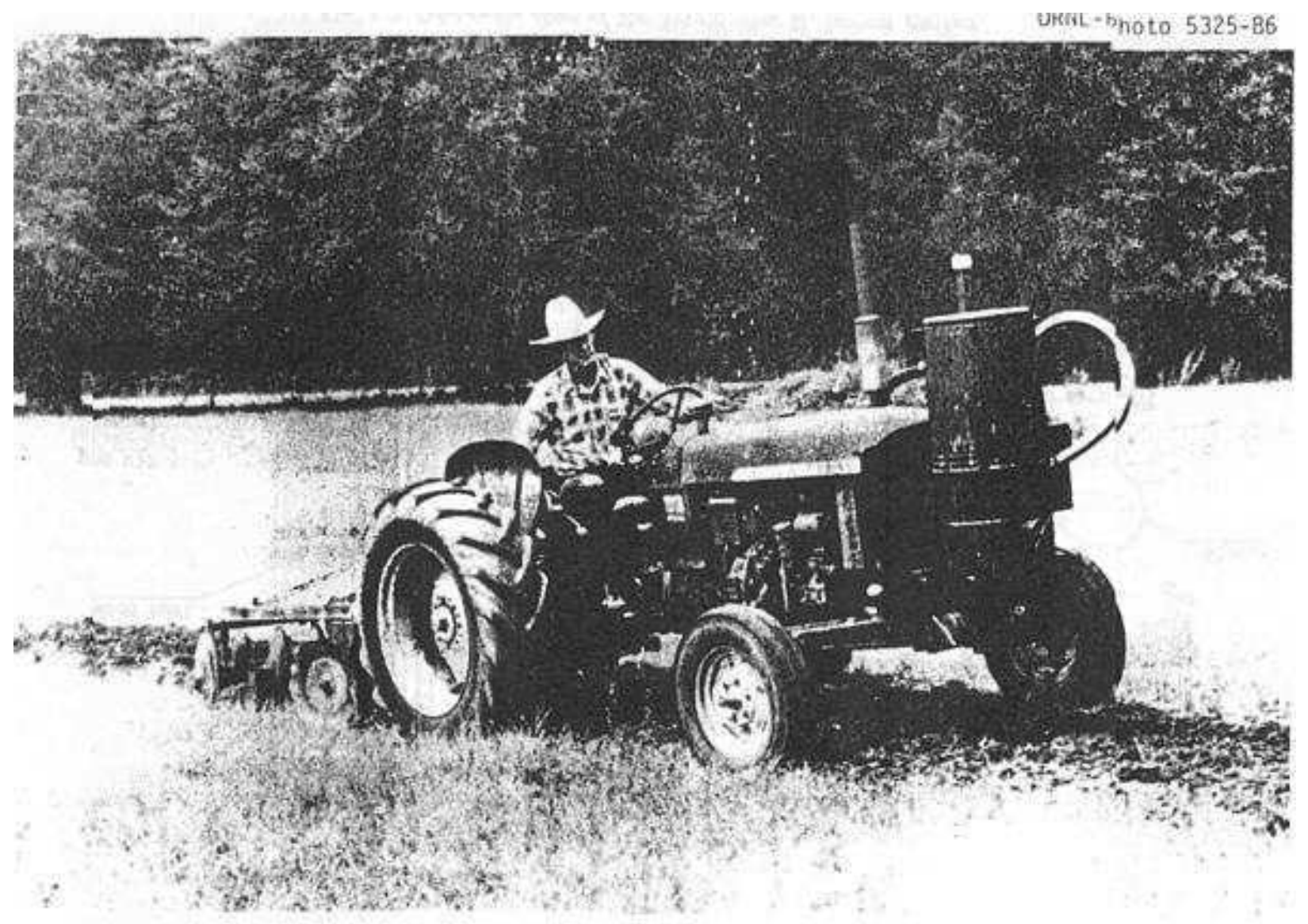

Fig. 1-1. Wood gas generator unit in operation during ficld testing. 


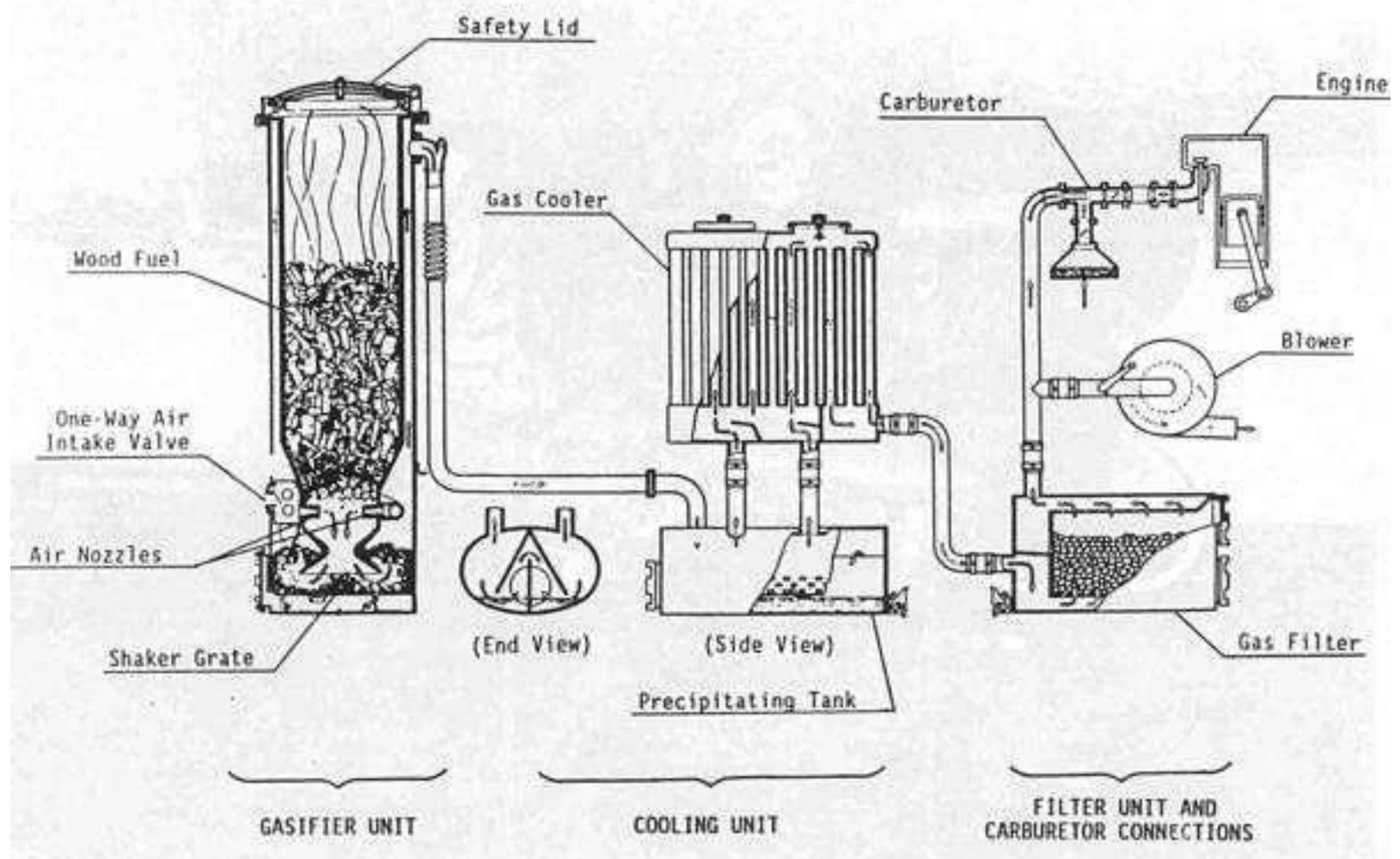

Fig. 1-2 Schematic view of the World War II, Imbert gasifier.

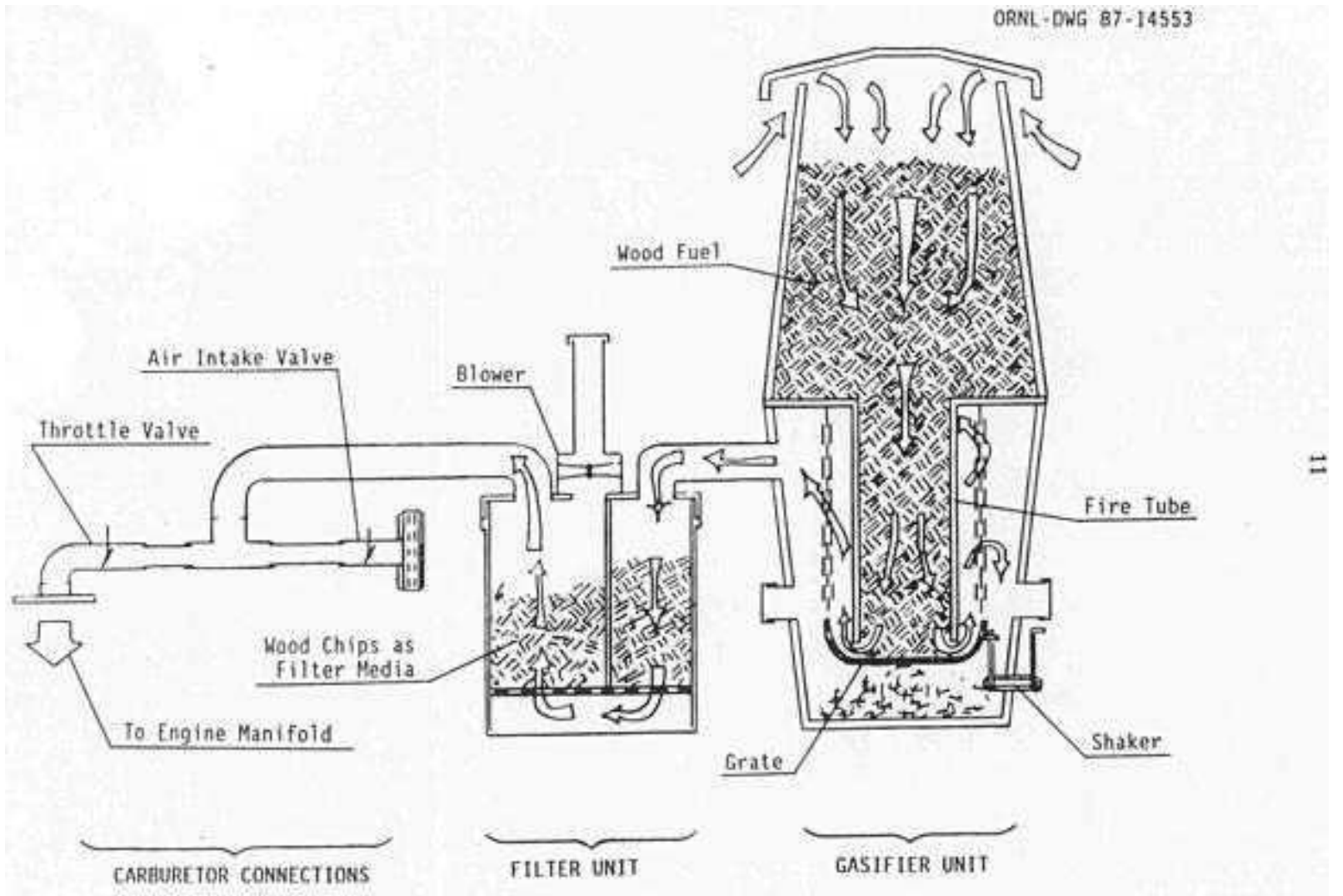

Fig, 1-3. Schematic view of the stratified, downdraft gasificr. 


\section{BUILDING YOUR OWN WOOD GAS GENERATOR}

The following fabrication instructions, parts lists, and illustrations describe the prototype Gasifier unit shown schematically in Fig. 1-3. These instructions are simple and easy to follow. The dimensions in the following plans are given in inches rather than in millimeters to make construction easier for those who might be unfamiliar with the metric system and to allow the builder to take advantage of available, alternate construction materials. It will be obvious to the experienced engineer, mechanic, or builder that most of the dimensions (for example, plate thicknesses and clean-out diameters) are not critical to the acceptable performance of the finished Gasifier unit.

The prototype Gasifier unit described in the following text was actually constructed and field tested on a gasoline engine farm tractor (a 35-hp, John Deere 1010 Special); see Fig. 2-1. The unit operated very well, and on par with the European, World War II designs, but it has not had the test of time nor the millions of operating hours like the older Imbert design. This new stratified design was developed for the construction of simple, inexpensive emergency wood gas generator units. The prototype design below should be considered to be the absolute minimum in regard to materials, piping and filter arrangement, and carburetor system connections.

The Gasifier unit, as described below, is designed to maintain proper cooling, even at moderate vehicle speeds. If this unit is to be used on stationary engines or on slow-moving vehicles, a gas cooler and a secondary filter must be placed in the piping system between the generator unit and the carburetor. The ideal temperature for the wood gas at the inlet to the carburetor manifold would be $70 \mathrm{oF}$, with acceptable peaks of 140 to $160 \mathrm{oF}$. For every 10 degrees above $70 \mathrm{oF}$, an estimated $1 \%$ horsepower is lost. Cooler gas has higher density and, therefore, contains more combustible components per unit volume.

The millions of wood gasifiers built during World War II proved that shape, form, and construction material bad little or no effect on the performance of the unit. Judicious substitution or the use of scavenged parts is, therefore, quite acceptable. What is important is that:

1. The fire tube dimensions (inside diameter and length) must be correctly selected to match the rated horsepower of particular engine which is to be fueled,

2. Air-tightness of the gas generator unit and all connecting piping must be maintained at all times, and

3. Unnecessary friction should be eliminated in all of the air and gas passages by avoiding sharp bends in the piping and by using piping sizes which are not too small. 


\subsection{BUILDING THE GAS GENERATOR UNIT AND THE FUEL HOPPER}

Figure 2-2 shows an exploded view of the gas generator unit and the fuel hopper; the list of materials is given in Table 2-1 (all figures and tables mentioned in Sect. 2 are presented at the end of Sect. 2). Only the dimensions of the fire tube (Item 1A) must be reasonably close; all other dimensions and materials can be substituted as long as complete air-tightness is maintained. In the following instructions, all item numbers refer both to Fig. 2-2 and to Table 2-1.

The prototype unit described in this report was constructed for use with a 35-hp gasoline engine; the unit has a fire tube diameter of 6 in. (as determined from Table 2-2). A gas generator unit containing a fire tube up to 9-in. diameter (i.e., a gasifier unit for fueling engines up to about $65 \mathrm{hp}$ ) can be constructed from the following instructions. If your engine requires a fire tube diameter of $10 \mathrm{in.}$ or more, use a 55 -gal drum for the gas unit and another 55 -gal drum for the fuel hopper.

The following fabrication procedure is very general and can be applied to the construction of gas generator units of any size; however, the specific dimensions which are given in the parts list and in the instructions below are for this particular prototype unit. All accompanying photographs were taken during the actual assembly of the prototype unit. The fabrication procedure is as follows:

1. Using the displacement or horsepower rating of the engine to be fueled by the gasifier unit, determine the dimensions (inside diameter and length) of the fire tube (Item 1A) from Table 2-2. Fabricate a cylindrical tube or cut a length of correctly sized pipe to match the dimensions from Table 2-2. (For the prototype gasifier unit illustrated in this report, a 6-in.-diam firetube was used; its length was 19 in.)

2. The circular top plate (Item 2A) should be cut to a diameter equal to the outside diameter of the Gasifier housing drum (Item 3A) at its top. A circular hole should then be cut in the center of the top plate; the diameter of this hole must be equal to the outside diameter of the fire tube. The fire tube (Item 1A) should then be welded at a right angle to the top plate (Item $2 \mathrm{~A})$ as shown in Fig. 2-3.

3. The grate (Item 4A) should be made from a stainless steel mixing bowl or colander. Approximately 125 holes with diameters of $1 / 2$ in. should be drilled in the bottom and up the sides of the mixing bowl; see Fig. 2-4. A U-bolt (Item 5A) should be welded horizontally to the side of the grate, 2 inches from its bottom. This U-bolt will be interlocked with the shaker mechanism (Item 12A) in a later step.

4. The support chains (Item 6A) are to be attached to the grate in three evenly spaced holes drilled under the lip of the mixing bowl or colander; see Fig. 2-5. These chains are to be connected to the top plate (Item 2A) with eye bolts (Item 7A), as shown in Fig. 2-6. Each eyebolt should have two nuts, one on each side of the top plate, so that the eye bolts can be adjusted to the proper length. When assembled, the bottom of the firetube should be $1.25 \mathrm{in}$. above the bottom of the mixing bowl. 
5. A hole equal to the outside diameter of the ash clean out port (Item SA) should be cut into the side of the gasifier housing drum (Item 3A); the bottom edge of this hole should be about $1 / 2$ in. from the bottom of the drum. Because of the thin wall thickness of oil drums and garbage cans, welding is not recommended; brazing such parts to the drums or cans will ensure both strength and airtightness (see Fig. 2-7).

6. Two holes, equal to the outside diameters of the ignition ports (Item 10A), are to be cut with their centers at a distance from the top of the housing drum (Item 3A) equal to the firetube length less $7 \mathrm{in.} \mathrm{(19} \mathrm{in.} \mathrm{less} 7 \mathrm{in}$. equals $12 \mathrm{in.} \mathrm{for} \mathrm{this} \mathrm{prototype} \mathrm{unit);} \mathrm{the} \mathrm{holes} \mathrm{should} \mathrm{be} \mathrm{placed}$ opposite each other as shown in Fig. 2-2. The ignition ports should be attached to the wall of the housing drum by brazing.

7. When the ash clean out port (Item 8A) and the ignition ports (Item 10A) have been attached to the wall of the gasifier housing drum (Item 3A), they should then be closed with pipe caps, Items 9A and 11A respectively. The threads of the pipe caps should be first coated with high temperature silicone (Item 27A) to ensure airtightness. An optional steel crossbar welded to the pipe cap will reduce the effort required to open these caps later.

8. The shaker assembly (Item 12A) is shown in Fig. 2-8. The 1/2-in. pipe (Item 1AA) should be brazed into the side of the housing drum (Item $3 \mathrm{~A}$ ), 1.5 inches from the bottom of the drum; the length of this pipe which protrudes into the drum must be chosen so that the upright bar (Item 2AA) is in line with the U-bolt (Item 5A) on the grate. Likewise, the length of the upright bar must be selected so as to connect into the U-bolt.

9. Weld the upright bar (Item 2AA) to the head of the bolt (Item 3AA). The threaded end of the bolt should be ground down or flattened on one side, as shown in Fig. 2-9, to positively interlock with a slot to be drilled and filed in the handle (Item 4AA). The handle can be formed or bent into any desired or convenient shape.

10. A hole should be drilled in the pipe cap (Item 7AA) so that there is a close fit between this hole and the bolt (Item 3AA). The close fit will help to ensure air-tightness.

11. Before assembling the shaker, as shown in Fig. 2-8, coat the bolt (Item 3AA) with a small amount of grease. Before inserting the bolt, fill the pipe (Item 1AA) with high temperature silicone (Item 27A) to ensure air-tightness. Tighten the nuts (Item 6AA) so that the position of the handle (Item 4AA) is maintained by friction, yet is capable of being turned and agitated during clean-out or stationary operation.

12. Fabricate the supports (Item 13A) for the Gasifier unit housing drum (Item 3A) out of rectangular, iron bar stock. The shape and height of the support flanges must be determined by the frame of the vehicle to which the gasifier is to be mounted. The supports can either be bolted to the bottom and side with the 114-in. bolts (Item 14A) or can be brazed directly to the drum; see Fig. 2-10. Remember to seal all bolt holes for air-tightness.

13. Completely cover the bottom of the housing drum (Item $3 \mathrm{~A}$ ) with $1 / 2 \mathrm{in}$. of hydraulic cement (Item 28A). The cement should also be applied to the inside of the drum for about 5 inches up the inside walls near the bottom. All edges should be rounded for easy ash removal. 
14. The fuel hopper (Item 15A) is to be made from a second container with its bottom up as shown in Fig. 2-11. Remove the bottom, leaving a 1/4-in. lip around the circumference.

15. A garden hose (Item 17A) should be cut to a length equal to the circumference of the fuel hopper (Item 15A) and should then be, slit along its entire length. It should be placed over the edge of the fuel hopper from which the bottom was removed. This will prevent injury to the operator when adding wood fuel to the unit. To insure close fit of the garbage can lid (Item 16A), a piece of weather stripping (Item 18A) should be attached under the lid where it makes contact with the fuel hopper.

16. Cut four support bars (Item 19A) to lengths $2.5 \mathrm{in}$. longer than the height of the fuel hopper (Item 15A). Drill a 3/8-in. hole in each end of all four support bars; these holes should be centered 3/4 in. from the ends. Bend 2 in. of each end of these support bars over at a right angle; then, mount them evenly spaced around the fuel hopper (Item 15A) with 1/4-in. bolts (Item 20A). One of the bends on each support bar should be as close to the lower edge of the fuel hopper as possible.

17. Cut four metal triangular standoffs (Item 21A) and braze, weld, or rivet them flat against the edge of the garbage can lid (Item 16A) as shown in Fig. 2-12; they must be aligned with the four support bars (Item 19A) attached to the fuel hopper. During operation, the garbage can lid must have a minimum 3/4-in. opening for air passage; the standoffs should provide this clearance, where they are engaged into the holes in the top edges of the support bars (Item 19A); see Fig. 2-13.

18. Two eye-hooks (Item 22A) should be attached to opposite sides of the garbage can lid (Item 16A). Two screen door springs (Item 23A) should be attached to the garbage can handle-s and used under tension to keep the top lid (Item 16A) either open or closed.

19. Cut the oil drum lock ring (Item 24A) to the exact circumference of the top plate (Item 2A) so that it will fit snugly around the Gasifier unit housing drum (Item 3A).

20. Cut four 2 by 2 by $1 / 4$-in. tabs (Item $25 \mathrm{~A}$ ); then, braze these tabs to the lock ring (Item 24A), evenly spaced and in alignment with the support bars (Item 19A) on the fuel hopper. Drill a 3/8-in. hole in each tab to align with the holes in the fuel hopper support bars (Item 19A). The lock ring is shown in Fig. 2-14.

21. The connecting pipe (Item 29A) between the Gasifier unit and the filter unit should be attached to the gasifier housing drum (Item 3A) at a point 6 in. below the top of the drum. This pipe must be a minimum of 2-in. in diameter and should be at least $6 \mathrm{ft}$ long for cooling purposes. At least one of the ends of this pipe must be removable for cleaning and maintenance. On this prototype unit, an airtight electrical conduit connector was used; this connection is visible in Fig. 2-1. Many similar plumbing devices are available and can be used if they are suitable for operation at $400 \mathrm{~F}$ and above.

The pipe can also be welded or brazed directly to the housing drum.

22. When assembling the Gasifier unit, the upright bar (Item 2AA) on the shaker assembly must be placed inside the U-bolt (Item 5A) on the grate. 
23. The lock ring will then clamp the gasifier unit housing drum (Item $3 \mathrm{~A}$ ) and the top plate (Item 2A) together. The fuel hopper support bars (Item 19A) must be attached to the tabs (Item 25A) on the lock ring with bolts (Item 26A). High temperature silicone (Item 27A) should be applied to all edges to make an airtight connection. The lock ring connections are shown in the lower portion of Fig. 2-13.

\subsection{BUILDING THE PRIMARY FILTER UNIT}

Figures 2-15 and 2-16 show exploded views of the primary filter unit; the list of materials is given in Table 2-3 (all figures and tables mentioned in Sect. 2 are presented at the end of Sect. 2). In the following instructions, all item numbers refer to either Fig. 2-15 or 2-16 and to Table 2-3.

The prototype primary filter unit was made from a 5-gal paint can. That size seems to be sufficient for gasifiers with fire tubes up to $10 \mathrm{in}$. in diameter. If a fire tube diameter of more than 10 in. is required, then a 20 -gal garbage can or a 30-gal oil drum should be used. The Filter unit could be fabricated in any shape or form as long as air-tightness and unobstructed flow of gas are provided. If a 5-gal container is used, it must be clean and free of any chemical residue. The top edge must be straight and without any indentations. If an alternate container can be found or fabricated, a larger diameter will permit longer operation between cleanings.

The piping (Item 29A in Figs 2-2 and 2-15) which connects the gas generator unit to the primary filter should be considered to be a necessary part of the cooling system and should never have an inside diameter less than 2 inches. A flexible automotive exhaust pipe was used on the prototype filter unit described below; it was shaped into a semicircular are so that increased length would achieve a greater cooling effect. The fabrication procedure for the filter unit follows:

1. A hole equal to the outside diameter of the drain tube (Item 13B in Fig. 2-15) should be cut into the side of the filter container (Item 1B); the bottom edge of this hole should be about $1 / 2$ in. from the inside bottom of the container.

2. The drain tube (Item 13B) should be inserted into the previously cut hole in the filter container and should be positioned so that its non-threaded end is near the center of the container and is about $1 / 2$ in. off the bottom. Once this position has been ensured, braze (do not weld) the drain pipe into the side of the filter container. Close the threaded, exterior end of the drain pipe with the pipe cap (Item 14B).

3. Coat the bottom of the filter container (Item IB) with a 1/2-in. layer of hydraulic cement (Item 28A), taking care not to plug or obstruct the end of the drain tube (Item 13B) with cement (i.e., fill the drain tube with a paper, styrofoam, or other easily removable, but rigid material). The cement should also be applied for about 1.5 in. up the inside walls of the container near its bottom. Round the edges slightly; the cement is to provide a pathway for any liquid condensate to drain out through the drain tube. The cement must be allowed to harden before proceeding with the fabrication steps below. Remove the filler material from the drain tube when the cement has hardened. 
4. A circular bottom plate (Item $2 \mathrm{~B}$ ) should be cut to a diameter $1 / 2$ in. smaller than the inside diameter of the filter container (Item 1B). This will allow for heat expansion and easy removal for cleaning. This bottom plate should be drilled with as many $3 / 4$-in. holes as are practical for the size of the plate. Three evenly spaced 3/8-in. holes should also be drilled around the edge of the bottom plate for the spacer bolts (Item 3B).

5. Fig. 2-16 shows the detail of using three bolts (Item 3B) as spacers for the bottom plate (Item 2B). The length of the bolts should be adjusted to provide a clearance of about 2-in. between the layer of cement in the bottom of the container (Item 1B) and the bottom plate (Item 2B).

6. A rectangular divider plate (Item $4 \mathrm{~B}$ ) should be cut to a width $1 / 4 \mathrm{in}$. less than the inside diameter of the filter container (Item IB) and to a height $2.5 \mathrm{in}$. less than the inside height of the container. This divider plate should then be welded at a right angle to the centerline of the bottom plate (Item 2B) as shown in Fig. 2-17.

7. Cut a piece of high-temperature hydraulic hose (Item 5B) to a length equal to the circumference of the filter container. It should be slit along its entire length and then placed over the top edge of the filter container (Item 1B) to ensure air-tightness.

8. A circular lid (Item $6 \mathrm{~B}$ ) should be cut equal to the outside diameter of the filter container (Item IB). Three holes should be cut into this lid for the exhaust pipe (Item 29A) from the Gasifier unit, the blower (Item 7B), and the filter exhaust pipe (Item 1OB) to the engine manifold. Note the arrangement of these holes: the pipe (Item 29A) from the Gasifier unit must enter the lid on one side of the divider plate (Item 4B); the blower (Item 7B) and the filter exhaust pipe (Item 1OB) to the engine manifold must be located on the other side of the divider plate. This arrangement can be seen in Fig. 2-18.

9. The connecting pipe (Item 29A) between the gasifier unit and the filter unit should be attached to the lid (Item 5B) of the filter container. At least one of the ends of the connecting pipe (Item 29A) must be removable for cleaning and maintenance. On this prototype unit, an airtight electrical conduit connector was used. Many similar plumbing devices are available and can be used if they are suitable for operation at $400 \mathrm{~F}$ and above. The pipe can also be welded or brazed directly to the lid.

10. Attach the blower (Item 7B) to the filter container lid (Item 6B). On the prototype gasifier illustrated in this report, a heater blower from a Volkswagen automobile was used. Connections for a vertical extension tube (Item SB) will have to be fabricated as shown in Fig. 2-19. A closing cap (Item 9B) is required for the blower exhaust tube. A plumbing cap of steel or plastic with a close fit can be used or fabricated to fit. The vertical extension and the closing cap are visible in Fig. 2-1.

11. The gas outlet (Item 10B) to the carbureting unit on the engine should be $1.25 \mathrm{in}$. minimum diameter. In fabricating this connection, all abrupt bends should be avoided to ensure free flow of gas. Using plumbing elbows is one solution. The gas outlet (Item 10B) can either be welded or brazed to the lid (Item 6B) of the filter container or an airtight, electrical conduit connector can be used. 
12. Latching devices (Item 11B) should be welded or brazed to the lid (see Fig. 2-20) and to the sides (see Fig 2-21) of the filter container. An air-tight connection between the lid and the filter container must be maintained.

13. Cut two lengths of high-temperature hydraulic hose (Item 12B) equal to the height of the divider plate (Item 4B); cut a third length of hose equal to the width of the divider plate. Slit each hose along its entire length. Place the first two hoses on each side of the divider plate, and place the third hose along the top edge of the divider plate as shown in Fig. 2-17.

14. Insert the divider plate (Item 4B) into the filter container (Item 1B), making sure that the hoses (Item 12B) create an airtight seal along all sides. By changing the length of the spacer bolts (Item 3B), adjust the height of the divider plate so that it is exactly flush with the top of the filter container. Make sure that the lid (Item 5B) will seat flatly and tightly against the top edge of the divider plate.

15. Fill the filter container (Item 1B) on-both sides of the divider plate with wood chips, the same kind as would be used for fuel in the Gasifier unit. After carefully packing and leveling these wood chips, place the lid (Item 6B) on the filter container, and close the latches tightly.

\subsection{BUILDING THE CARBURETING UNIT WITH THE AIR AND THROTTLE CONTROLS}

Figures 2-22 and 2-23 show exploded views of the carbureting unit; the list of materials is given in Table 2-4 (all figures and tables mentioned in Sect. 2 are presented at the end of Sect. 2). In the following instructions, all item numbers refer both to Figs. 2-22 and 2-23 and to Table 2-4. The following is a simple and easy way to assemble a carburetor to achieve both air mixture and throttle control. It can be mounted to either updraft or downdraft manifolds by simply turning the unit over. Most of the fabrication procedure below is devoted to the assembly of two butterfly valves: one for the throttle valve and one for the air mixture valve. The remainder of the carburetor unit can be assembled from ordinary, threaded plumbing parts.

The inside diameter of the piping used in the carburetor unit must be related to the size of the engine and should never be smaller than the intake opening on the engine manifold. If in doubt on the inside diameter for the pipe and/or hose sizes, always go with a larger diameter. This will reduce friction losses and will give longer operating hours between cleanings.

When the wood gas leaves the filter unit it should normally be below $180 \mathrm{oF}$. About $2 \mathrm{ft}$ from the filter container, an automotive water hose can be connected to the pipe on the carbureting unit. This rubber hose will keep engine vibration from creating air leaks in the filter unit or in the connecting piping. The hose must be a fairly new item; such hoses have a steel spring inside to keep them from collapsing when negative pressure is applied. The spring will soon rust if it has first been subjected to water and then to the hot wood gas enriched with hydrogen. 
The fabrication procedure for the assembly of two butterfly valves follows:

1. The manifold adapter (Item 1C in Fig. 2-22) must be fitted with bolts and/or holes for mounting onto the engine's existing intake manifold. Because gasoline engines are produced with so many different types of intake manifolds, ingenuity and common sense must be used to modify the manifold adapter (Item 1C) for each different engine to be operated on wood gas. A gasket (Item 7C) should be cut to match the shape of the engine intake fitting.

2. The butterfly valve (Item 3C) is shown in Figs. 2-24 and 2-25; two such valves are required. A 3/8-in. hole should be drilled through the diameter of each valve body (Item 1CC) at the midpoint of its length.

3. The valve plate (Item 2CC) must be oval in shape with the dimensions given in Table 2-4. An oval valve plate must be used so that, in the closed position, the valve will be about 10o off center. This will ensure that the valve will come to a complete stop in the closed position.

4. The edges of the valve plate (Item 2CC), around the longer diameter of the oval, should be beveled to provide a positive, airtight closure. Two evenly spaced, $1 / 4$-in. holes should be drilled along the shorter diameter of the oval plate.

5. The valve support rod (Item $3 \mathrm{CC}$ ) should be filed or ground flat on one side as shown in Fig. 2-24; the flat area must begin 1/4 in. from one end and must continue for a distance equal to the inside diameter of the valve body (Item $1 \mathrm{CC}$ ).

6. Two 3/16-in. holes should be drilled into the flat area of the valve support rod (Item $3 \mathrm{CC}$ ); these holes must align with the holes in the valve plate (Item $2 \mathrm{CC}$ ). They must also be tapped (with threads) to accept the valve plate screws (Item 4CC).

7. The butterfly valve (Item 3C) should be assembled by first placing the valve support rod (Item 3CC) through the hole in the valve body (Item 1CC). The valve plate (Item 2CC) should be dropped into one end of the valve body and then inserted into the flat area of the valve support rod. The two screws (Item 4CC) should be used to attach the valve plate to the support rod. Check to see that the assembled valve plate rotates freely and seats completely in the closed position.

8. A nut (Item 6CC) should be welded flat against one side of the throttle arm (Item 5CC) near its end. A 1/8-in. hole should be drilled into the side of the nut and must be threaded to accept the set screw (Item 7CC). At least one hole should be drilled into the throttle arm for attachment of the engine throttle control or air control linkages.

9. Place the nut (Item 6CC) on the throttle arm over the end of the valve support rod (Item 3CC) and use the set screw (Item 7CC) to secure the assembly. The throttle arm can be placed in any convenient orientation. Assembled butterfly valves are shown in Fig. 2-26.

10. The remaining parts of the carburetor assembly should be screwed together as shown in Fig. 2-27. Pipe thread compound should be used to make airtight connections. The assembled carburetor unit should be attached to the engine's intake manifold as shown in Fig. 2-28. 
11. This prototype Gasifier was designed to operate if gasoline were unavailable; but, if dual operation on wood and gasoline is desired, the elbow (Item 2C) could be replaced with a tee, allowing a gasoline carburetor to also be mounted.

12. The arm on the butterfly valve (Item 3C) which is closest to the elbow (Item 2C) is to be connected to the foot- (or, on tractors, hand-) operated accelerator. The other butterfly valve is to be used as the air mixture control valve and can be operated with a manual choke cable. If the engine has an automatic choking device, then a hand operated choke cable should be installed. Both butterfly valves and their connecting control linkages must operate smoothly with the ability to adjust the valve yet keep it stationary in the selected position during operation. The linkages must close the valves airtight when the engine is off.

13. The air inlet (Item 6C) should be connected by an extension hose or pipe, either iron or plastic, to the existing engine's air filter in order to prevent road dust or agricultural residue from entering the engine.

14. The wood gas inlet (Item 5C) is to be connected to the outlet piping (Item 10B as shown in Fig. 2-15) from the wood gas filter unit. Part of this connection should be a high-temperature rubber or neoprene hose to absorb engine vibration. 
ORNL-Photo $5321-86$

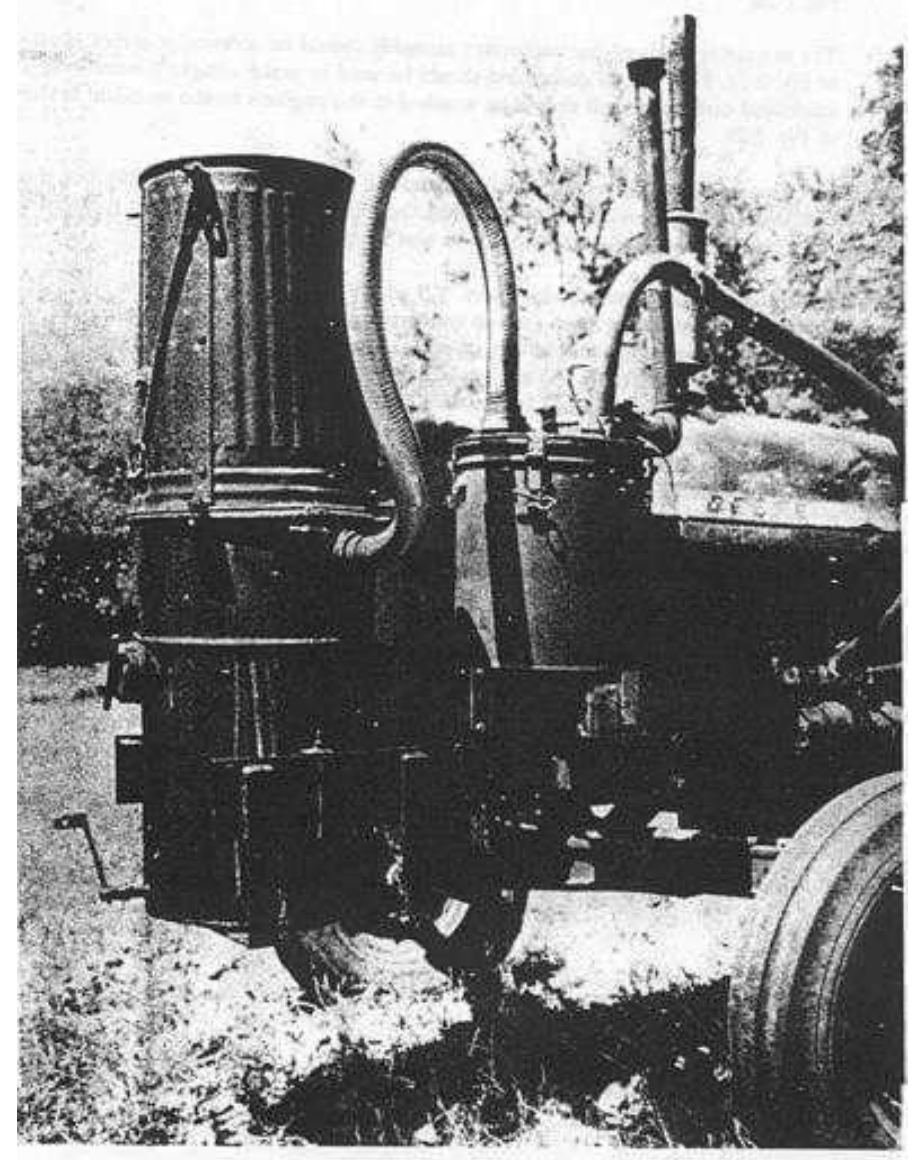

Fig. 2-1. The prototype wood gas generator unit moutted onto a tractor. 


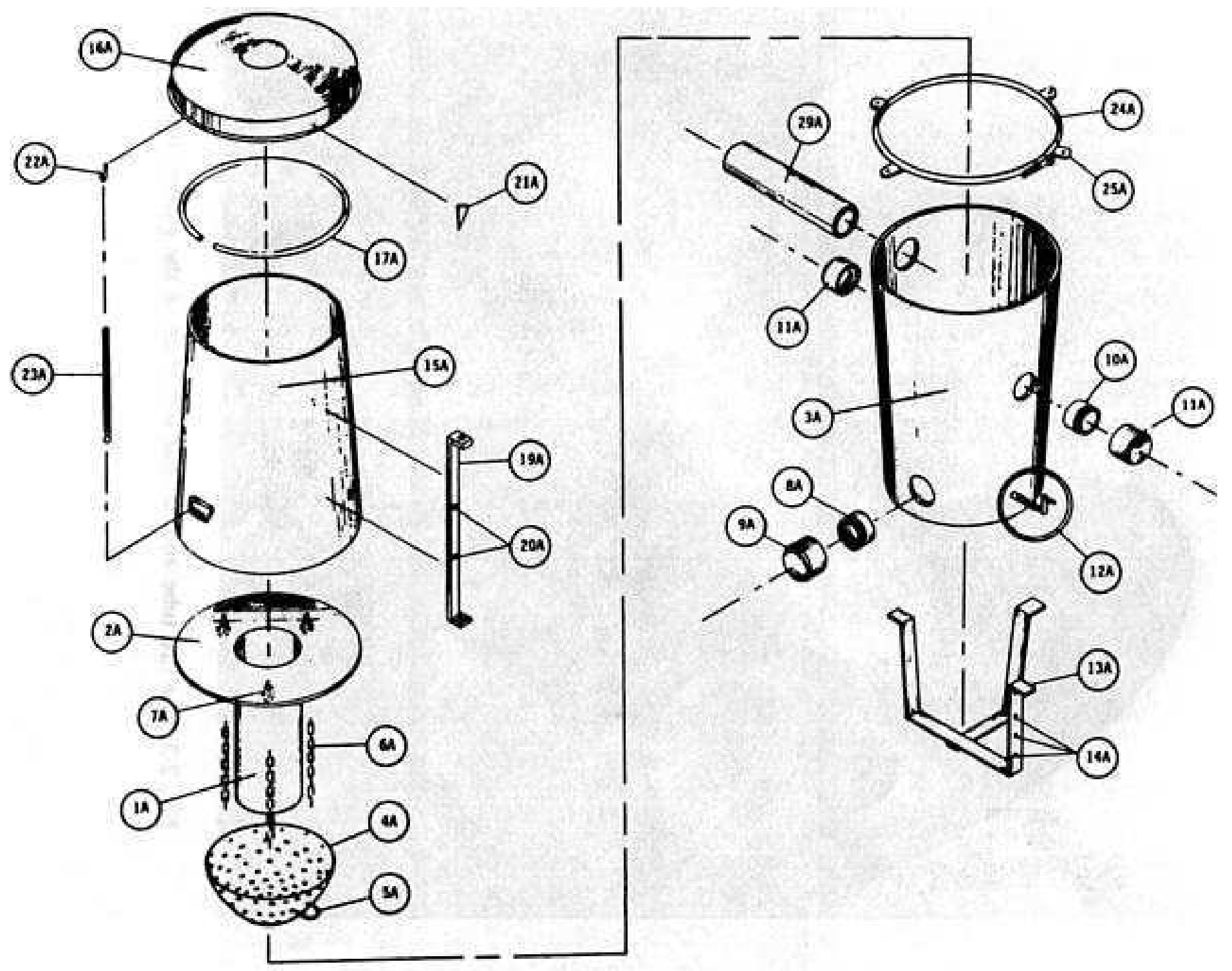

Fig. 2-2. Exploded, schematic diagram of the wood gas generator unit and the fuel hopper. 


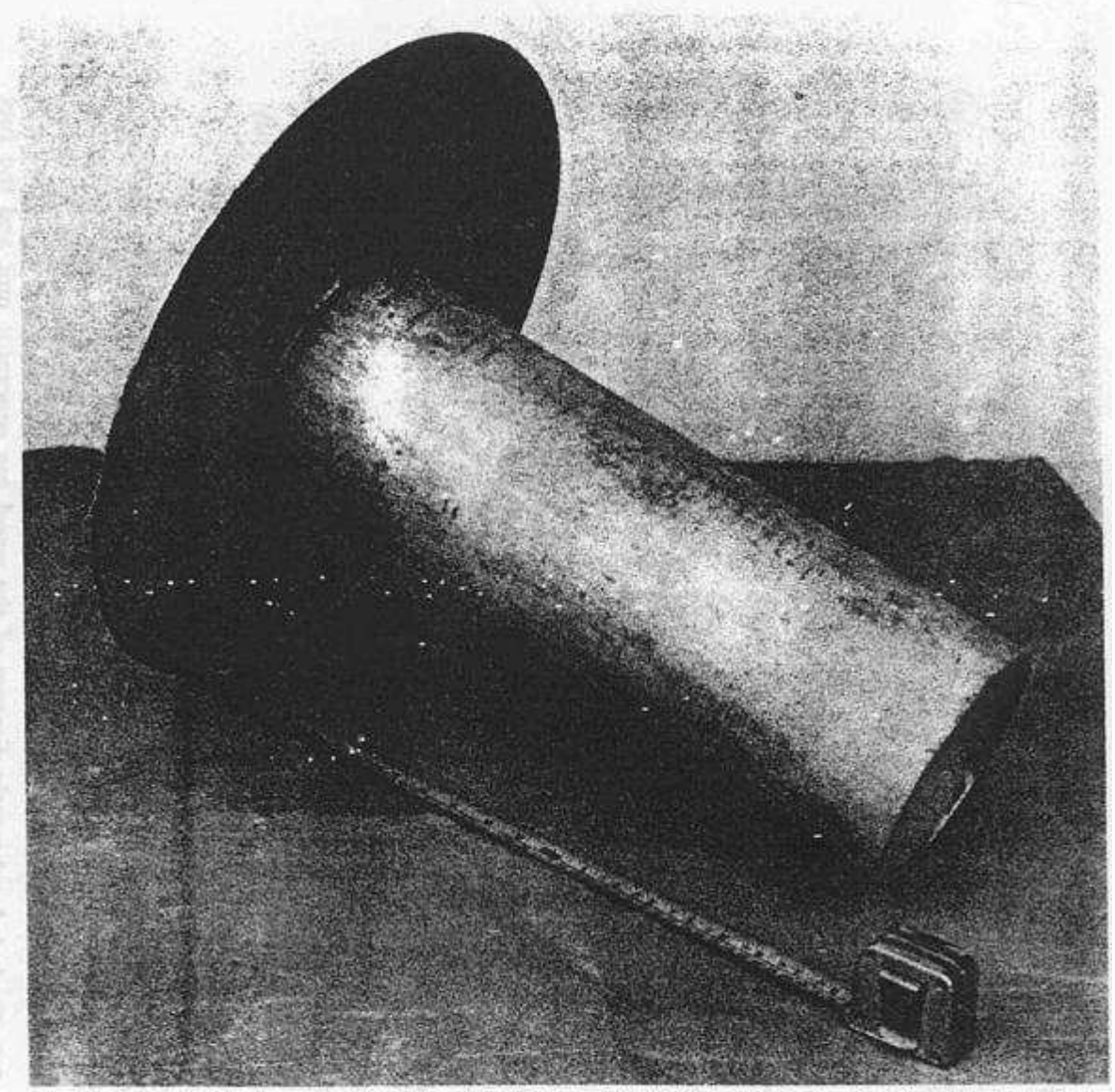

Fig. 2-3. The fire tube and circular top plate of the gasifier unit.

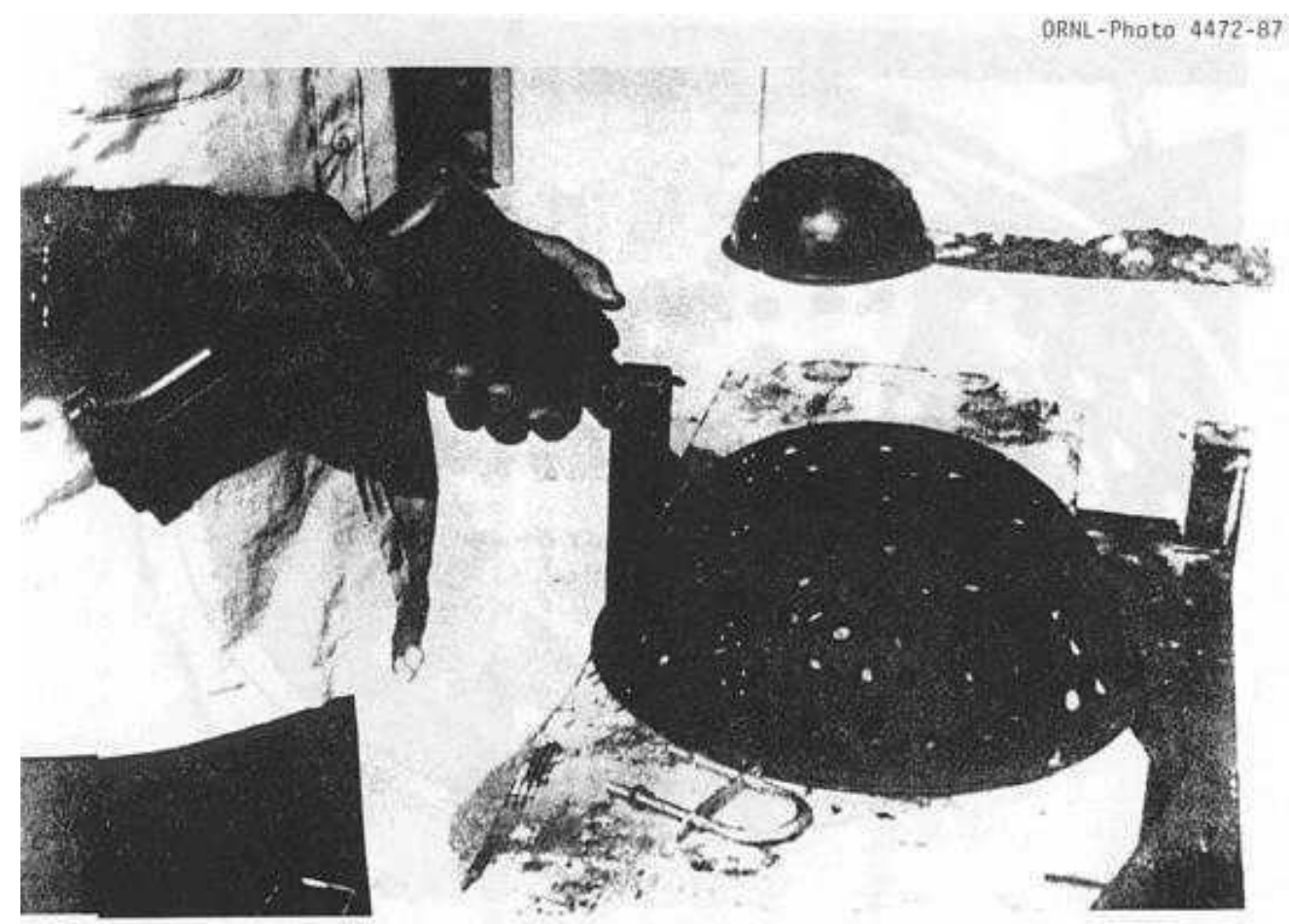

Fig. 24. Drilling holes into the stainless steel mixing fowl to be used for the grate. Note the U-bolt in the foreground. 


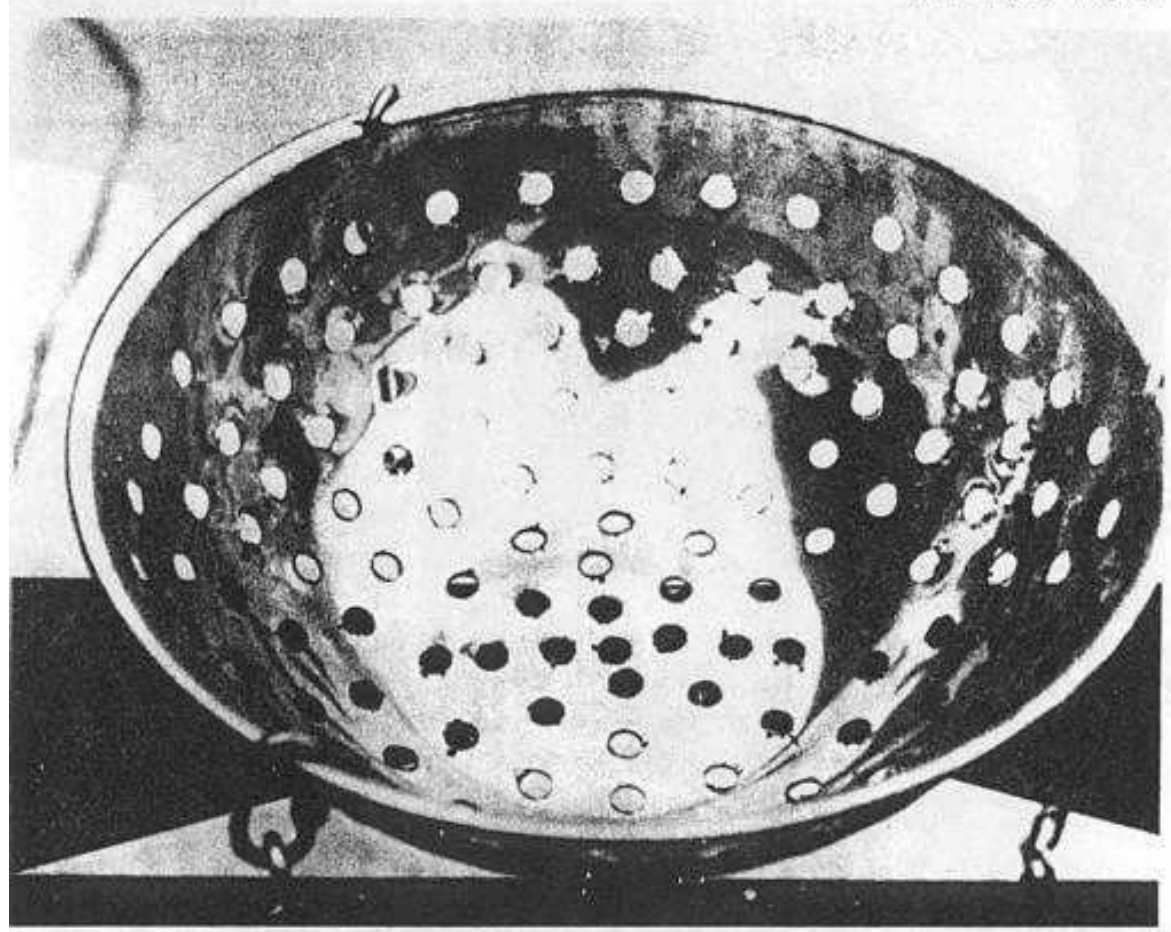

Fig. 2-5. Chains attached to the lip of the stainless steel mixing bowl.

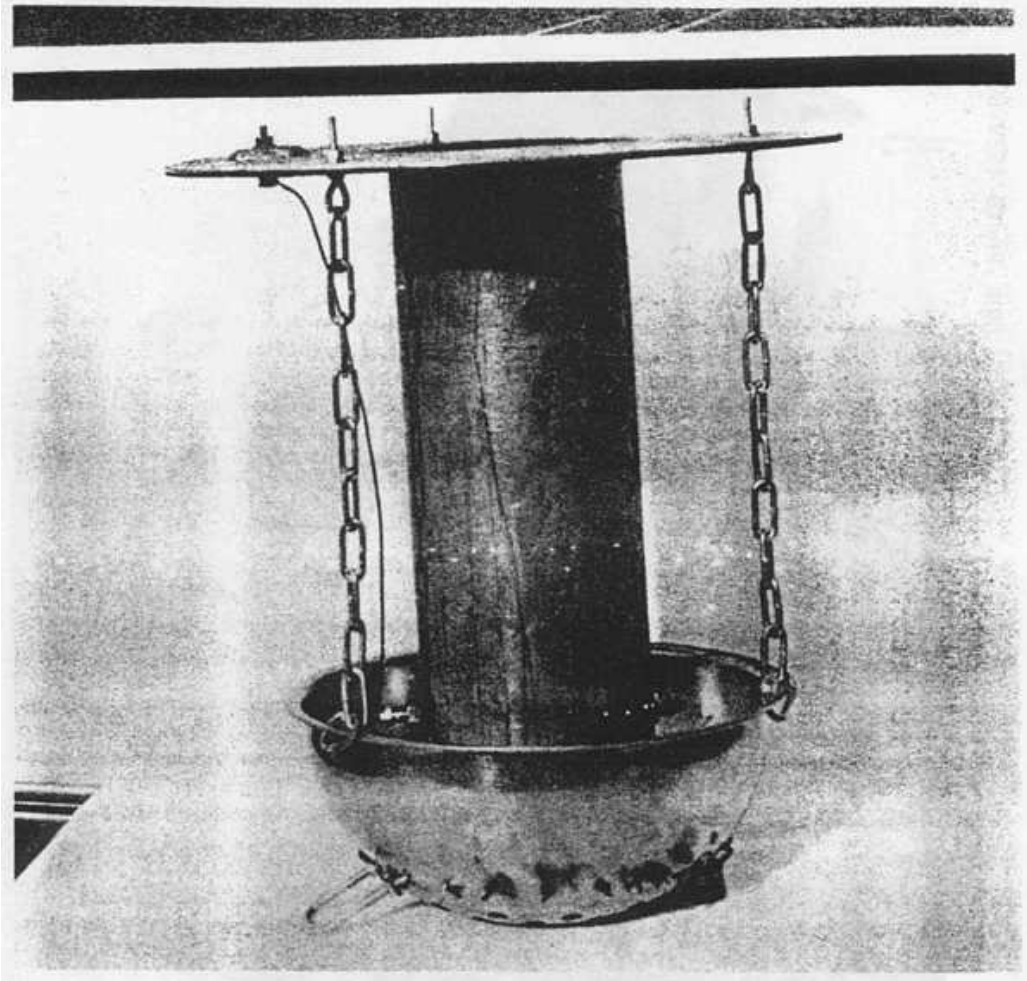

Fig. 2-6. Connect the mixing bowl to the top plate with chains. Note that the diesel ignitor "glow plugs" shown in this photograph were included for experimentation only; they were abandoned in the final prototype design. 
ORNL-Photo $4529-87$

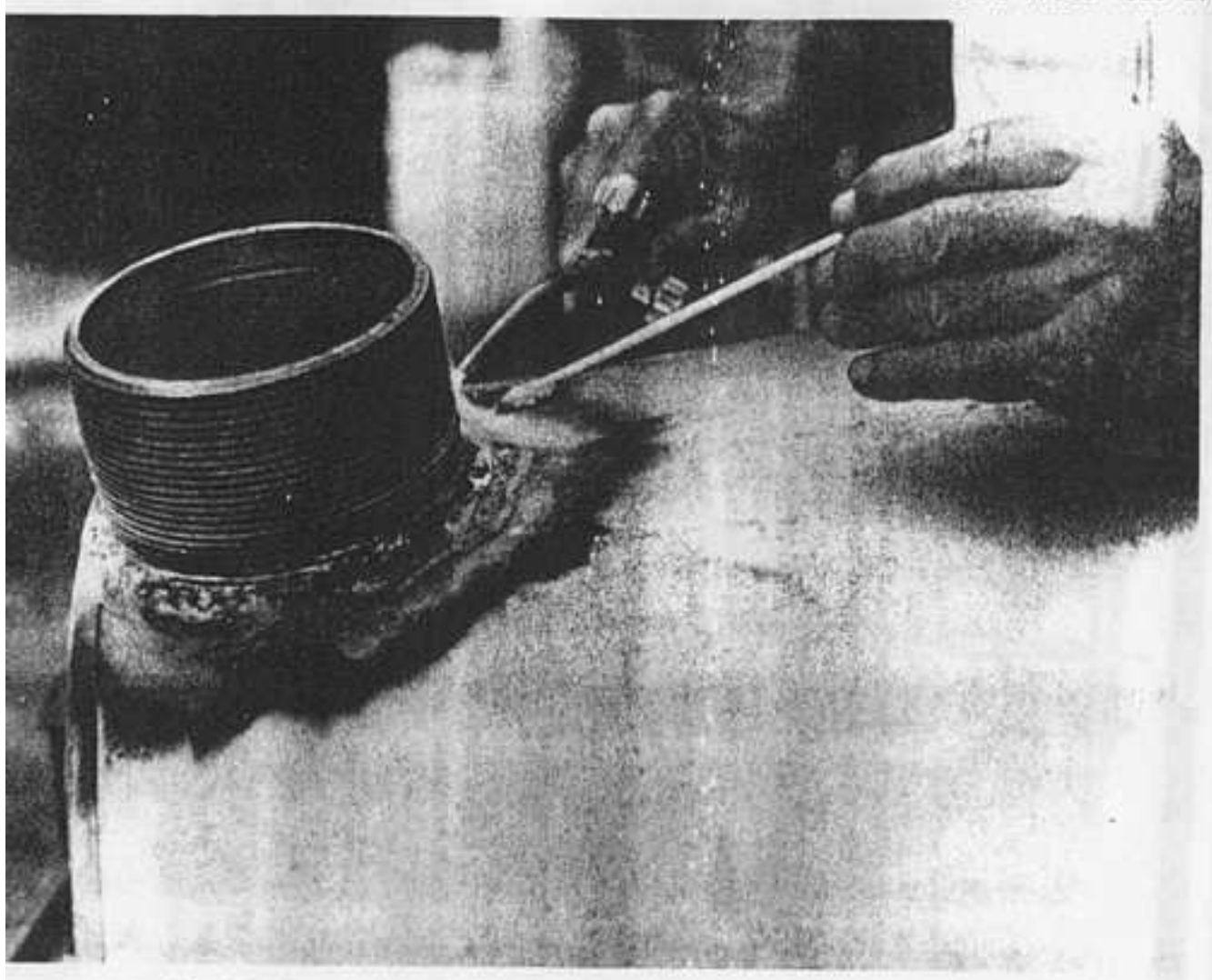

Fig, 2-7. Braze, do not weld, the plumbing fittings to the thin walled drums. 


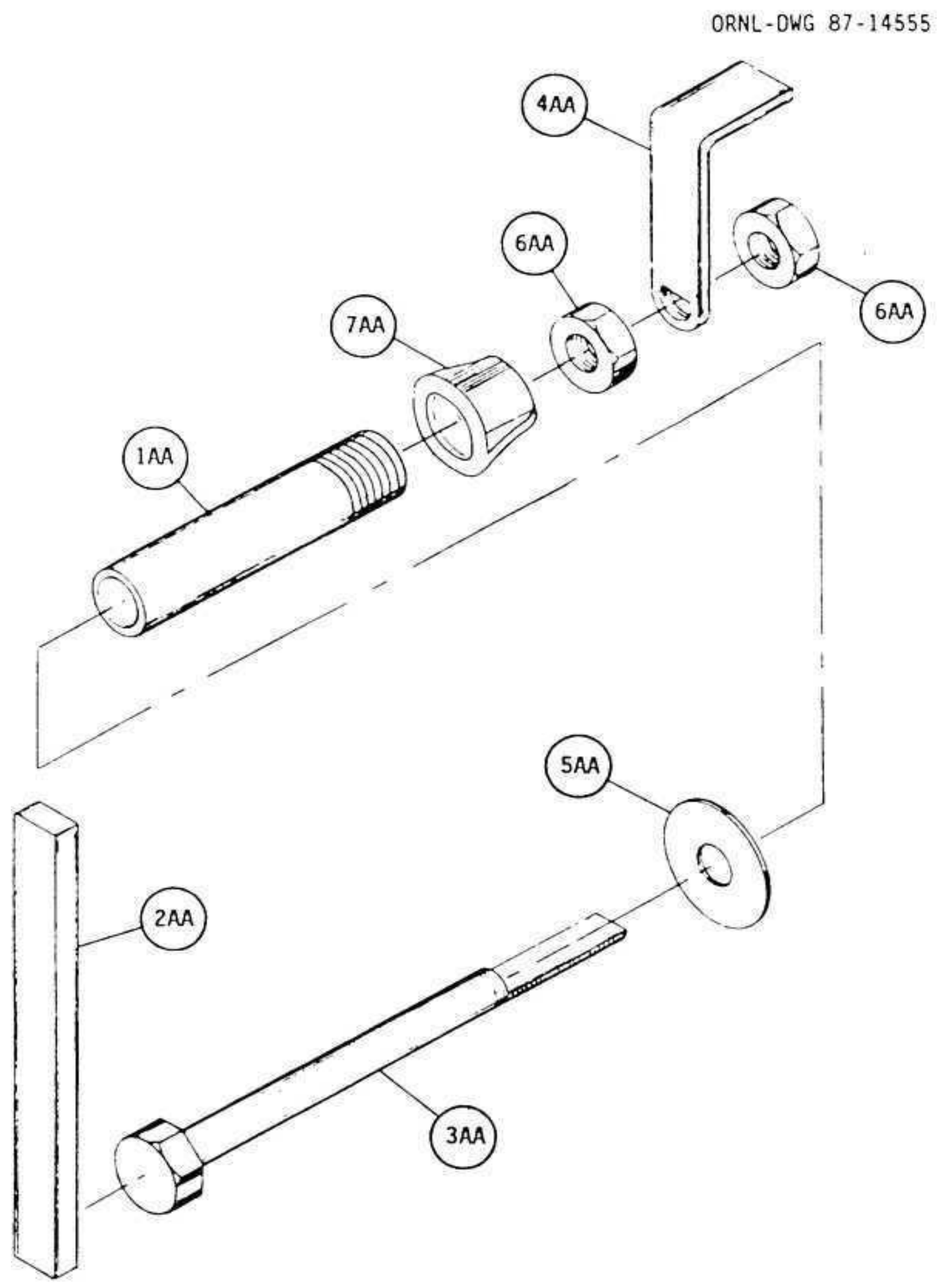

Fig. 2-8. Exploded, schematic diagram of the grate shaking mechanism. 


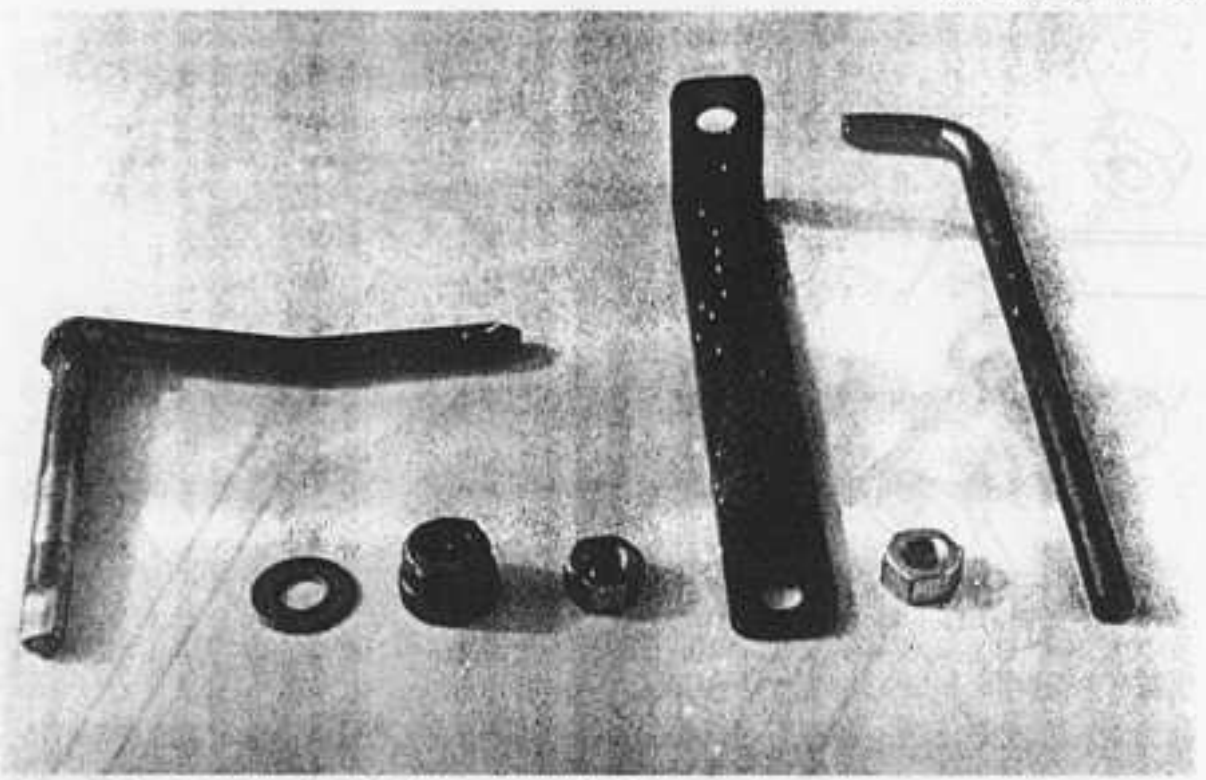

Fig. 2-9. Parts for the shaker assembly. Note the flattened portion of the bolt (at extreme lefi) which positively locks into the handle (third from right). At the extreme right is a "poker bar" which engages into the hole in the top of the handle to operate the shaker mechanism; the shaker handle will get very hot during normal gasifier operation.

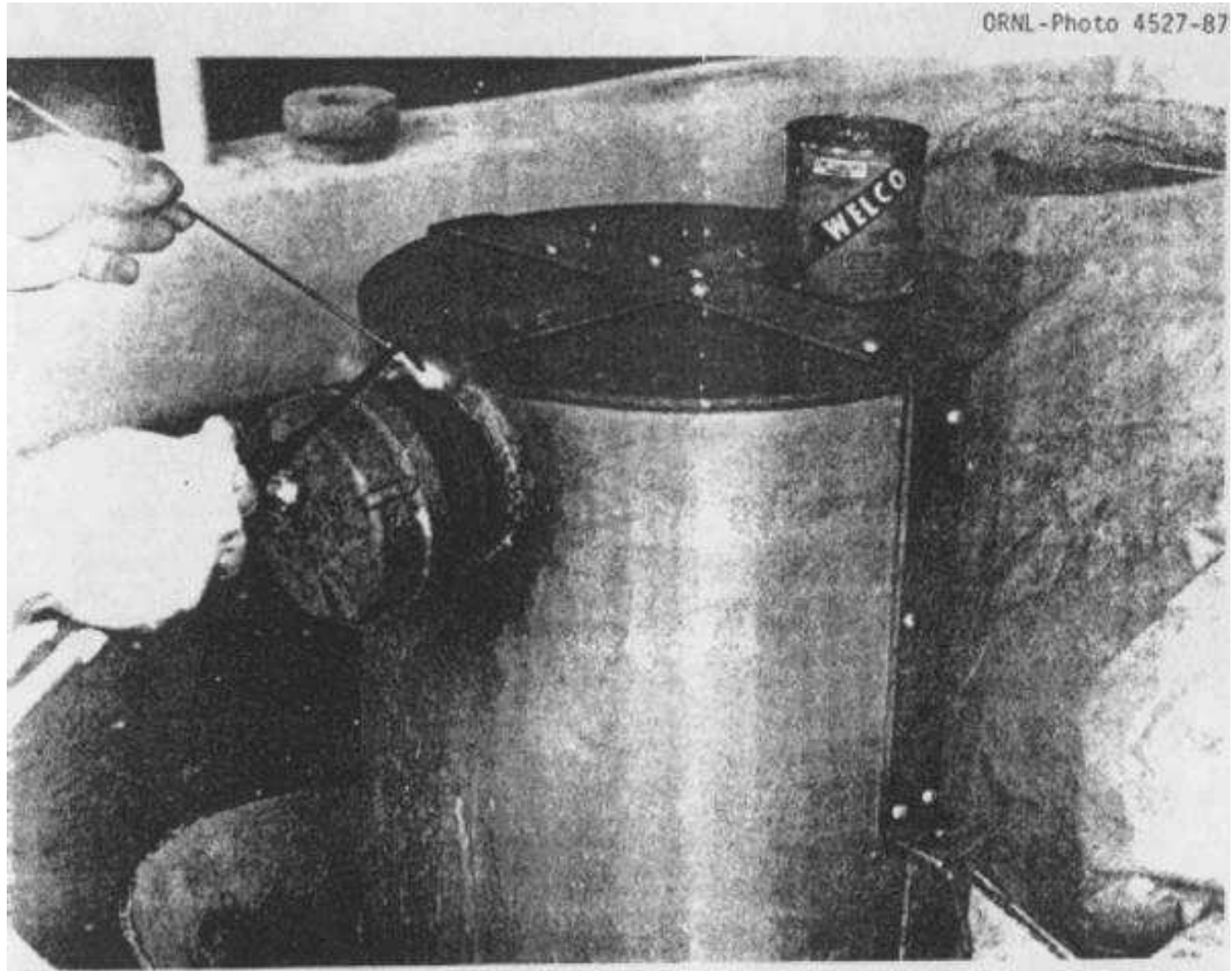

Fig. 2-10. The support frame can be brazed or bolted to the side of the gasifier unit. All bolts should be sealed air tight. 


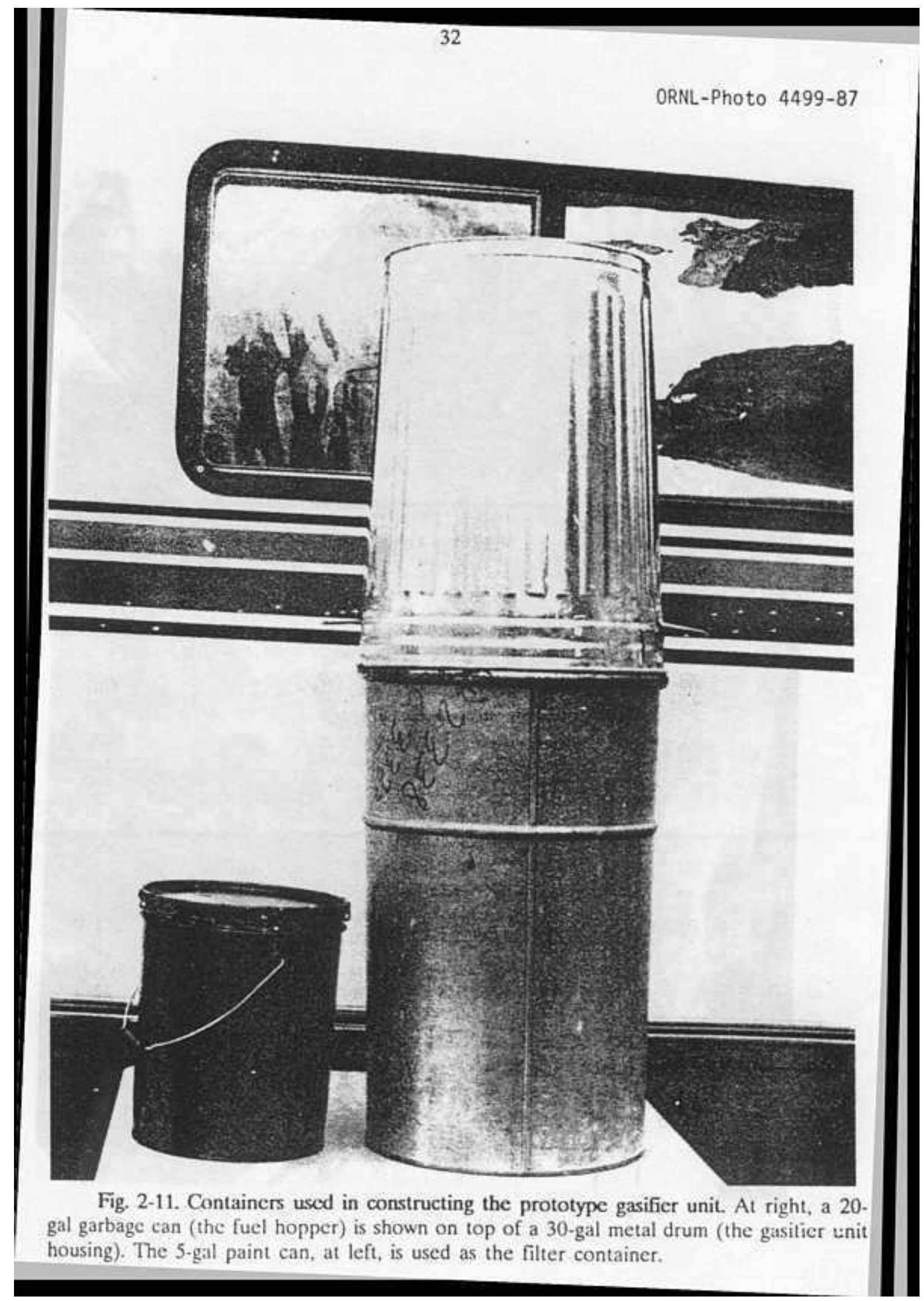




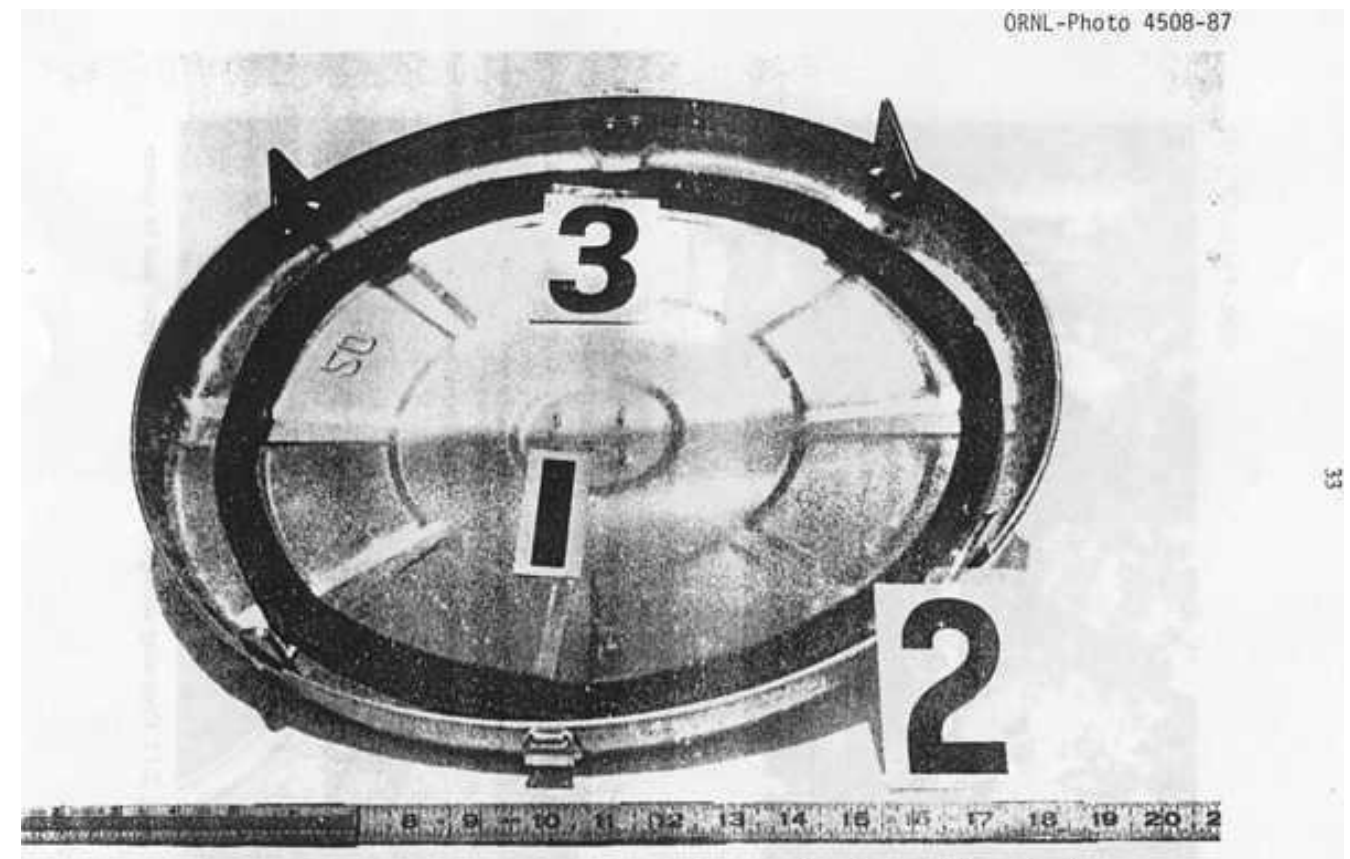

Fig. 2-12 Cover for the fuel hopper. Note the foam weatherstripping (\#3) attached to the underside of the lid where it contacts the fuel hopper. Attach four standofts (\#2) to the lid $(\# 1)$ as shown.

ORNL-Photo 5342-86

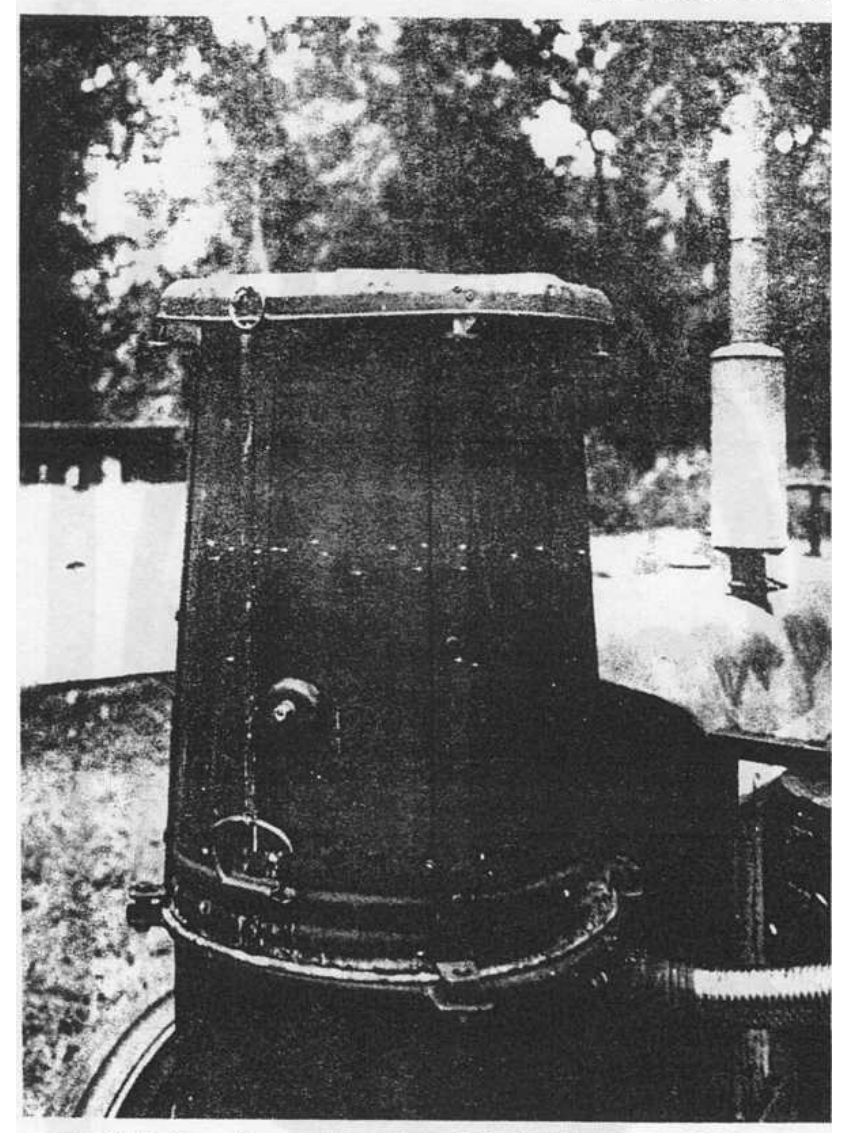

Fig. 2-13. Operating configuration of the fuel hopper and its cover. 


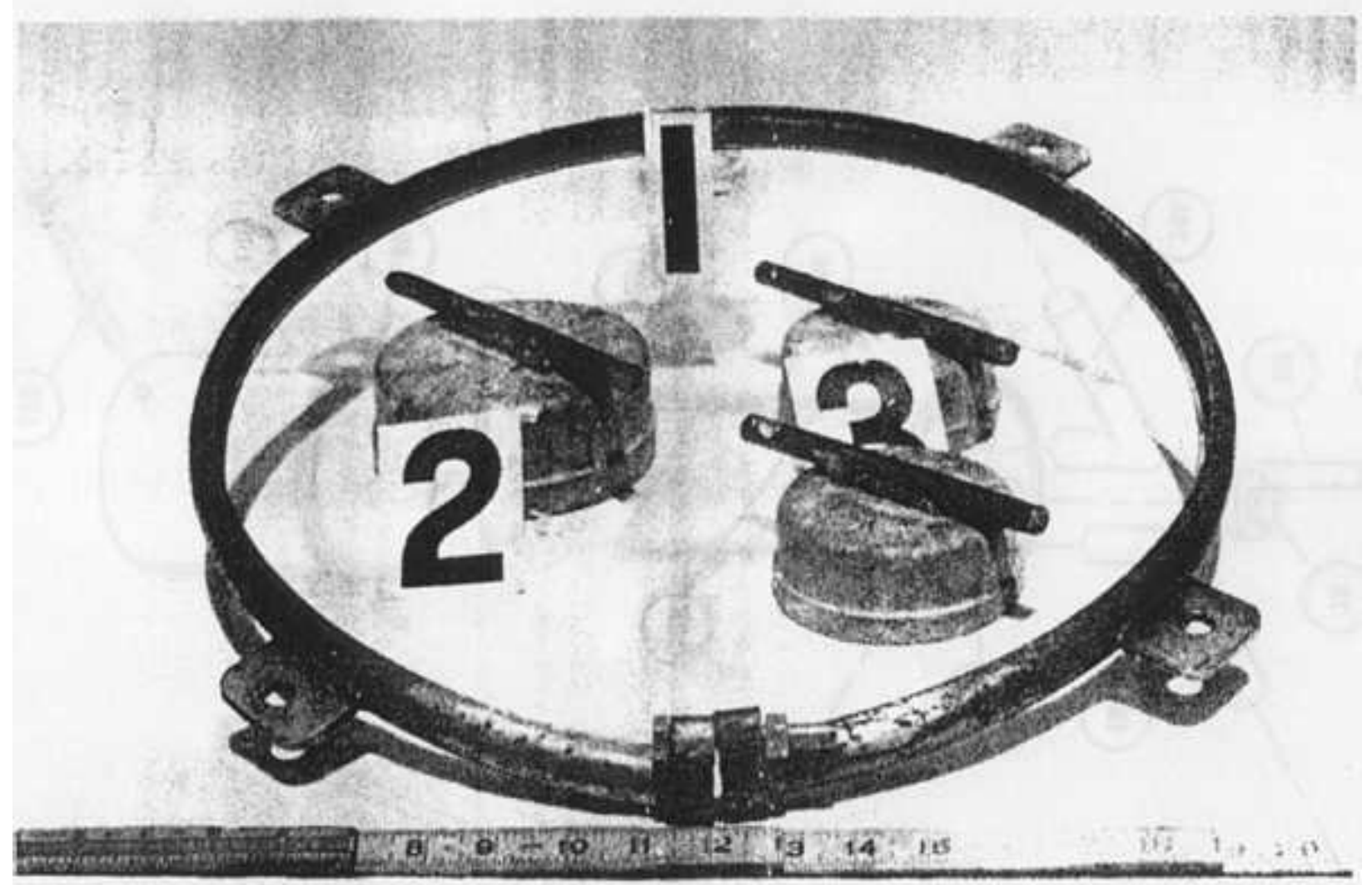

Fig. 2-14. Lock ring and welded tabs. Also pictured inside the lock ring (\#1): the ash cleanout cover cap (\#2), and the ignition cover cap (\#3). 


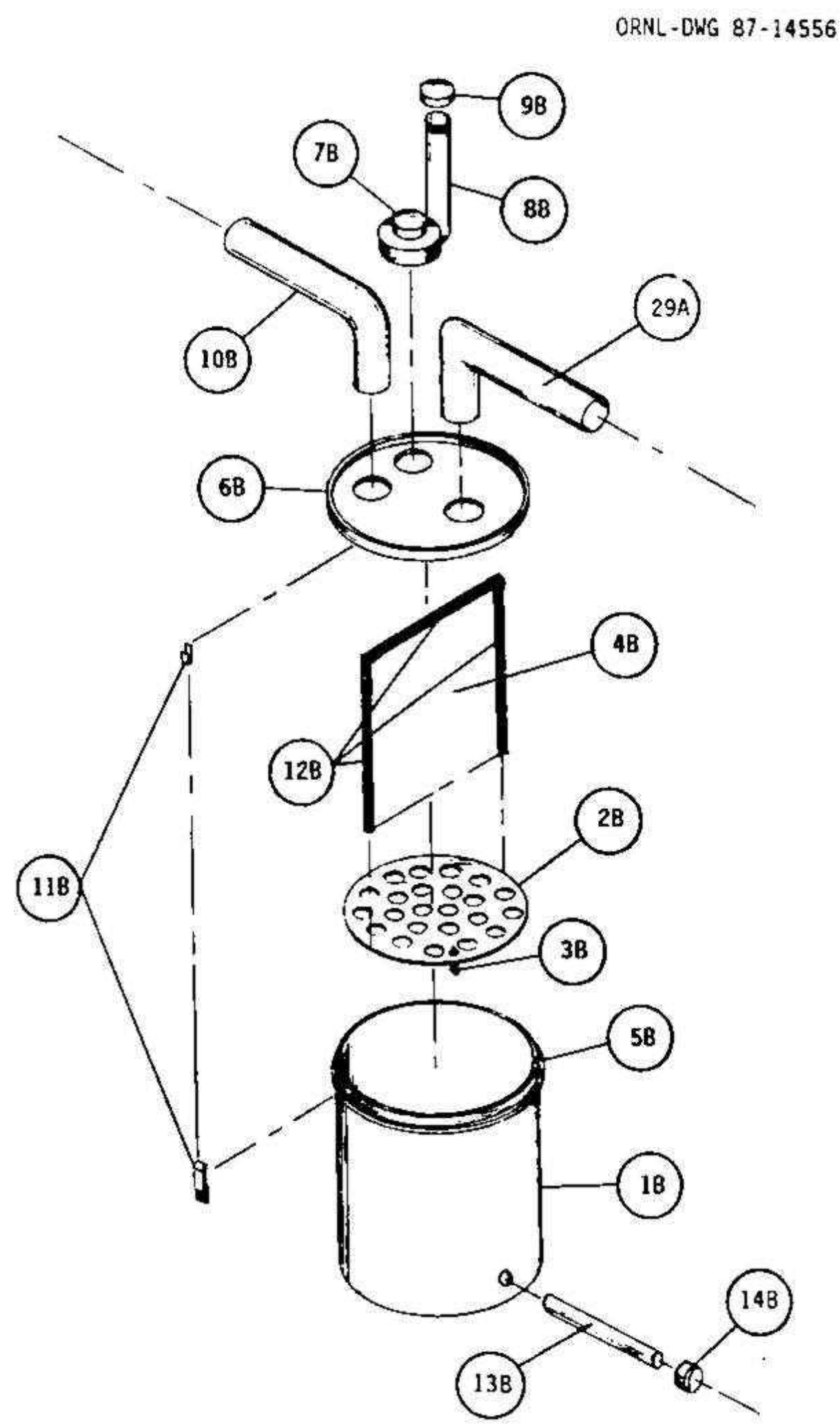

Fig. 2-15. Exploded, schematic diagram of the filter unit. 


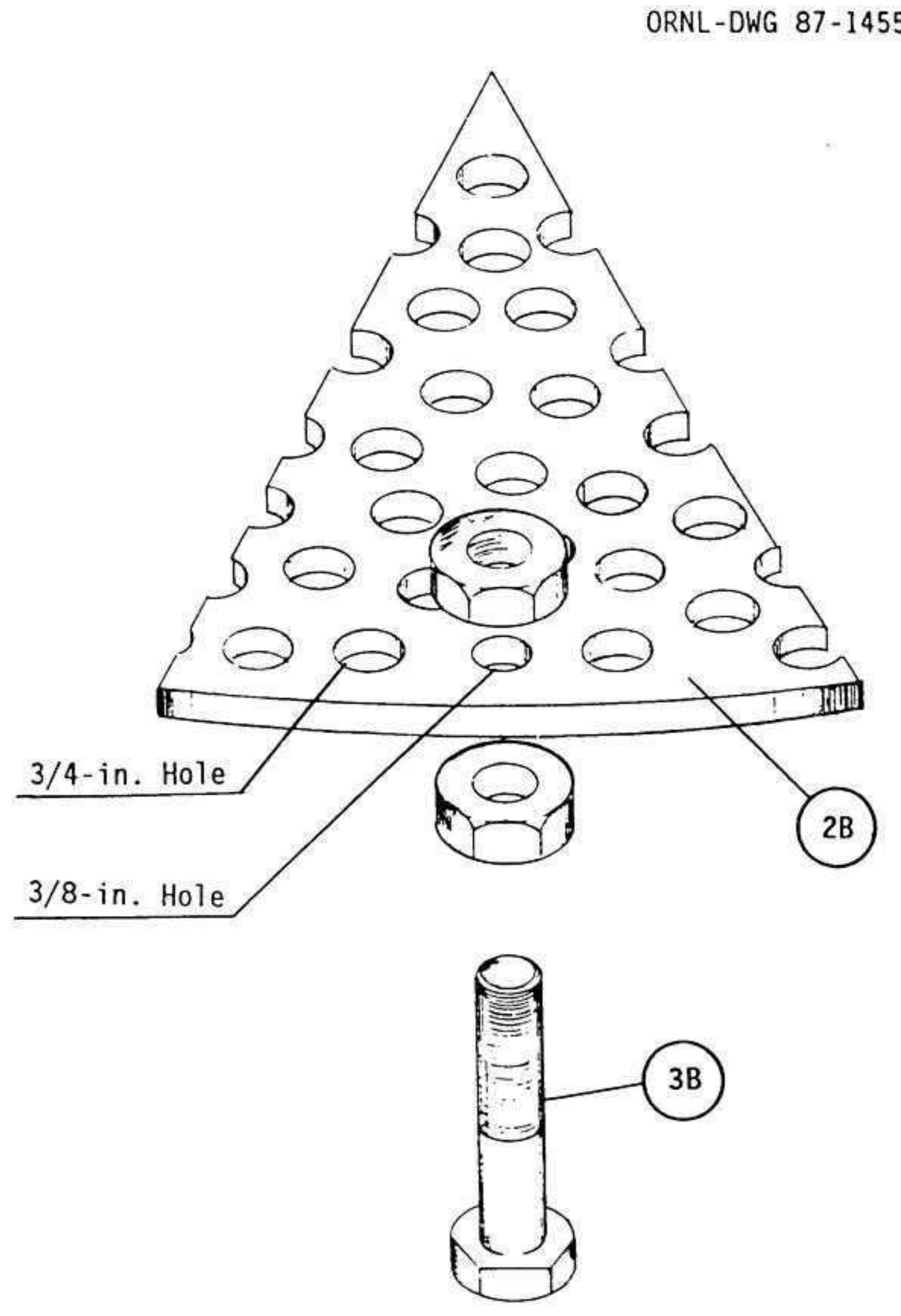

Fig. 2-16. Detail of the standoffs for the bottom plate of the filter unit. 


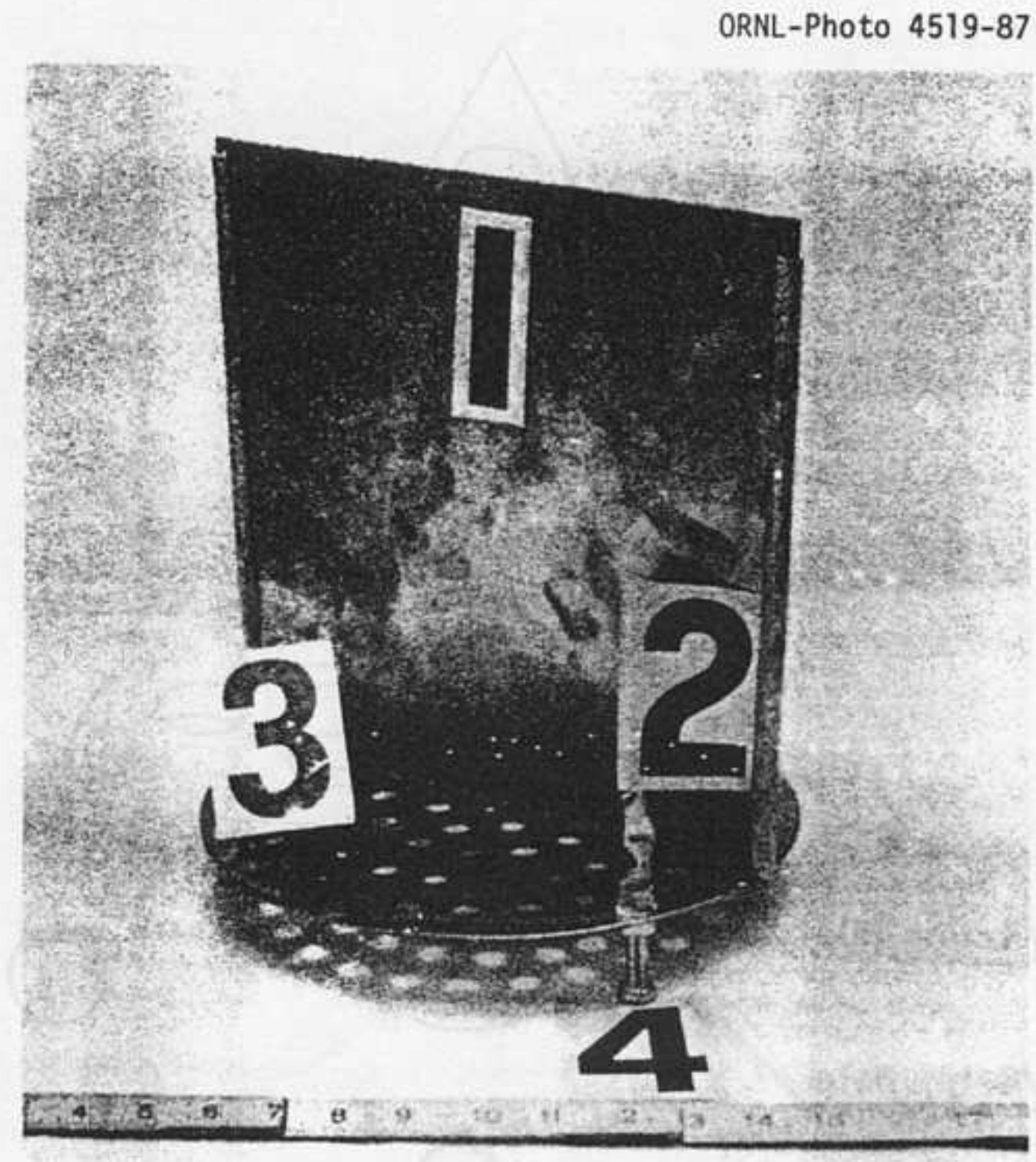

Fig. 2-17. Divider plate (\#1) and bottom plate (\#3), with standoffs (\#4), for the filter unit. Note the high-temperature hose lining the sides of the divider plate. 


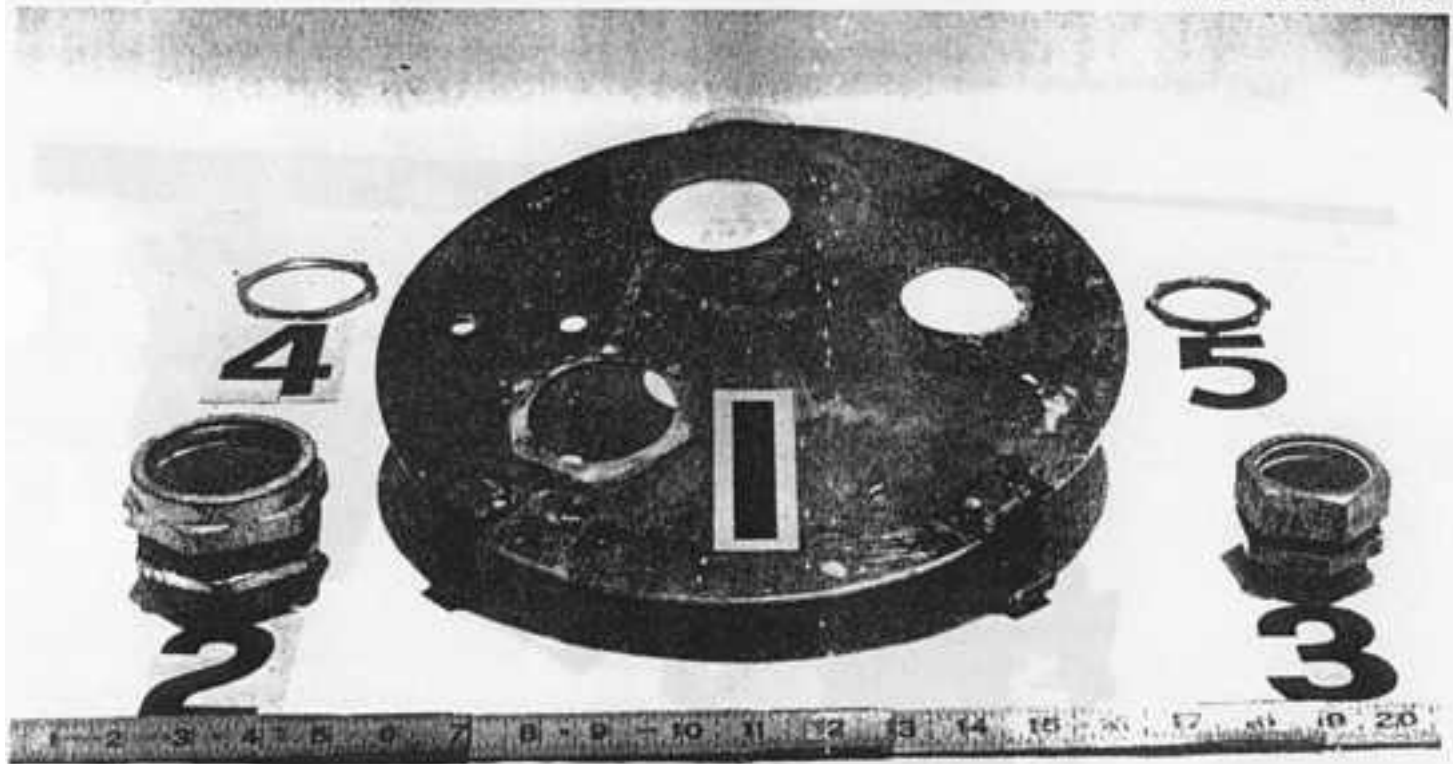

Fig. 2-18 Circular lid (\#1) for the filter unit. Note the arrangement of the holes; divider plate would roughly run from 10 o'clock position to 4 o'clock position (assuming 12 o'clock is taken to be at the rear of the photograph). Also shown are the conduit connectors ( $\# 2$ and $\# 3$ ) and accompanying nuts ( $\# 4$ and $\# 5$ ) for inside the lid.

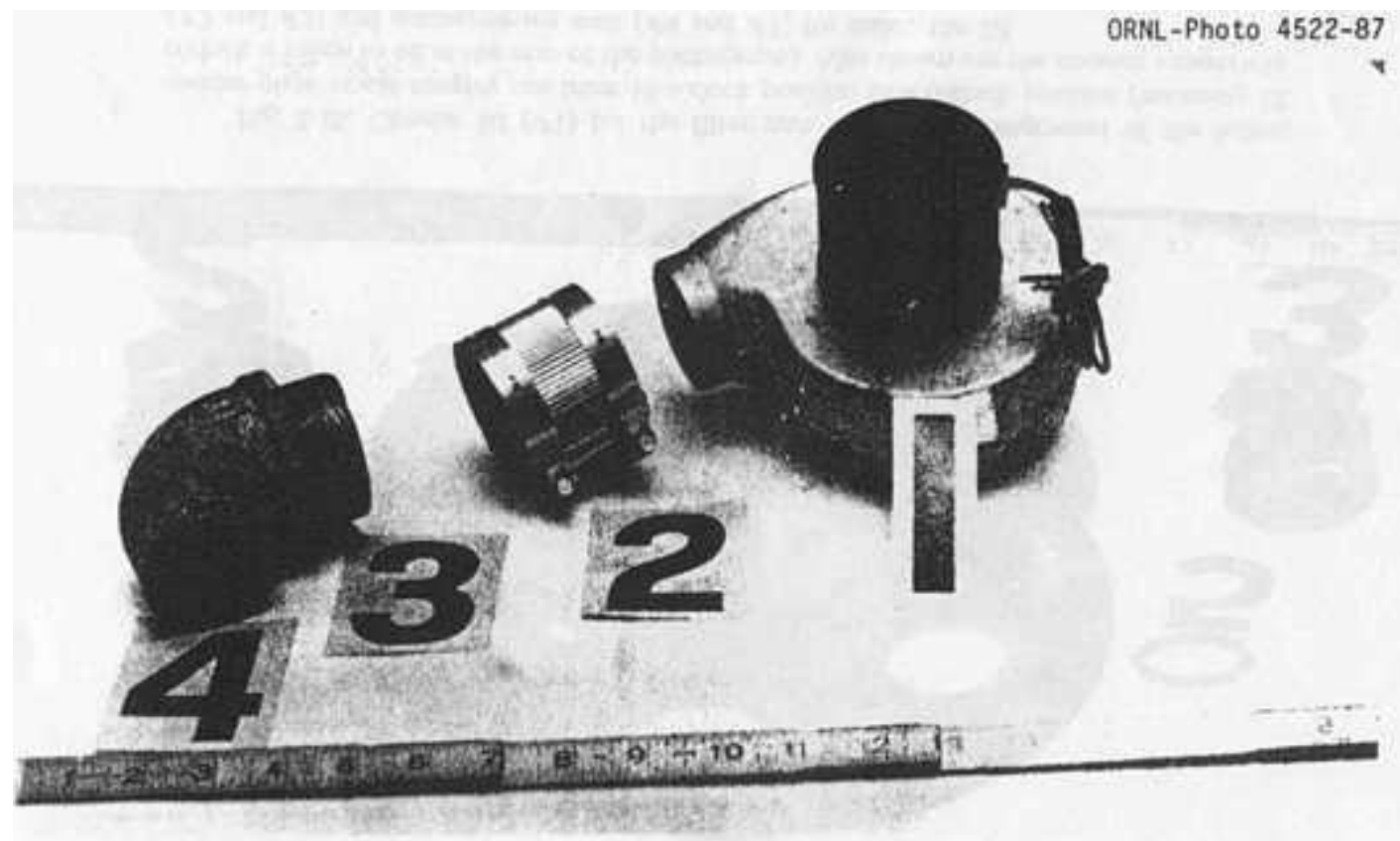

Fig. 2-19. Blower (\#1) with exhaust extension assembly. Note adapter coupling (\#2), pipe nipple ( $\# 3$ ), and elbow (\#4) for vertical exhaust pipe. 
ORNL-Photo $4512-87$

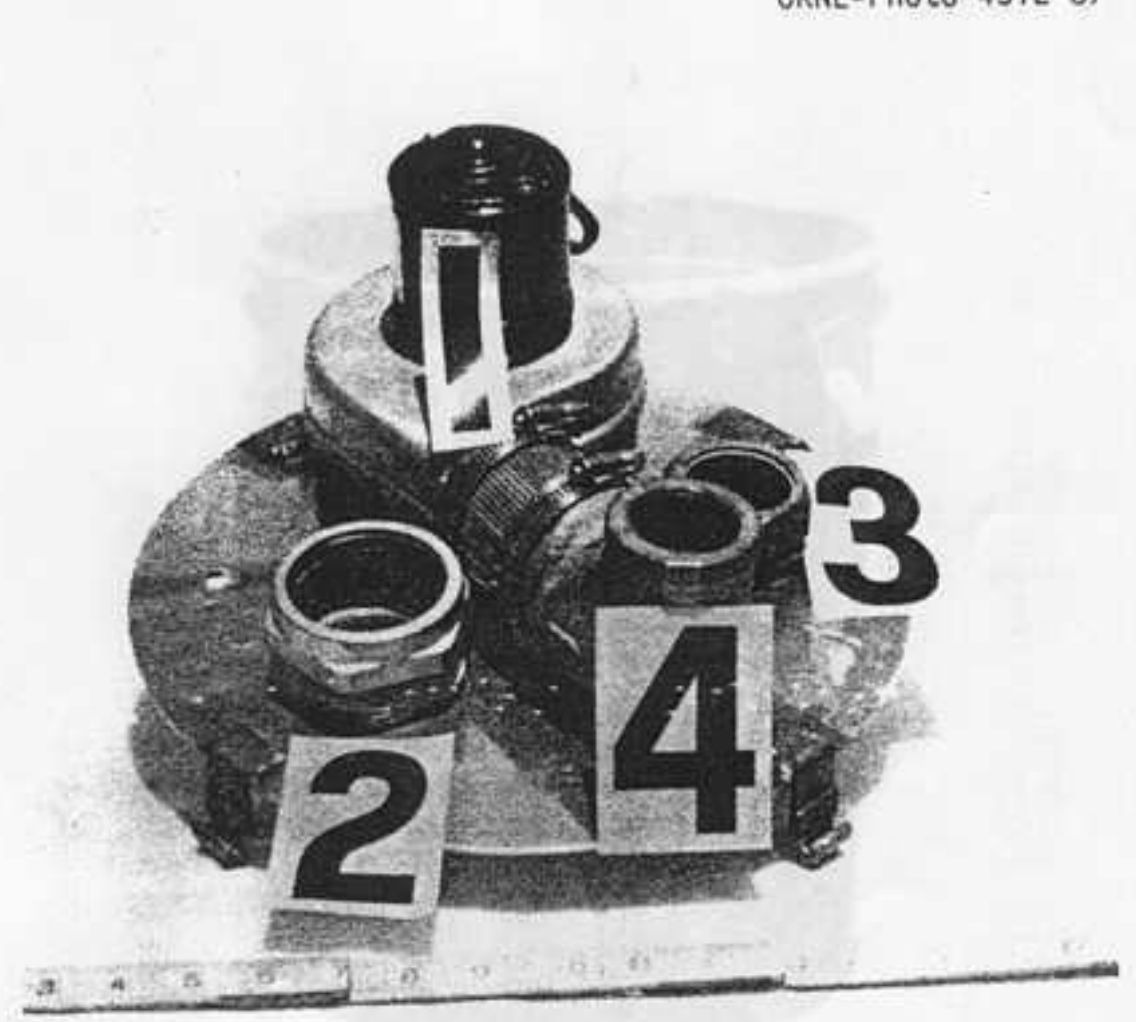

Fig, 2-20. Assembled and installed blower (\#1), extension assembly (\#4), and conduit connectors for gas inlet (\#2) and outlet (\#3) on lid of filter unit. Note hook attachments. at edge of lid for latches. 
ORNL-Photo $4517-87$

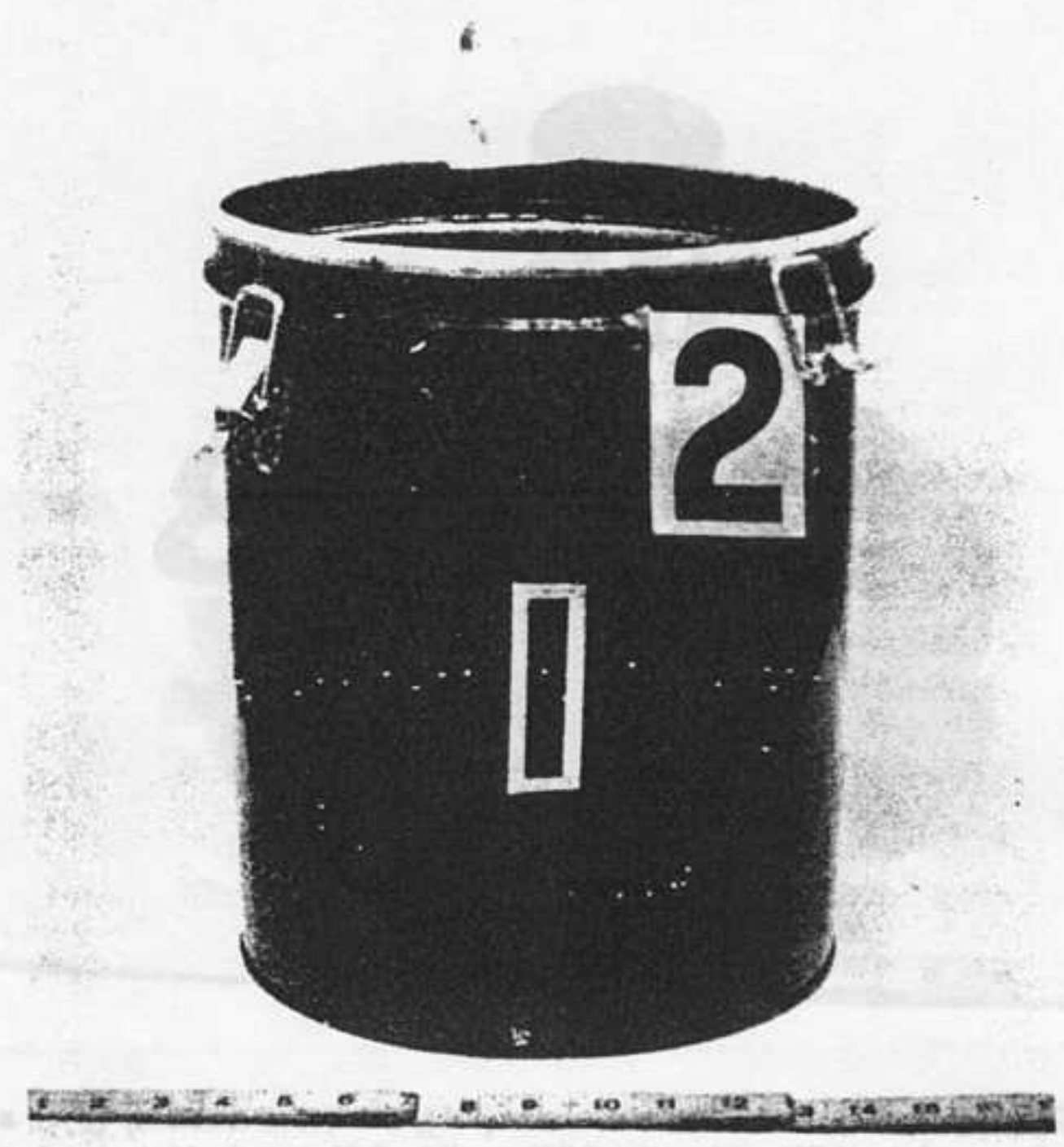

Fig. 2-21. Filter container (\#1) showing latches (\#2) for lid and hose (\#3) around top. 


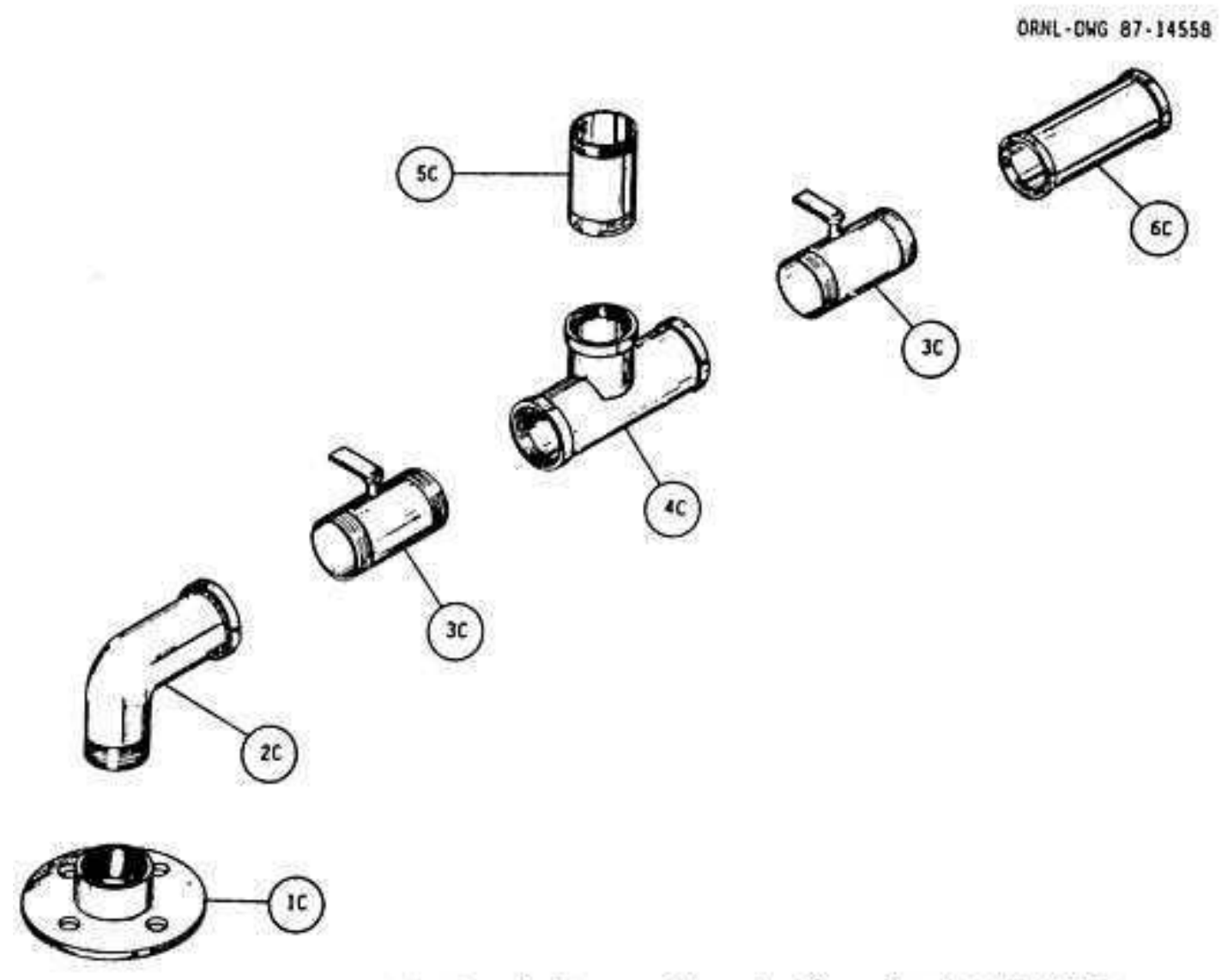

Fig, 2.22. Exploded, schematic diagram of the carbureting unit and control valves. 


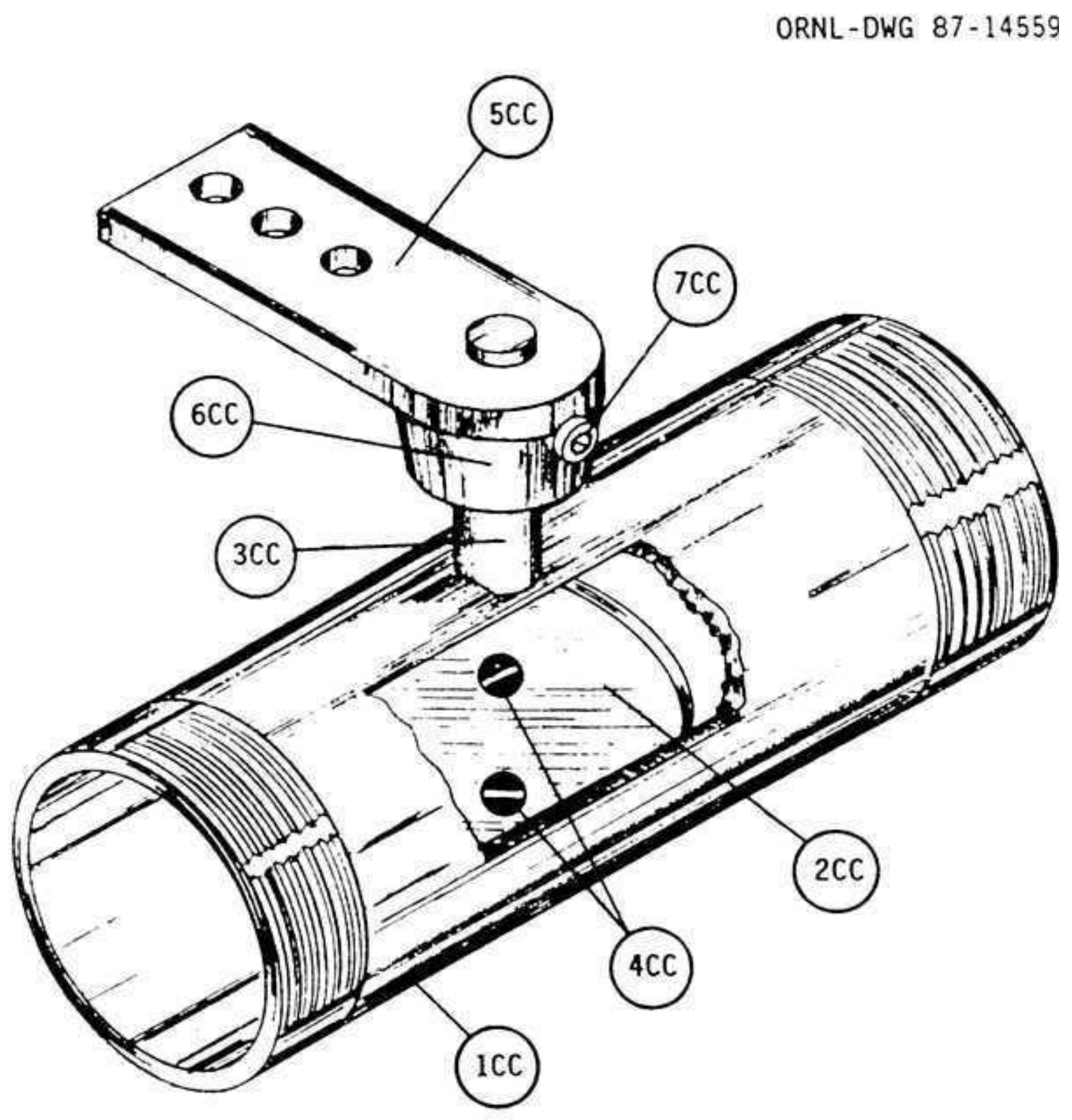

Fig. 2-23. Schematic diagram of a butterfly control valve. 


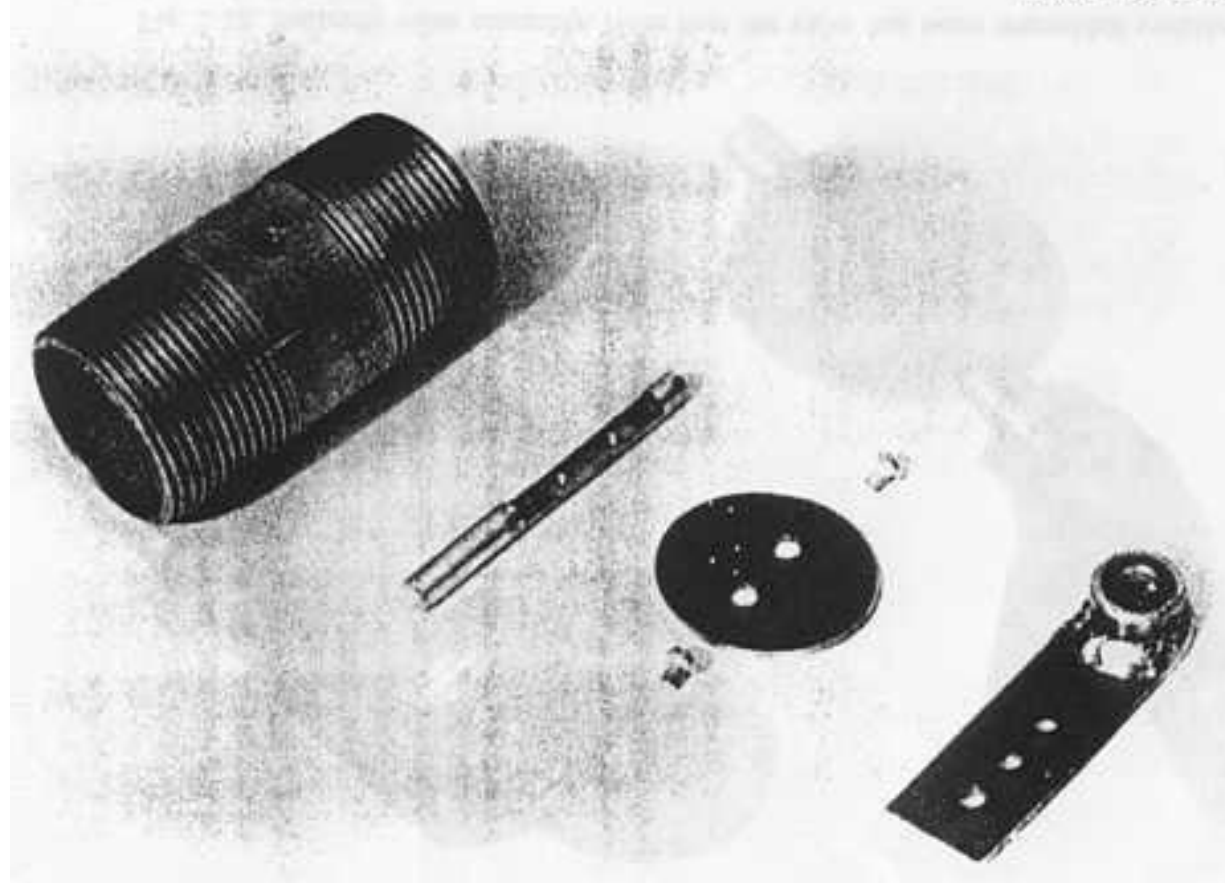

Fig. 2-24. Parts required for the butterfly valve.

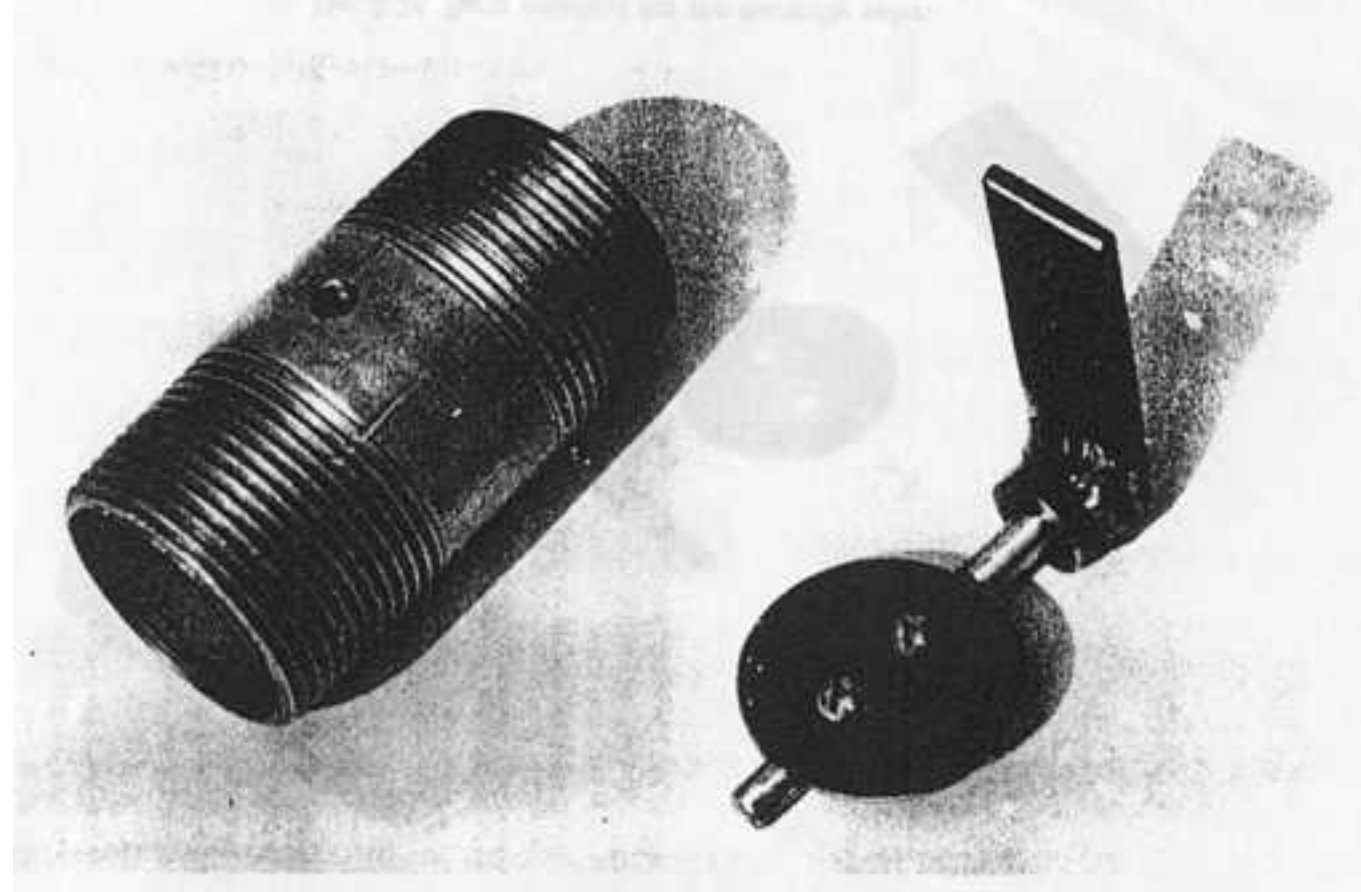

Fig. 2-25. Butterlly valve assembly. Note that the valve has been assembled outside of the valve body for clarity. 


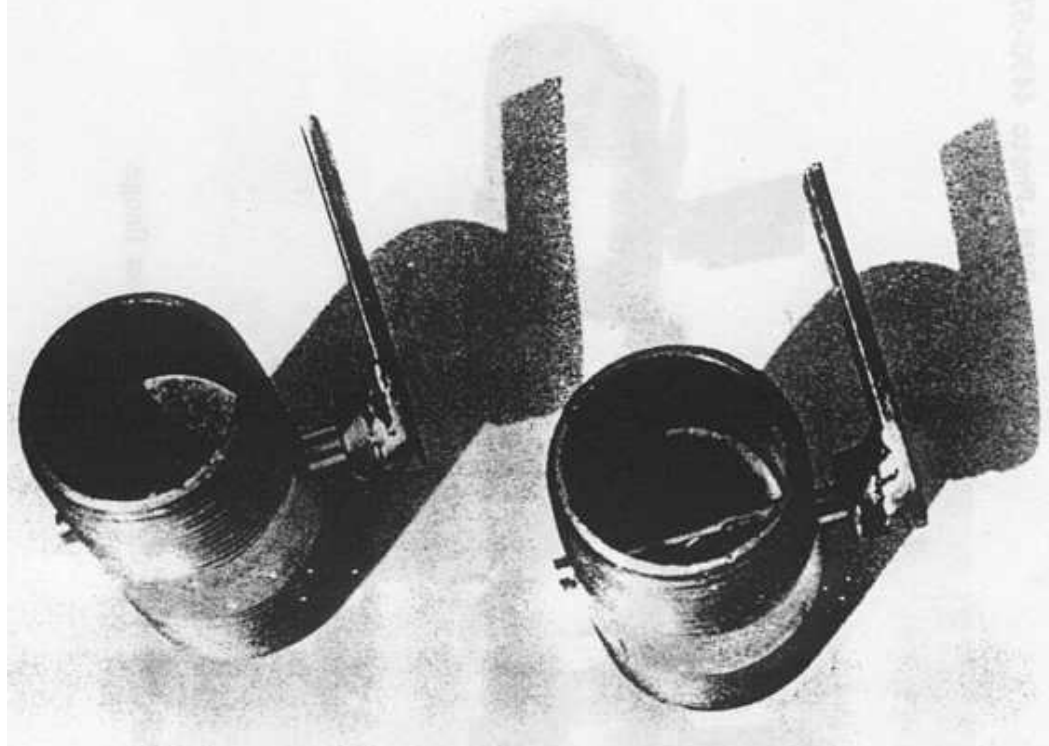

Fig. 2-26. Assembled butterfly valves.

ORNL-Photo $4490-8$

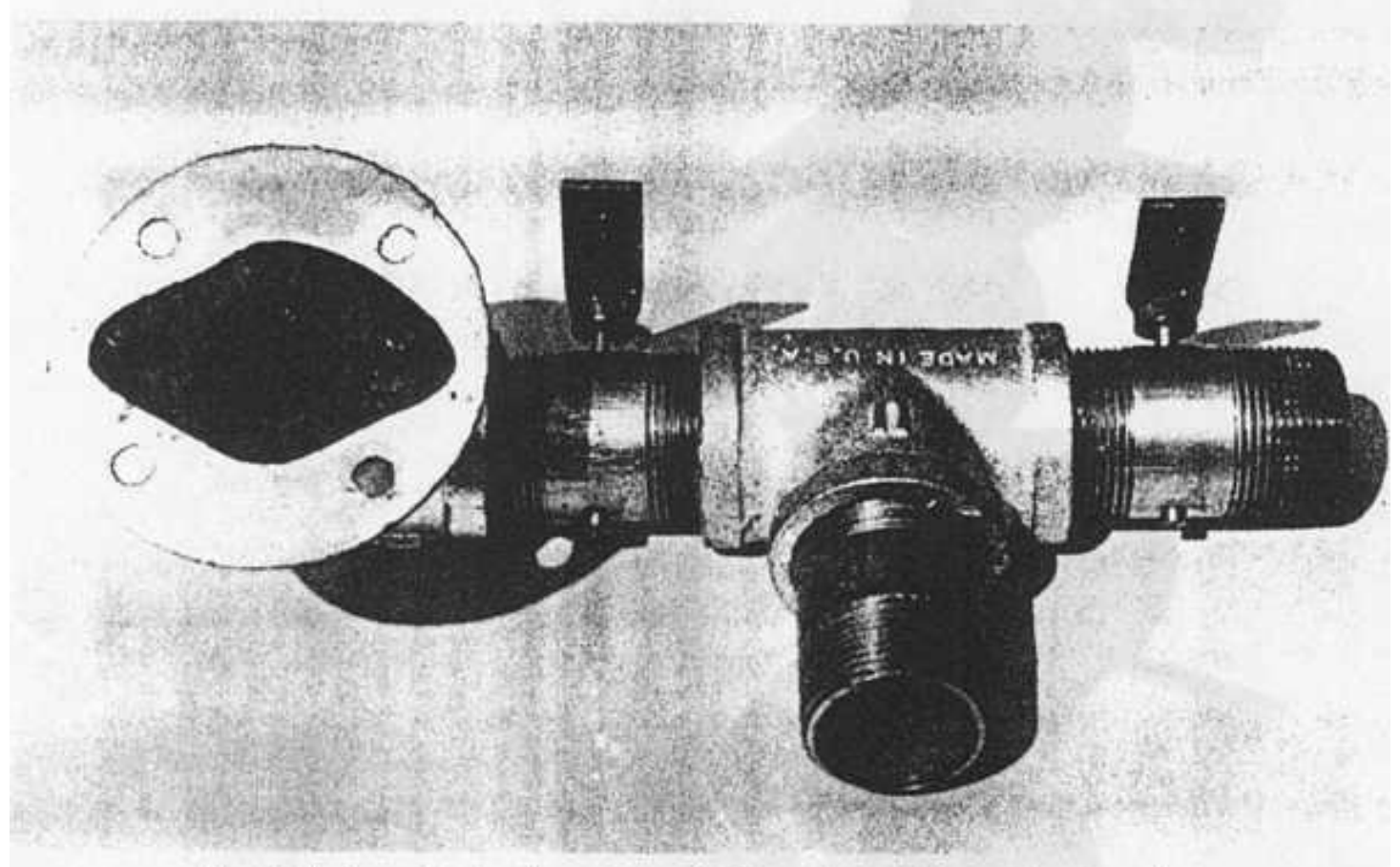

Fig. 2-27. Assembled carburetion unit. Note the gasket on the closet flange. 


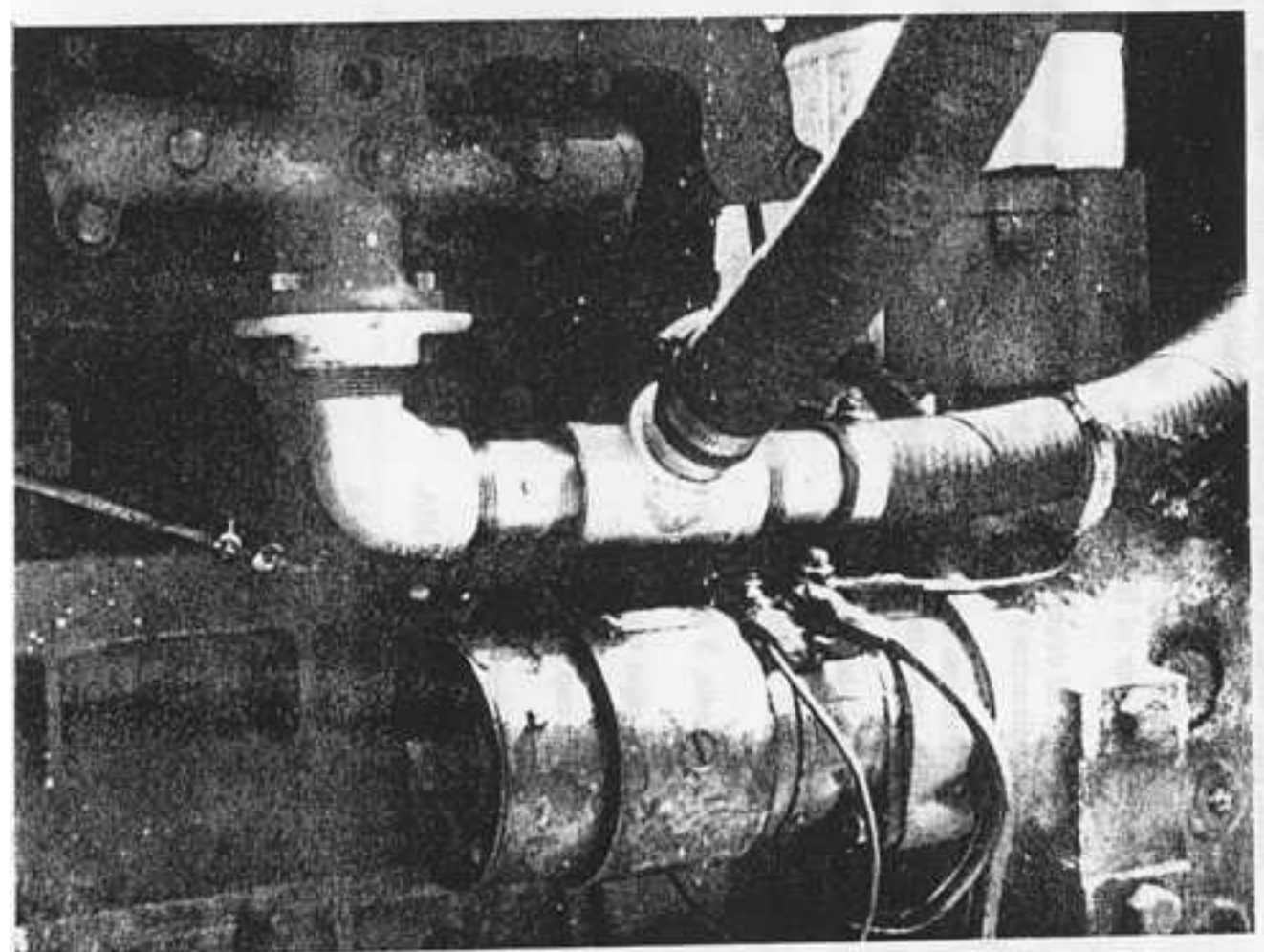

Fig. 2-28. Carburction unit attached to engine's existing intake manifold. Wood gas enters from the side of the tee; air enters from the right-hand end. The butterlly valve at the right (partially ohscured) is connected to the air control (choke) cable; the left valve is connected to the throttle linkage. 


\title{
Table 2-1.
}

\section{List of materials for the gasifier unit and the wood fuel hopper.}

\author{
Item Quantity Description
}

1A 1 Metal pipe, tube, or other, open-ended metal cylinder; diameter and length from Table 2-2; minimum wall thickness of $1 / 4$ in.

2A 1 Circular metal plate with thickness of $1 / 8$ in.; diameter equal to outside diameter of Item $1 \mathrm{~A}$.

3A i 30-gal metal oil drum or metal container with approximate dimensions of 18 in. (diameter) by 29 in. (height); container must have a bottom.

4A 1 10-quart stainless steel mixing bowl, container, or other stainless steel bowl with

5A 1 2-in. metal U-bolt.

6A 1 3/16-in. metal chain with 1 -in. links; $7 \mathrm{ft}$ total length.

7A 3 1/4-in. eyebolts, 3 in. length with two nuts for each eyebolt.

8A 14 -in. metal pipe nipple.

9A 1 Metal pipe, cap for Item 8A.

10A 2 3-in. metal pipe nipple.

11A 2 Metal pipe cap for Item 10A.

12A Shaker assembly; see Fig. 2-8.

1AA 1 Metal 1/2-in. pipe; 6 in. length.

2AA 1 Iron bar stock; square or round, 1/2 in.; 6 in. length.

3AA 1 1/2-in. bolt; 8 in. long.

4AA 1 Iron bar stock; rectangular, $1 / 4$ by 1 in.; 10 in. length.

5AA 1 1/2-in. flat washer.

6AA 2 1/2-in. nuts.

7AA 1 Metal pipe cap or bushing for Item 1AA.

13A 1 Iron bar stock; rectangular, $1 / 4$ by 2 in.; $10 \mathrm{ft}$ length.

14A 25 1/4-in. bolts; 314 in. length; with nuts.

15A 120 -gal metal garbage can or metal container with approximate dimensions of 18 in.

(top diameter) by 24 in. (height); bottom is not required

16A 1 Lid for 20-gal garbage can.

17A 1 Garden hose; $1 / 2$ to 5/8 in. diameter; length equal to circumference of Item $15 \mathrm{~A}$.

18A 1 Foam weather stripping with adhesive backing; 1/4 by I in.; length equal to

19A 1 Iron bar stock; rectangular, $1 / 4$ by 2 in.; $10 \mathrm{ft}$ length.

20A 12 1/4-in. bolts; 3/4 in. length; with nuts.

21A 4 Metal triangles; 2 by 2.5 in., $1 / 8$ to $1 / 4$ in. thick.

22A 2 Metal eye hook.

23A 2 Screen door spring, 14 in. length. 


\section{Table 2-1 Cont.}

Item Quantity

Description

24A 1 Lock ring for 30-gal (or larger) oil drum.

25A 4 Metal squares; 2 by 2 in., $1 / 4$ in. thick.

26A 4 3/8-in. bolts; 3 in. length.

27A 1 Tube. of high temperature silicone or liquid high temperature gasket material.

28A 1 60-lb. sack of hydraulic or other waterproof cement [such as SEC-PLUG (tm), which is maunfactured by the Atlas Chemical Company, Miami, FL]. 2-in. pipe, electrical conduit, flexible automobile exhaust pipe, or other metal

29A 1 tubing; 6-ft minimum length. Pipe must be able to withstand temperatures of $400^{\circ} \mathrm{F}$. 


\section{Table 2-2.}

\section{Fire tube dimensions}

$\begin{array}{cccc}\begin{array}{c}\text { Inside diameter } \\ \text { (inches) }\end{array} & \begin{array}{c}\text { Minimum length } \\ \text { (inches) }\end{array} & \begin{array}{c}\text { Engine power } \\ (\mathrm{hp})\end{array} & \begin{array}{c}\text { Typical engine displacement (cubic } \\ \text { inches) }\end{array} \\ 2- & 16 & 5 & 10 \\ 4- & 16 & 15 & 30 \\ 6 & 16 & 30 & 60 \\ 7 & 18 & 40 & 80 \\ 8 & 20 & 50 & 100 \\ 9 & 22 & 65 & 130 \\ 10 & 24 & 80 & 160 \\ 11 & 26 & 100 & 200 \\ 12 & 28 & 120 & 240 \\ 13 & 30 & 140 & 280 \\ 14 & 32 & 160 & 320\end{array}$

*A fire tube with an inside diameter of less than. 6 in. would create bridging problems with wood chips and blocks. If the engine is rated at or below 15 horsepower, use a 6-in. minimum fire tube diameter and create a throat restriction in the bottom of the tube corresponding to the diameter entered in the above table.

NOTES:

For engines with displacement rated in liters, the conversion factor is 1 liter $=61.02$ cubic inches. The horsepower listed above is the SAE net brake horsepower as measured at the rear of the transmission with standard accessories operating. Since the figures vary when a given engine is installed and used for different purposes, such figures are representative rather than exact. The above horsepower ratings are given at the engine's highest operating speed. 


\title{
Table 2-3.
}

\section{List of materials for the primary filter unit}

\author{
Item Quantity \\ Description \\ 1B $\quad 1^{5}$-gal metal can or other metal container with minimum dimensions of 11.5-in. \\ diameter and 13 in. tall. \\ 2B 1 Circular metal plate; diameter equal to $1 / 2$ in. smaller than inside diameter of Item \\ 3B 3 3/8-in. bolts; 3 in. length with two nuts for each bolt. \\ Rectangular metal plate; width equal to $1 / 4$ in. smaller than inside diameter of \\ 4B 1 Item 1B; height equal to 2.5 in. smaller than internal height of Item $1 \mathrm{~B} ; 1 / 8$ in. \\ thick. \\ 5B 1 High-temperature hose, $3 / 8$ to $5 / 8$ in. diameter; length equal to circumference of \\ Item 1B. \\ 6B 1 Circular metal plate; diameter equal to outside diameter of Item 1B; thickness of \\ $1 / 8$ in. \\ 7B 1 12-volt blower (automotive heater type); case and fan must be all metal. \\ 8B 1 Metal extension pipe for blower outlet, including elbows and connections for \\ vertical orientation; $1 \mathrm{ft}$. minimum length. \\ 9B 1 Cap for Item 8B; plastic is acceptable. \\ 10B 1 1.25-in. metal pipe, electrical conduit, automotive exhaust pipe, or other metal \\ tubing; $2 \mathrm{ft}$ minimum length. \\ Metal latch for securely connecting Items 1B and 6B together. Such devices as \\ 11B 3 suitcase or luggage catches, bail-type latches, window sash catches (with strike), \\ or wing-nut latches are acceptable. \\ 12B 1 High-temperature hose, $3 / 8$ to $5 / 8$ in. diameter; length equal to three times the \\ 13B 1 Metal 1/2-in. pipe, threaded on one end; 8 in. length. \\ 14B 1 Metal pipe cap for Item 13B.
}




\section{Table 2-4.}

\section{List of materials for the carbureting unit}

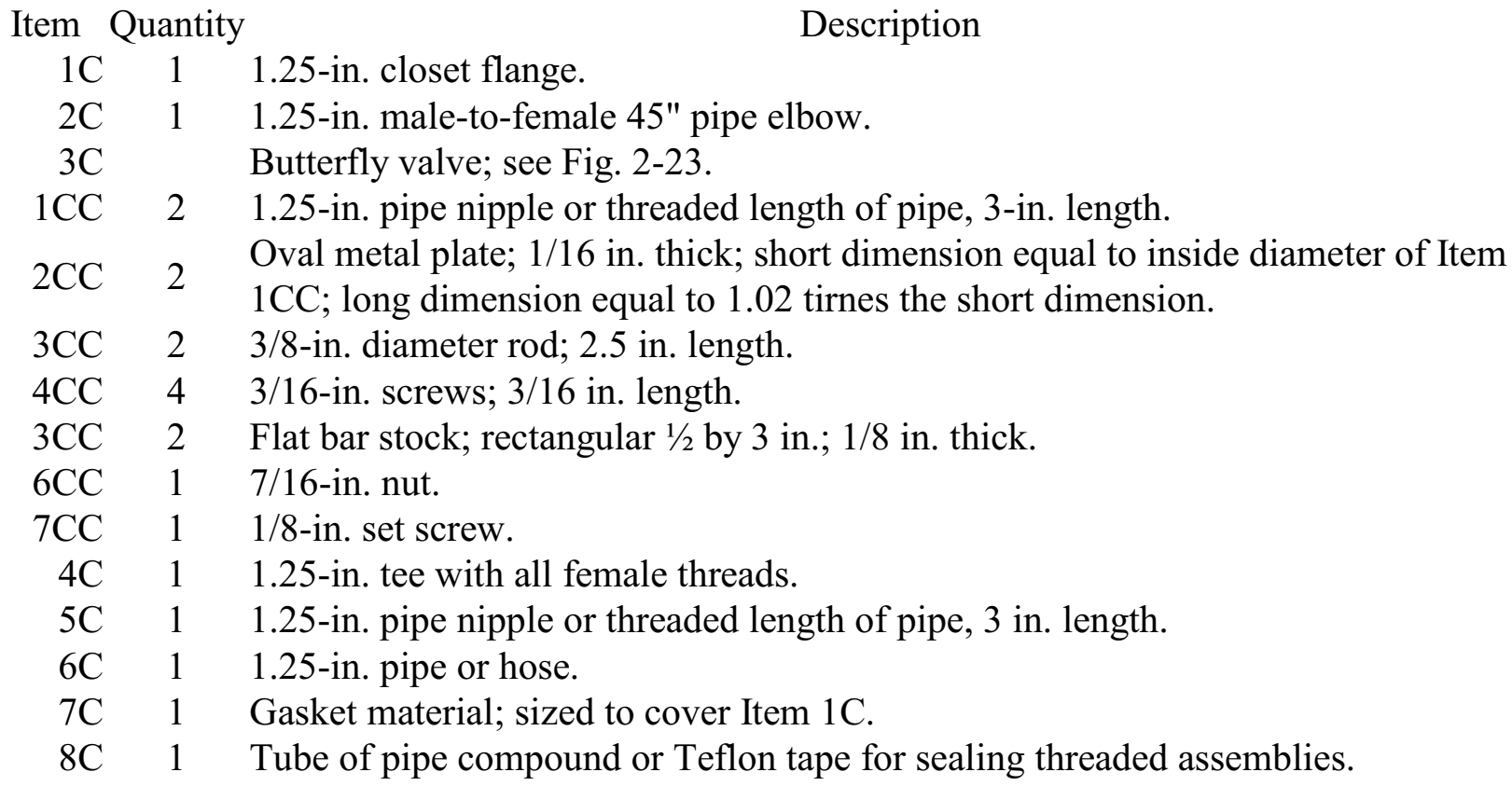




\section{OPERATING AND MAINTAINING YOUR WOOD GAS GENERATOR}

\subsection{USING WOOD AS A FUEL}

Because wood was used extensively as generator fuel during World War II, and since it is plentiful in most parts of the populated United States, it merits particular attention for use as an emergency source of energy. When used in gas generators, about $20 \mathrm{lb}$ of wood have the energy equivalence of one gallon of gasoline. Wood consists of carbon, oxygen, hydrogen, and a small amount of nitrogen.

As a gas generator fuel, wood bas several advantages. The ash content is quite low, only 0.5 to $2 \%$ (by weight), depending on the species and upon the presence of bark. Wood is free of sulfur, a contaminant that easily forms sulfuric acid which can cause corrosion damage to both the engine and the gas generator. Wood is easily ignited a definite virtue for the operation of any gas generator unit.

The main disadvantages for wood as a fuel are its bulkiness and its moisture content. As it is a relatively light material, one cubic yard of wood produces only 500 to $600 \mathrm{lbs}$. of gas generator fuel. Moisture content is notoriously high in wood fuels, and it must be brought below $20 \%$ (by weight) before it can be used in a gas generator unit. By weight, the moisture in green wood runs from 25 to $60 \%$, in air-dried wood from 12 to $15 \%$, and in kiln-dried wood about $8 \%$.

Moisture content can be measured quite easily by carefully weighing a specimen of the wood, placing it in an oven at 220 o F for thirty minutes, re-weighing the specimen, and re-heating it until its weight decreases to a constant value. The original moisture content is equivalent to the weight lost.

The prototype unit in this manual (with a 6-in.-diam firetube) operated well on both wood chips (minimum size: $3 / 4$ by $3 / 4$ by $1 / 4$ in.) and blocks (up to 2 -in. cubes); see Fig. 3-1 (all figures and tables mentioned in Sect. 3 are presented at the end of Sect. 3). Larger sizes could be used, if the firetube diameter is increased to prevent bridging of the individual pieces of wood; of course, a throat constriction would then have to be added to the bottom of the firetube so as to satisfy the dimensions in Table 2-2 in Sect. 2.

\subsection{SPECIAL CONSIDERATIONS AND ENGINE MODIFICATIONS}

To start the fire in the gasifier, the blower must be used to create a suction airflow through the wood in the hopper and downward in the firetube. If an especially high horse power engine is to be fueled by the gasifier unit, then it might be necessary to install two such blowers and run them simultaneously during start-up. When the wood gas leaves the gasifier unit, all the oxygen pulled down with the air through the firetube has been chemically converted and is contained in carbon monoxide (CO) and water $(\mathrm{H} 20)$. The wood gas is unable to burn without being mixed with the proper amount of additional oxygen.

If an air leak develops below the grate area, the hot gas will burn while consuming the available oxygen and will create heat; this will almost certainly destroy the gasifier unit if it is not detected soon. If an air leak develops in the filter unit or in the connecting piping, the gas will become saturated with improper amounts of oxygen and will become too dilute to power the engine. Therefore airtightness from the gasifier unit to the engine is absolutely essential. 
Ideally, as the wood gas enters the engine manifold it should be mixed with air in a ratio of 1:1 or 1.1:1 (air to gas) by volume. The carbureting system described in this report will provide this mixture with a minimum of friction losses in the piping. The throttle control valve and the air control valve must be operable from the driver's seat of the vehicle. The engine's spark plug gaps should be adjusted to between 0.012 and 0.015 in.; the ignition timing should be adjusted to 'early.'

\subsection{INITIAL START-UP PROCEDURE}

Initially, you will need to add charcoal to the grate below the fire tube. Subsequent operation will already have the grate full of charcoal which has been left over from the previous operating period. Fill the fire tube with charcoal to a level 4 in. above the grate. Fill the hopper with air-dried wood; then, proceed with the routine start-up directions below. Charcoal produced for outdoor barbecue grills is not well suited for gas generator use. To produce a better grade of charcoal, place a rag soaked in alcohol on the grate, or place 3 to 5 pages of newspaper on the grate, then fill the fire tube to a height of 10 to $12 \mathrm{in.} \mathrm{with} \mathrm{well-dried} \mathrm{wood.} \mathrm{Have} \mathrm{all} \mathrm{the} \mathrm{valves}$ closed and let the fire tube act as a chimney until the wood is converted to charcoal.

\subsection{ROUTINE START-UP PROCEDURE}

1. Agitate the grate shaker handle for at least twenty seconds to shake down the cCharcoal from the previous operating period.

2. Open the ash clean out port and remove the ashes from the generator housing drum. Lubricate the threads of the clean out port with high-temperature silicone, and close the cover of the clean out port so that it is airtight.

3. Fill the hopper with wood fuel, and tamp the fuel down lightly. Either leave the lid completely off the fuel hopper, or adjust the opening around the lid to a 3/4-in. (or larger) clearance.

4. Close the carburetor's air control valve and remove the cover from the blower exhaust on top of the filter unit. Start the blower, and let it run for thirty seconds to avoid explosion of residual gas in the system. Then, with the blower still operating, proceed with the next step.

5. Open the ignition port, and ignite a 12- by 12-in. piece of newspaper; with a long stick or wire, push the burning sheet of newspaper into the grate; see Fig 3-2. Close the ignition port. If no smoke appears at the blower's exhaust port, repeat the start-up sequence from Step (5). If repeated attempts fail. new charcoal should be added to the unit as described in Sect. 3.3, above, and the start-up ignition sequence should be repeated.

6. After a few minutes of smoky exhaust, test the gas at the, blower exhaust by safely and carefully attempting to ignite it, see Fig. 3-3. When the gas burns consistently well, stop the blower and replace the cover on the blower exhaust.

7. Open the carburetor's air control valve, adjust the engine's accelerator, and start the engine in a normal manner. Let the engine warm up slowly (two to five minutes). If the engine fails to start or dies repeatedly, restart the blower and repeat the ignition sequence from Step (4). 


\subsection{DRIVING AND NORMAL OPERATION}

Shift gears so as to keep the engine speed (rpm) high at all times. Remember that it is the vacuum created by the pistons that provides the force which moves the gas from the gasifier unit into the engine. Refill the hopper with wood (as shown in Fig 3-4) before it is completely empty, but avoid refilling just before the end of engine operation. Periodically shake down the ashes from the grate. If your system is equipped with a gas cooler, drain water from the cooler from time to time.

Under operation in dry weather, the gasifier can be operated without the lid on the fuel hopper. However, when the Gasifier unit is shut down the hopper must be covered to prevent air from continuing to burn the wood in the hopper. Under wet-weather operation, the cover must be placed on the fuel hopper, and then lifted up and rotated about 2 in. until the triangular pieces line up with the holes in the support bars. The tension of the screen door springs will then hold the lid closed. See Fig 3-5 for clarification.

\subsection{SHUTTING DOWN THE GASIFIER UNIT}

When shutting down the gasifier unit, turn off the ignition switch and open the carburetor's air control valve for ten seconds to relieve any pressure from within the system. Then, completely close the air control valve, and place the cover tightly on the fuel hopper. When restarting after a short stopover, let the engine warm up briefly. After longer stops (up to one hour), tamp down the wood lightly and try to use the blower for restarting without relighting the wood fuel. After very long stops (over two hours) the charcoal must be ignited again.

\subsection{ROUTINE MAINTENANCE}

Periodically check all nuts on the gasifier unit, the fuel hopper, the filter unit, and the carburetor for snugness; check all penetrations and fittings for airtightness. In addition, perform the following maintenance activities as scheduled:

\subsubsection{Daily Maintenance}

Open the ash clean out port of the gasifier housing drum and remove the ashes after shaking the grate for at least thirty seconds. Replace the cover of the port after coating the threads with high-temperature silicone to ensure airtightness. Open the drain tube, at the bottom of the filter container and allow any liquid condensate to drain out; remember to close the drain tube when finished.

\subsubsection{Weekly Maintenance (or every 15 hours of operation)}

Clean out the gasifier housing drum, the fuel hopper, and the filter. Rinse out the piping and connections to and from the filter. Replace the wood chips inside the filter, (The used wood chips from the filter can be dumped into the fuel hopper and burned to produce wood gas.) Use high-temperature silicone on all pipe connections and on the filter lid to ensure air tightness.

\subsubsection{Biweekly Maintenance (or every 30 hours of operation)}

Make sure that all pipe connections are secure and airtight. Check and tighten all mounting connections to the vehicle chassis. Check for rust on the outside of the gas generator housing drum, especially on the lower region. Coat with high-temperature protective paint as necessary. 


\subsection{OPERATING PROBLEMS AND TROUBLE-SHOOTING}

A discussion of problems and their related causes and cures is contained in the trouble-shooting guide of Table 3-1. Many operational problems can be traced to failure to maintain the air tightness of all piping connections and fittings; the piping should be routinely checked to prevent such problems.

\subsection{HAZARDS ASSOCIATED WITH Gasifier OPERATION}

Unfortunately, gas generator operation involves certain problems, such as toxic hazards and fire hazards. These hazards should not be treated lightly; their inclusion here, at the end of this report, does not mean that these hazards are unimportant. The reader should not underestimate the dangerous nature of these hazards.

\subsubsection{Toxic Hazards}

Many deaths in Europe during World War II were attributed to poisoning from wood gas generators. The danger of 'generator gas poisoning' was one of the reasons that such gasifiers were readily abandoned at the end of World War II. It is important to emphasize that 'generator gas poisoning' is carbon monoxide ( $\mathrm{CO}$ ) poisoning. Acute 'generator gas poisoning' is identical with the symptoms that may develop if a heating stove damper is closed too early, or if a gasoline vehicle is allowed to idle in a poorly ventilated garage. Table 3-2 shows how poisoning symptoms develop according to the concentration of carbon monoxide in breathable air. It is important to note that rather brief exposures to very small concentrations of carbon monoxide result in undesirable physiological effects.

In case of carbon monoxide poisoning, first aid should consist of the following procedures:

1. Move the victim quickly out into the open air or to a room with fresh air and good ventilation. All physical exertion on the part of the victim must be avoided.

2. If the victim is unconscious, every second is valuable. Loosen any tight clothing around the neck. If breathing has stopped, remove foreign objects from the mouth (false teeth, chewing gum, etc.) and immediately give artificial respiration.

3. Keep the victim warm.

4. Always call a physician.

5. In case of mild carbon monoxide poisoning without unconsciousness, the victim should be given oxygen if possible.

\subsubsection{Technical Aspects of 'Generator Gas Poisoning'}

Generator gas poisoning is often caused by technical defects in the functioning of the gas generator unit. When the engine is running, independent of the starting blower, the entire system is under negative pressure created by the engine's pistons; the risk of poisoning through leakage is therefore minimal. However, when the engine is shut off, formation of wood gas continues, causing an increase of pressure inside the generator unit. This pressure increase lasts for approximately 20 minutes after the engine is shut off. 
For this reason, it is not advisable to stay in the vehicle during this period. Also, the gas generator unit should be allowed to cool for at least 20 minutes before the vehicle is placed in an enclosed garage connected with living quarters. It should be emphasized that the gas formed during the shutdown period has a carbon monoxide content of 23 to $27 \%$ and is thus very toxic.

\subsubsection{Fire Hazard}

The outside of a gas generator housing drum may reach the same temperature as a catalytic converter on today's automobiles. Care should be taken when operating in areas where dry grass or combustible material can come into contact with the housing drum of the gas generator unit. If a gas generator unit is mounted on a personal car, bus, van or truck, a minimum 6-in. clearance must be maintained around the unit. Disposal of ashes must only be attempted after the unit has cooled down (to below $150 \mathrm{oF}$ ). Such residue must be placed away from any combustible material and preferably be hosed down with water for absolute safety.

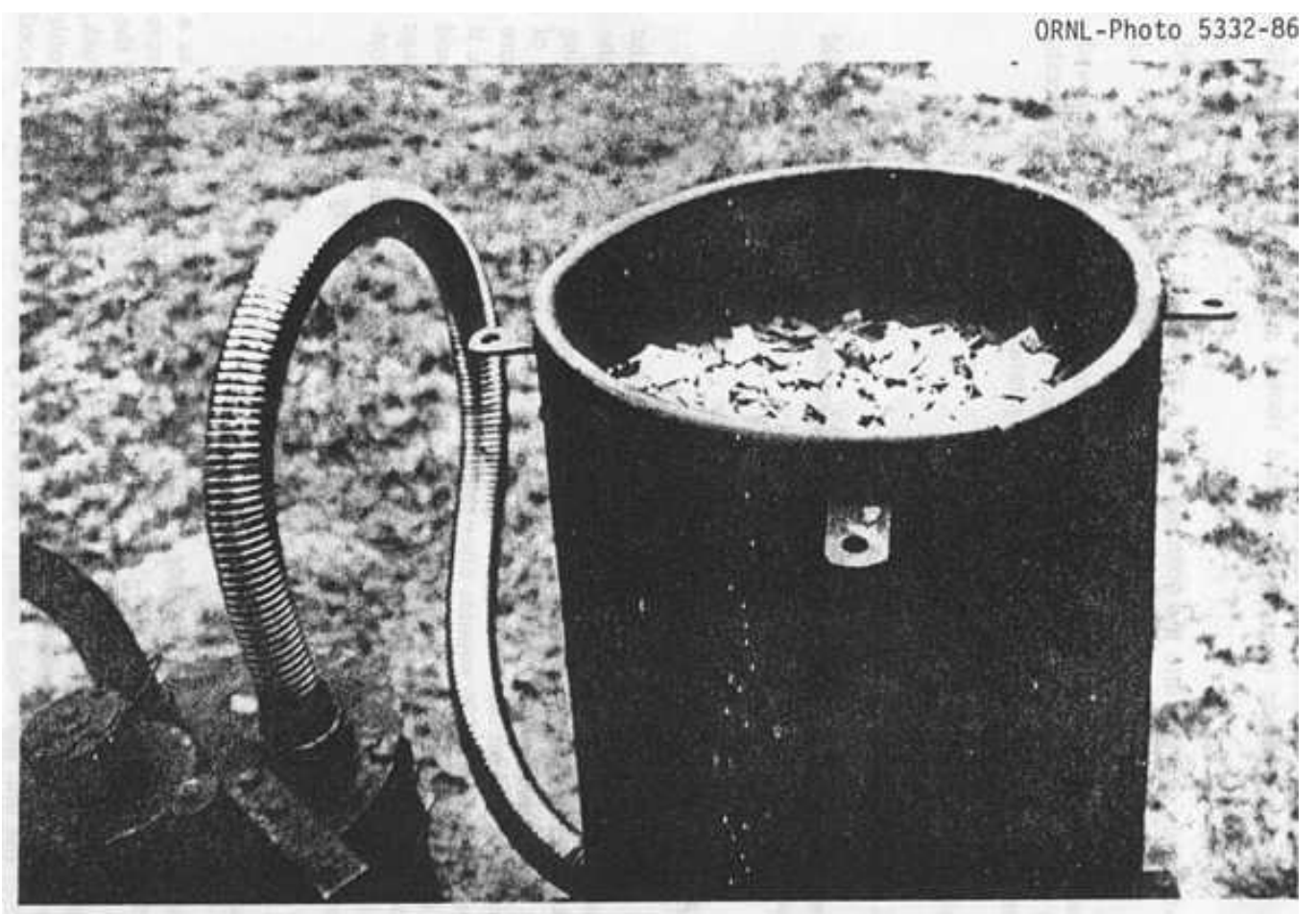

Fig. 3-1. Virtually all varieties of wood chips can be used for fuel. (Minimum size for this 6 -in. firetube unit: $3 / 4$ by $3 / 4$ by $1 / 4$ in.; maximum size: 2 -in. cubes.) 
OR:LL-Photo :313-86

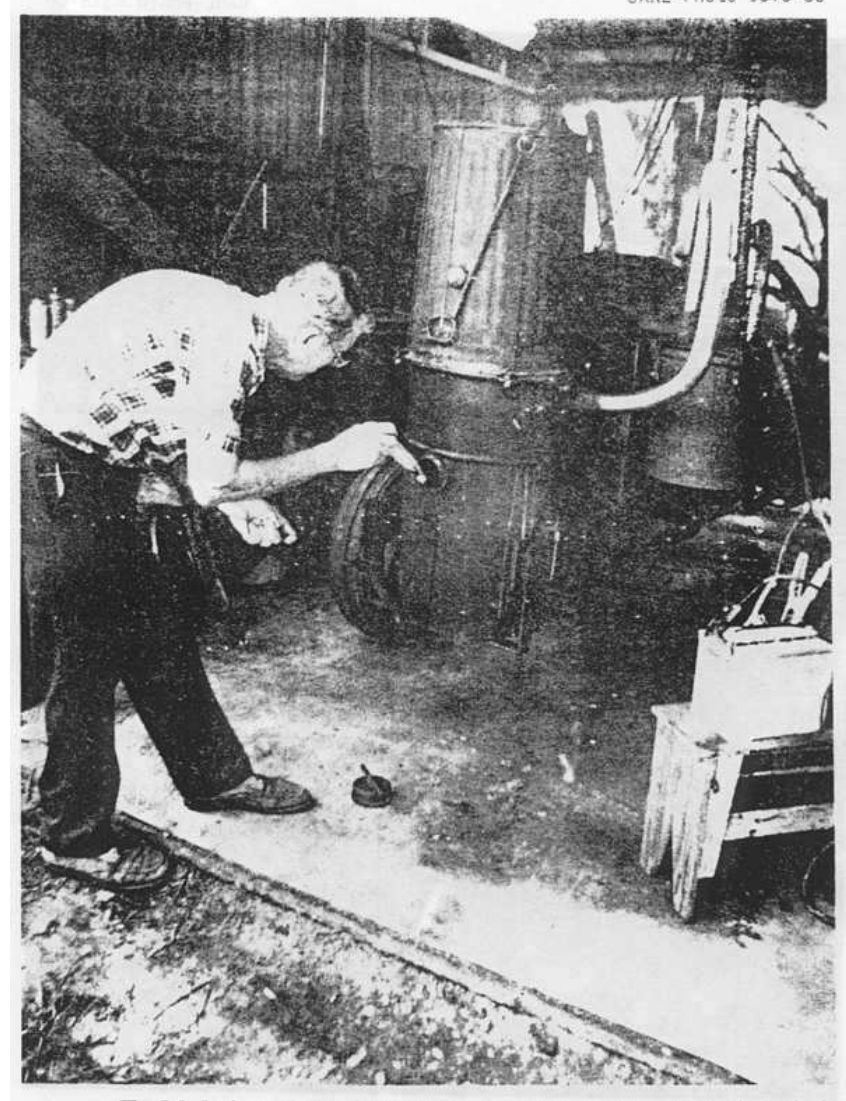

Fig. 3-2 Ignite a single picce of newspaper to start the gasificr unit. Push the flaming newspaper through the ignition port and directly into the grate. (At the right of the photo, note the battery which is operating the blower atop the filter unit.)

62

ORNL-Photo $5315-86$

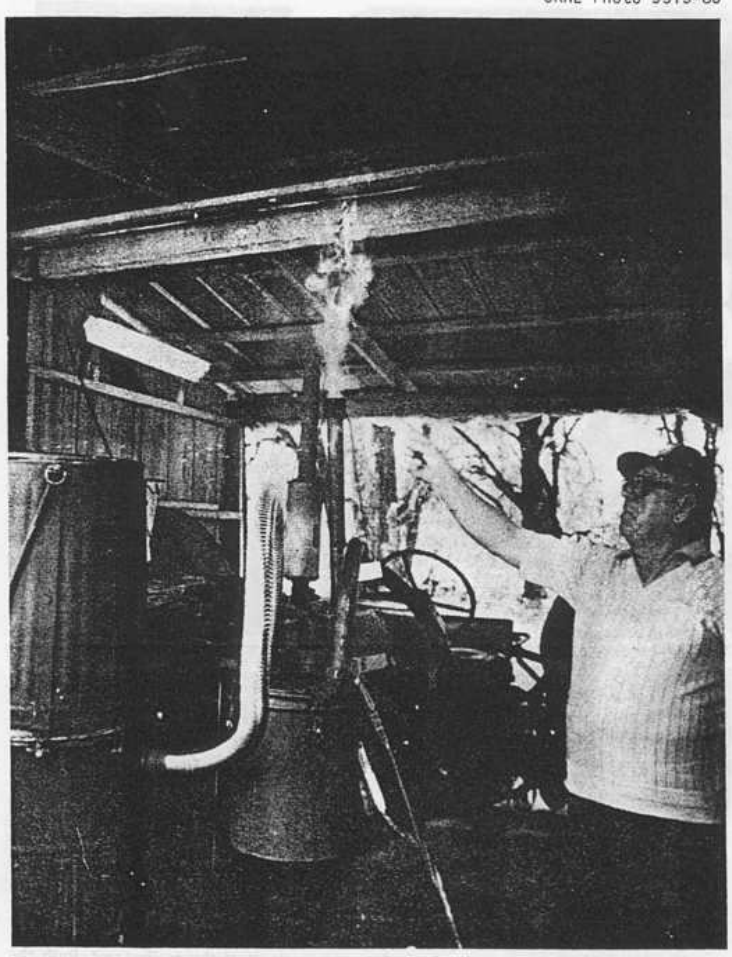

Fig. 3-3. Igniting the exhaust gas will demonstrate that the gasifier unit is working properly. 


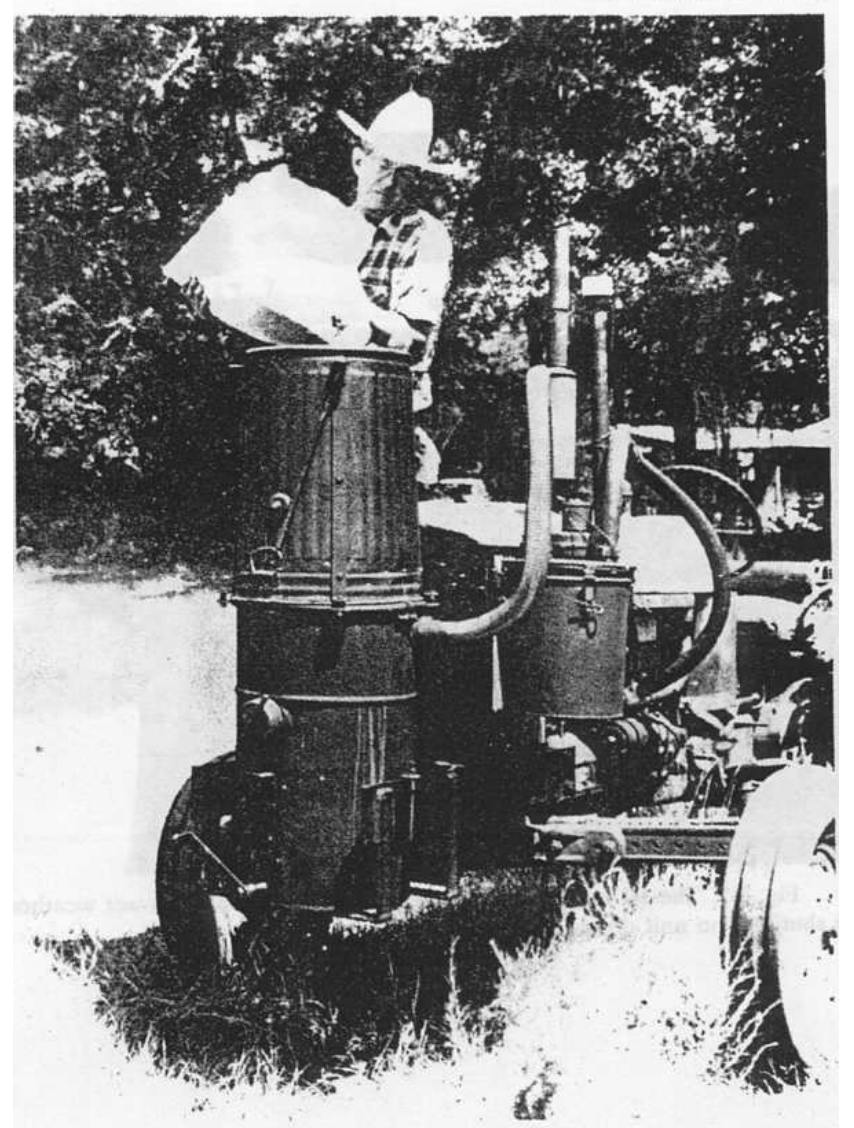

Fig. 3-4. Refill the fuel hopper before it becomes two-thirds empty.

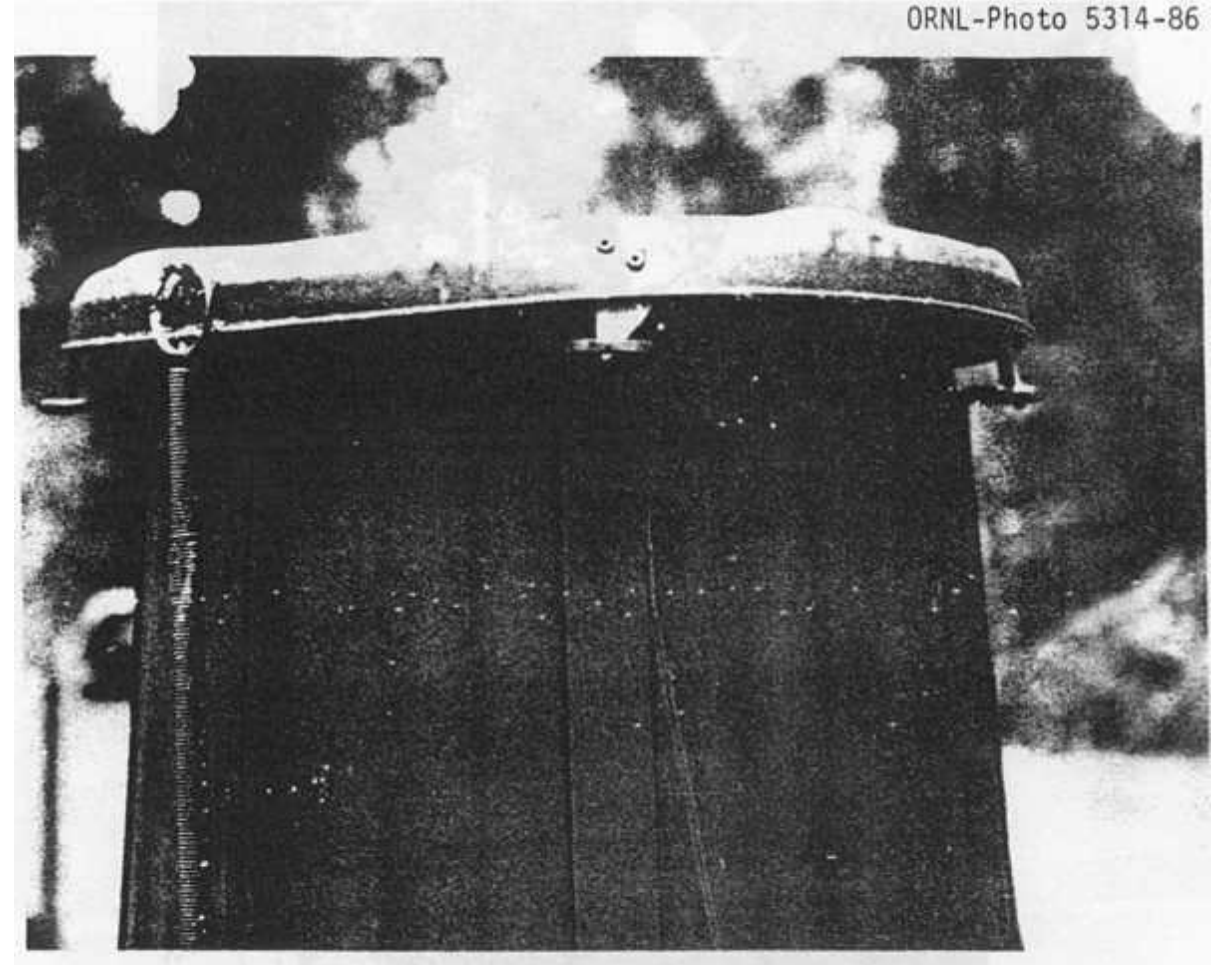

Fig. 3-5. The lid must be used to cover the fuel hopper in wet weather or when shutting the unit down. 


\title{
Table 3-1.
}

\section{Trouble-shooting your wood gas generator}

\author{
Trouble Cause Remedy \\ Start up takes too Dirty system or Clean the Gasifier unit and all the connecting piping.
long clogged pipes. \\ long \\ Blower is too weak Check the blower and test the battery's charge. \\ Wet or poor quality Check charcoal and replace or refill to proper level. \\ charcoal \\ Wood fuel bridges Lightly tamp down the wood fuel in the hopper and fire tube \\ in the fire tube. or replace the fuel with smaller-sized chips. \\ Engine will not \\ start. \\ Insufficient gas Use the blower longer during start up. \\ Wet wood fuel. Vent steam and smoke through the fire tube and fuel hopper \\ for several minutes. \\ Incorrect fuel-air \\ mixture. \\ Regulate the carburetor's air control for proper mixing \\ Engine starts, Not enough gas has Use low RPM while starting engine and do not rev engine \\ but soon dies \\ been produced. for several minutes. \\ Air channels Tamp down wood fuel lightly in hopper. Do not crush \\ through fire tube. charcoal above the grate.
}

Engine loses Restricted gas flow iReduce air mixture valve setting. Check for partial blockage power under loadpiping. of unit or piping.

Leaks in system. Check all covers and pipes for air tightness 


\section{Table 3-2.}

Carbon monoxide contentt of inhaled air (\%)

0.020

0.040

0.080

0.160

0.320

0.640

1.280

\section{Physiological effects}

Possible mild frontal headache after two to three hours

Frontal headache and nausea after one to two hours; occipital (rear of head) headache after 2.5 to 3.5 hours.

Headache, dizziness, and nausea in $45 \mathrm{~min}$; collapse and possible unconsciousness in who hours.

Headache, dizziness, and nausea inn $45 \mathrm{~min}$; collapse and possible unconsciousness in two hours.

Headache and dizziness in 5 to $10 \mathrm{~min}$; unconsciousness and danger of death in $30 \mathrm{~min}$.

Headache and dizziness in 1 to 2 min; unconsciousness and danger of death in 10 to $15 \mathrm{~min}$.

Immediate physiological effect; unconsciousness and danger of death in 1 to $3 \mathrm{~min}$. 


\section{APPENDIX II \\ LIST OF FIGURES}

Fig. S-1. Schematic view of the stratified, downdraft Gasifier

Fig. S-2. The prototype wood gas generator unit mounted onto a tractor

Fig. S-3. Wood gas generator unit in operation during field testing

Fig. 1-1. Wood gas generator unit in operation during field testing

Fig. 1-2. Schematic view of the World War II, Imbert gasifier Fig.

Fig. 1-3. Schematic view of the stratified, downdraft gasifier

Fig. 2-1.The prototype wood gas generator unit mounted onto a tractor

Fig. 2-2. Exploded, schematic diagram of the wood gas generator unit and the fuel hopper

Fig. 2-3. The fire tube and circular top plate of the gasifier unit

Fig. 2-4. Drilling holes into the stainlcss steel mixing bowl to be used for the grate

Fig. 2-5. Chains attached to the lip of the stainless steel mixing bowl

Fig. 2-6. Connect the mixing bowl to the top plate with chains

Fig. 2-7. Braze, do not weld, the plumbing fittings to the, thin walled drums

Fig. 2-8. Exploded, schematic diagram of the grate shaking mechanism

Fig. 2-9. Parts for the shaker assembly

Fig. 2-10. The support frame can be brazed or bolted to the side of the Gasifier unit

Fig. 2-11. Containers used in constructing the prototype Gasifier unit

Fig. 2-12. Cover for the fuel hopper

Fig. 2-13. Operating configuration of the fuel hopper and it's cover

Fig. 2-14. Lock ring and welded tabs

Fig. 2-15. Exploded, schematic diagram of the filter unit

Fig. 2-16. Detail of the standoffs for the bottom plate of the filter unit

Fig. 2-17. Divider plate (\#1) and bottom plate (\#3), with standoffs (\#4), for the filter unit

Fig. 2-18. Circular lid (\#1) for the filter unit

Fig. 2-19. Blower (\#1) with exhaust extension assembly

Fig. 2-20. Assembled and installed blower (\#1), extension assembly (\#4),

and conduit connectors for gas inlet (\#2) and outlet (\#3) on lid of filter unit

Fig. 2-21. Filter container (\#1) showing latches (\#2) for lid and hose (\#3) around top

Fig. 2-22. Exploded, schematic diagram of the carbureting unit and control valves

Fig. 2-23. Schematic diagram of a butterfly control valve

Fig. 2-24. Parts required for the butterfly valve

Fig. 2-25. Butterfly valve assembly

Fig. 2-26. Assembled butterfly valves 
Fig. 2-27. Assembled carbureting unit

Fig. 2-28. Carbureting unit attached to engine's existing intake manifold

Fig. 3-1. Virtually all varieties of wood chips can be used for fuel

Fig. 3-2. Ignite a single piece of newspaper to start the Gasifier unit;

push the flaming newspaper through the ignition port and directly into the grate

Fig. 3-3. Igniting the exhaust gas will demonstrate that the Gasifier unit is working properly

Fig. 3-4. Refill the fuel hopper before it becomes two-thirds empty

Fig. 3-5. The lid must be used to cover the fuel hopper in wet weather or when shutting the unit down 


\section{APPENDIX III \\ LIST OF TABLES}

Table 2-1. List of materials for the Gasifier unit and the wood fuel hopper Table 2-2. Fire tube dimensions

Table 2-3. List of materials for the primary filter unit

Table 2-4. List of materials for the carbureting unit

Table 3-1. Trouble-shooting your wood gas generator

Table 3-2. Effects of breathing carbon monoxide 


\section{APPENDIX IV}

\section{Bibliography}

Anonymous, 'Coast to Coast on Homemade Fuel,' The Mother Earth News (No. 73) pp. 178-179 (January/February 1982).

Anonymous, 'Wood Gas Update,' ne Mother Earth News (No. 71) pp. 164-165 (September/October 1981).

Anonymous, "Mother's Woodburning Truck,' The Mother Earth News (No. 69) pp. 126-129

(May/June 1981).

Chatterjee, A.K., State of the An Report on Pyrolysis of Wood and Agricultural Biomass, PN-AAK-818, U.S. Department of Agriculture, Newark, NJ, March 1981.

Cruz, I.E., Producer-Gas Technology for Rural Applications, published by the Food and Agriculture Organization of the United Nations, New York, NY, 1985.

Donath, E.E., "Vehicle Gas Producers,' Processing Technology (3) pp. 141-153 (1980).

Eoff, K.M., and D.M. Post, 'How to Power a Gasoline Engine with Wood,' Technical Reprint No. 1, The Mother Earth News, Hendersonville, NC, 1981.

Kaupp, A., and J.R. Goss, State of the Art Report for Small Scale (to 50kW) Gas Producer-Engine Systems, USDA Contract No. 53-319R-O-141, University of California, Davis, CA, March 1981.

Miller, B., State-of-the-Art Survey of Wood Gasification, EPRI-AP-3101, Fred C. Hart Associates, Inc., Washington, DC, May 1983.

Nygards, N., Wood Gas Generator Vehicles (a translation of the Swedish book), published by Purwaco International, Minneapolis, MN, 1979.

Oliver, E.D., Technical Evaluation of Wood Gasification, EPRI-AP-2567, Synthetic Fuels Association, Inc., Palo Alto, CA, August 1982.

Reed, T.B. (ed), A Survey of Biomass Gasification, VoL 1--Synopsis and executive Summary, SERI/TR-33-239 (Vol. I), Solar Fnergy Research Institute, Golden, CO, July 1979.

Reed, T.B. (ed), A Survey of Biomass Gasification VoL II -- Principles of Gasification, SERM-33-239 (Vol. II), Solar Energy Research Institute, Golden, CO, July 1979.

Reed, T.B. (ed), A Survey of Biomass Gasification, VoL III -- Current Technology and Research, SERM-33-239 (Vol. III), Solar Energy Research Institute, Golden, CO, April 1980.

Reed, T.B., and A- Das, Handbook of Biomass Downdraft Gasifier Engine Systems, SERI/SP-271-3022, Solar Research Institute, Golden, CO, March 1988.

Reed, T.B., and D. Jantzen, Generator Gas: The Swedish experience from 1939-1945 (a translation of the Swedish book, Gengas), SERI/SP-33-140, Solar Energy Research Institute, Golden, CO, January 1979.

Skov, N., and M.L. Papworth, PEGASUS (Petroleum Gasoline Substitute Systems), published by the Pegasus Publishing Co., Miami, FL, 1974.

Vietmeyer, N.L., et al., Producer Gas: Another Fuel for Motor Vehicle Transport, published by the National Academy Press, Washington, DC, 1983.

Wise, D.L. (ed.), Fuel Gas from Biomass, published by the CRC Press, Boca Raton, FL, 1981. 